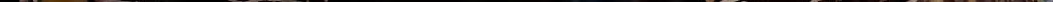



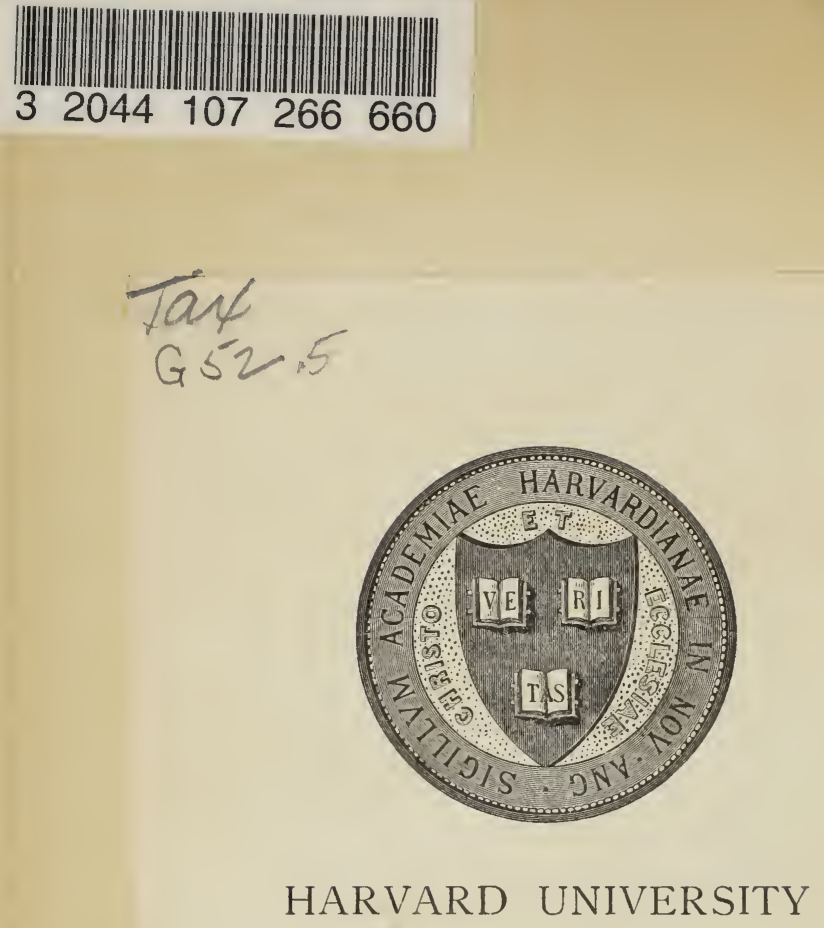

HARVARD UNIVERSITY

L I B F A R Y

OF THE

GRAY HERBARIUM

Received March 10,1910 


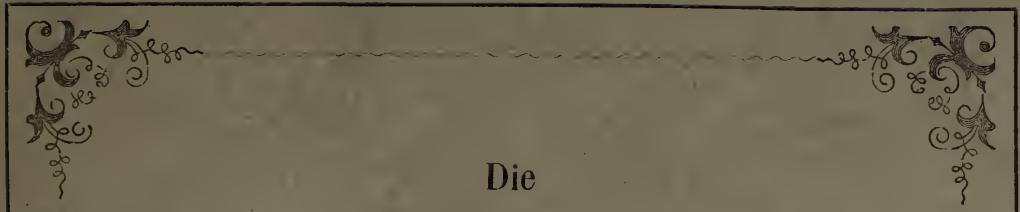

\title{
natürlichen Pflanzenfamilien
} nach ihren.

gegenseitigen Verwandtschaften.

Mit einer

vergleichenden Uebersicht

der Sysleme

3
3
3
3

Jussieu, DeClandolle und Endlicher und einer Beschreibung

der für die Systematik wichtigen Pflanzenorgane.

\author{
Von \\ P. G meli. \\ nit 1 Tafeln.
}

Stuttgart.

E. Schweizerbart'sche Verlagshandlung und Druckerei.

1867 .
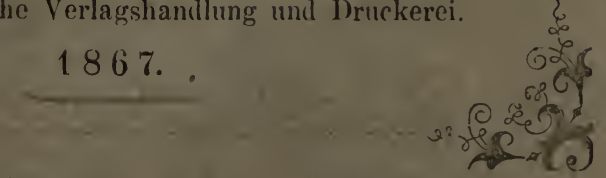



\title{
Die
}

\section{natürlichen Pflanzen-Familien}

nach ihren

\section{gegenseitigen Verwandtschaften.}

\author{
Mit einer \\ vergleichenden Uebersicht \\ der Systeme
}

von

\section{Jussien, DeCandolle und Endlicher}

und einer Beschreibung

der für die Systematik wichtigen Pflanzenorgane.

$$
\begin{aligned}
& \text { Von } \\
& \text { P. G m elim. } \\
& \text { Mit } 4 \text { Tafeln. }
\end{aligned}
$$

Stuttgart.

E. Schweizerbart'sche Verlagshandlung und Druckerei.

1867. 
MAR 10:919

Haryard Univercity. 


\section{Vorwort.}

Vorliegendes Schriftchen soll Anfängern in der Botanik eine Anleitung geben, sich eine klare Uebersicht über das ganze Gewächsreich zu verschafien. Um diesen Zweck zu erreichen, ist es nach des Verfassers vieljähriger Erfahrung nothwendig, dass nicht, wie es so häufig geschieht, die Familiencharactere als Memorirstoff betrachtet werden, sondern dass diesclben in ihrem gegenseitigen Zusammenhang studirt, dass dic Achnlichkeiten und Verschiedenheiten der cinander nahe stehenden Familien aufgesucht, dass dic Gründe erwogen werden, warum z. B. ciner und derselben Familie von einem Autoren diese, von dem andern eine ganz andere Stelle im System angewiesen wird. Weit entfernt, zu glauben, dass er diesen Gegenstand in diesen Blättern erschöpfend behandelt habe, möchte der Verfasser besonders die jungen Pharmaceuten zu cinem tieferen Eingehen in die 
Botanik, diese so schöne, aber heutzutage gegenüber der Chemie leider ziemlich vernachlässigte Wissenschaft, anregen.

Eine ganz ausführliche Beschreibung der Pflanzenfamilien wurde für überflüssig erachtet, denn wir haben botanische Bücher im Ueberfluss, in welchen dieselben mehr oder weniger genau beschrieben sind; ohnediess wurden diejenigen Charactere weggelassen, welche schon im Character der Section, Klasse oder Abtheilung enthalten sind; es wurde also z. B. nicht bei jeder zur Section derParietales gehörigen Familie ausdrücklich angeführt, dass das Ovarium wandständige, in der Mittellinie der Carpellarblätter befindliche Placenten habe; ebensowenig wurde bei den einzelnen zur Abtheilung der Monochlamydeae gehörigen Sectionen und Familien besonders bemerkt, dass nur e in er l e i Blüthendecken vorhanden sind. Dagegen wurden die gegenseitigen Verwandtschaften der Familien nachzuweisen gesucht, was in andern betreffenden Schriften gewöhnlich unberücksichtigt gelassen wird, mit fast alleiniger Ausnahme von Endlicher's vortreflichem Werke Enchridion bot anicum, das aber für den Anfänger viel zu ausführlich ist. Ferner wurde es für zweckmässig erachtet, die für Unterscheidung der Familien und grösseren Abtheilungen des Pflanzenreichs besonders wichtigen Pflanzenorgane etwas ausführlicher zu betrachten.

Von der grossen Anzahl der jetzt festgestellten Pflanzenfamilien wurden nur diejenigen aufgenommen, welche 
officinelle Pflanzen enthalten, und ausser diesen noch die wichtigsten einheimischen. Für den Anfänger wird das Studium nur erschwert, wenn ihm alle Familien auf cinmal vorgeführt werden; hat er aber cinmal die wichtigsten erfasst, so kamn er die noch fehlenden mit leichter Mühe sich aneignen. Bei den Kryptogamen wurden nur die Hauptabtheilungen hervorgehoben; Endlicher bezcichnet sie mit dem Namen "Klassen“ (unsere Sectionen), was etwa noch für die Gefässkiryptogamen in dem Sinn der Sectionen von phanerogamischen Familien zu verstehen ist. Dagegen haben die Klassen der Moose, Flechten u. s. w. einen weit grösseren Umfang und werden zuerst wieder in mehrere Gruppen und diese dann in Familien eingetheilt. Eine Beschreibung dieser letzteren liegt natürlich weit ausserhalb der Grenzen dieser Schrift.

Die meisten der jetzt in den verschiedenen Lehrbüchern der Botanik, wie z. B. von Schleiden, Seubert u. Anderen aufgeführten Pflanzensysteme sind Modificationen der Systeme von Jussieu und DeCandolle; das neueste ist das von Endlicher, welches gegẹnwärtig meist an öffentlichen Lehranstalten zu Grunde gelegt wird. In Deutschland hat sich durch Koch's Synopsis florae germanicae das DeCandolle'sche System eingebürgert, nach welchem auch viele Localfloren bis auf die neueste Zeit geordnet sind. Es wurde deshalb für passend gehalten, auch in diesem Schriftchen die Familien nach DeCandolle's System aufzuführen, dabei aber immer auf das von Endlicher hinzuweisen. Auch 
ist eine Uebersicht der hier beschriebenen Familien, nach Endlicher geordnet, beigegeben.

Möge nun das Büchlein eine freundliche Aufnahme finden.

Im Februar 1867.

Der Verfasser. 


\section{Endlicher's System.}

Regio I. Thallophyta.

Sectio I. Protophyta.

Classis 1. Algae.

»2. Lichenes.

Sectio II. Hysterophyta.

Cl. 3. Fungi.

Regio II. Cormophyta.

Sectio III. Acroboya.

CohorsI. A crobrya a nophyta.

Cl. 4. Hepaticae.

„5. Musci.

Cohors II. Acrobrya protophyta.

Cl. 6. Calamariae.

7 . Filices.

\8. Hydropterides.

9. Selagines.

¿10. Zamiae.

Cohors III. Acrobrya hysterophyta.

Cl. 11. Rhizanthae.

\section{Sectio IV. Amphibrya.}

Cl. 12. Glumaceae.

Gramineae. Cyperaceae.

Cl. 13. Enantioblastae.

Commelinaceae.

Cl. 14. Helobiae.

Alismaceae. Butomeae.

Cl. 15. Coronariae.

Juncaceae. Melanthaceae.

Liliaceae. Smilaceae (Asparageae).

Cl. 16. Artorhizae.

Dioscoreac. Taccaceas.
Cl. 17. Ensatae.

Ifydrocharideae. Irideae.

Ainaryllideae. Bromeliaceae.

Cl. 18. Gynandrae.

Orchideae Apostasieae.

Cl. 19. Scitamineae.

Zingiberaceae. Cannaceae. Musaceae.

Cl. 20. Fluviales.

Najadeae (u. Potomeae). Lemnaceae.

Cl. 21. Spadiciflorae.

Aroideae. Typhaceae. Pandanea.

Cl. 22. Principes.

Palmae.

\section{Sectio V. Acramphibrya.}

Cohors I. Gymnospermae.

Cl. 23. Coniferae.

Cupressineae. Abietineae.

Taxineae. Gnetaceae.

Cohors II. Apetalae.

Cl. 24. Piperitae.

Piperaceae.

Cl. 25. Aquaticae.

Ceratophylleae. Callitrichineae.

Cl. 26. Juliflorae.

Cupuliferae. Moreae. Urticear. Cannabineae. Artocarpeae. Salicineae.

Cl. 27. Oleraceae.

Chenopodeae. Amaranthaceae. Polygoneae.

Cl. 28. Thymeleae.

Laurineae Santalaceae. Daphnoideae.

Cl. 29. Serpentariae.

Aristolochiaceae. Nepentheae.

Cohors III. Gamopetalae.

Cl. 30. Plumbagines.

Plantaginea. Plumbarineae. 
Cl. 31. Aggregatae.

Valerianeae. Dipsaceae. Compositae.

Cl. 32. Campanulinae.

Lobeliaceae. Carnpanulaceae.

Cl. 33. Caprifoliaceae.

Rubiaceae. Lonicoreac.

Cl. 34. Contortae.

Jasmineae. Oleaccae. Loganiaceae. Apocyneae. Asclepiadeae. Gentiancae.

Cl. 35. Nuculiferae.

Labiatae. Verbenaceae. Asperifoliae (Borragineae).

Cl. 36. Tubiflorae.

Conrolvulaceae. Solanaccae.

Cl. 37. Personatae.

Scrophularineae. Acanthaceae. Bignoniaceae. Orobancheae. Lentibulariae.

Cl. 38. Petalanthae.

Primulaceae. Myrsineae. Sapotaceae. Ebenaceac. Styraceae.

Cl. 39. Bicornes.

Ericaceae. Pyrolaceac. Monotropeae.

Cohors IV. Dialypetalae.

Cl. 40. Discanthae.

Umbelliferae. Araliaceae. Ampelideae. Corneae. Loranthaceae.

Cl. 41. Corniculatae.

Crassulaceae. Saxifragaceae. Ribesiaccaə (Grossulariae).

Cl. 42. Polycarpicae.

Menispermeae. Myristiceae. Anonaceae. Magnoliaceae. Ranunculaceae. Berberideae.

Cl. 43. Rhoeades.

Papaveraceae (u. Fumariaceae). Cruciferae. Capparideae. Resedaceae.

Cl. 44. Nelumbia. Nymphaeaceae.

Cl. 45. Parietales.

Cistineae. Droseraceae.Violarieae. Bixaceae. Passifloreae.
Cl. 46. Peponiferae.

Cucurbitaceae. Begoniaceae.

Cl. 47. Opuntiae.

Cacteae.

Cl. 48. Caryophyllinae.

Mesembryanthemeae. Portulaceac. Caryophylleac. Phytolaceaceae.

C1. 49. Columniferae.

Malvaceae. Sterculiaceae. Büttneriaceae. Tiliaceae.

Cl. 50. Guttiferae.

Ternstroemiaceae (Camclliaceae). Clusiaceae. Canellaceae. Hypericineae.

Cl. 51. Hesperides.

Aurantiaceae. Meliaceae. Ce. drelaceae.

Cl. 52. Acera.

Acerineae. Malpighiaceac.

Sapindaceae. Hippocastaneae.

Cl. 53. Polygalinae.

Polygaleae.

Cl. 54. Frangulaceae.

Celastrineae. Rhamneae.

Cl. 55. Tricoccae.

Empetreae. Euphorbiaccae.

Cl. 56. Terebinthineae.

Jnglandeac. Anacardiaceae.

Burseraceae. Simarubaceae.

Rutaceae. Zygophylleae.

Cl. 57. Gruinales.

Geraniaceae. Lineae. Oxalideae. Balsamineas. Tropaeoleae.

Cl. 58. Calyciflorae.

Philadelpheae. Oenothereae (Onagrariae). Lythrarieae.

Cl. 59. Myrtiflorae.

Melastomaceae. Myrtaceae. Granateae.

Cl. 60. Rosiflorae.

Pomaceae. Rosaceac. Amygdaleae.

Cl. 61. Leguminosae.

Papilionaceae (u. Caesalpineae). Mimoseae. 


\section{I n h a $1 \mathrm{t}$.}

\section{Einleitung}

I. Vegetationsorgane . . . . . . . . . . . . . . 6

1. Der Stamm . . . . . . . . . . . . . . . 6

2. Die Blätter . . . . . . . . . . . . . . 10

II. Fructificationsorgane . . . . . . . . . . . . . 11

1. Der Blüthenboden . . . . . . . . . . . . . . 13

2. Die Blüthendecken . . . . . . . . . . . . . . 16

3. Die Staubgefässe . . . . . . . . . . . . . . 19

4. Der Stempel . . . . . . . . . . . . . . . . 20

5. Der Samen . . . . . . . . . . . . . 25

6. Die Frucht . . . . . . . . . . . . . . . . . . . 28

Pflanzensysteme . . . . . . . . . . . . . . . . 34

Beschreibung der Famliien und Sectionen . . . . . . . . 42

I. Plantae vasculares.

\section{A. Exogenae.}

I. Thalam if lorae.

1. Sect. Polycarpicae . . . . . . . . . 42

2. » Nelumbia. . . . . . . . . . . . . . 44

3. \ Rhoeades............. . . . . 44

4. \ Parietales. . . . . . . . . . . 47

5. $»$ Polygalinae . . . . . . . . . 48

6. » Caryophyllinae . . . . . . . . . . . 48

7. Columniferae. . . . . . . . . . 50

8. \Guttiferae . . . . . . . . . . 51

9. „ Hesperides . . . . . . . . . . . . . 52

10. " Acera . . . . . . . . . . . . . 53

11. Sarmentaceae . . . . . . . . 55

12. Gruinales. . . . . . . . . . 55

II. Calyciflorae.

13. Sect. Frangulaceae . . . . . . . . . . 60

14. $\gg$ Terebinthineae . . . . . . . . . . . 61

15. "Leguminosae . . . . . . . . . . 62

16. \ Rosiflorae . . . . . . . . . . 63

17. „ Myrtiflorae . . . . . . . . . . 65

18. " Calyciflorae . . . . . . . . . . . . 67

19. „ Peponiferae . . . . . . . . . 68 
20. Sect. Corniculatae

21. " Umbelliferae

22. " Caprifolia

23. " Aggregatae

24. " Campanulinae

25

Bicornes

III. Co rollifl orae.

26. Sect. Contortae . . . . . . . . . 80

27. " Tubiflorae . . . . . . . . . 83

28. " Nuculiferae . . . . . 84

29. " Personatae... 86

30. " Peialanthae...... . 87

31. Plumbagines ........... 89

IV. Monochlamydeae.

32. Sect. Oleraceae

91

33. » Thymelaeaceae . . . . . . . . . . 92

34. " Serpentariae . . . . . . 94

35. » Tricoccae . . . . . . . 95

36. » Urticinae . . . . . . . . . . . . . 96

37. " Amentaceae . . . . . . . . . . . . 97

38. " Piperitae . . . . . . . . . . . . . . 98

39. „ Coniferae . . . . . . . . . . . 99

40. "Zamiae . . . . . . . . . . . . . . 101

B. Endogenae phanerogamae . . . . . . . . . . . . . 102

41. Sect. Helobiae . . . . . . . . . . . . 102

42. " Fluviales . . . . . . . . . . . 104

43. " Spadiciflorae . . . . . . . . . . . 104

44. " Principes . . . . . . . . . . . 106

45. " Scitamineae . . . . . . . . . . 106

46. " Gynandrae . . . . . . . . 108

47. Ensatae . . . . . . 109

48. " Coronariae . . . . . . . . . 110

49. "Glumaceae . . . . . . . . . 111

Kryptogamischc Gewächse . . . . . . . . . . . . 114

C. Endogenac cryptogamae . . . . . . . . . . . . . 115

Equisetaceae . . . . . . . . . . 116

Lycopodiaceac .

Marsileaceae . . . . . 117

Filices............. . . . 117

II. Plantae cellulares . . . . . . . . . . . . . . 118

I). Acotyledoneae cellulares.

Acotyledoneae follacear . . . . . . . . . . . . 118

Musci . . . 118

Hepaticae . . . . . . . . . . . 119

Aphyllae . . . . . . . . . . . . . . 119

Lichenes . . . . . . . . . 120

Fungi . . . . . . . . . . . . . . . 120

Algae . . . . . . . . . . . . . . 121 


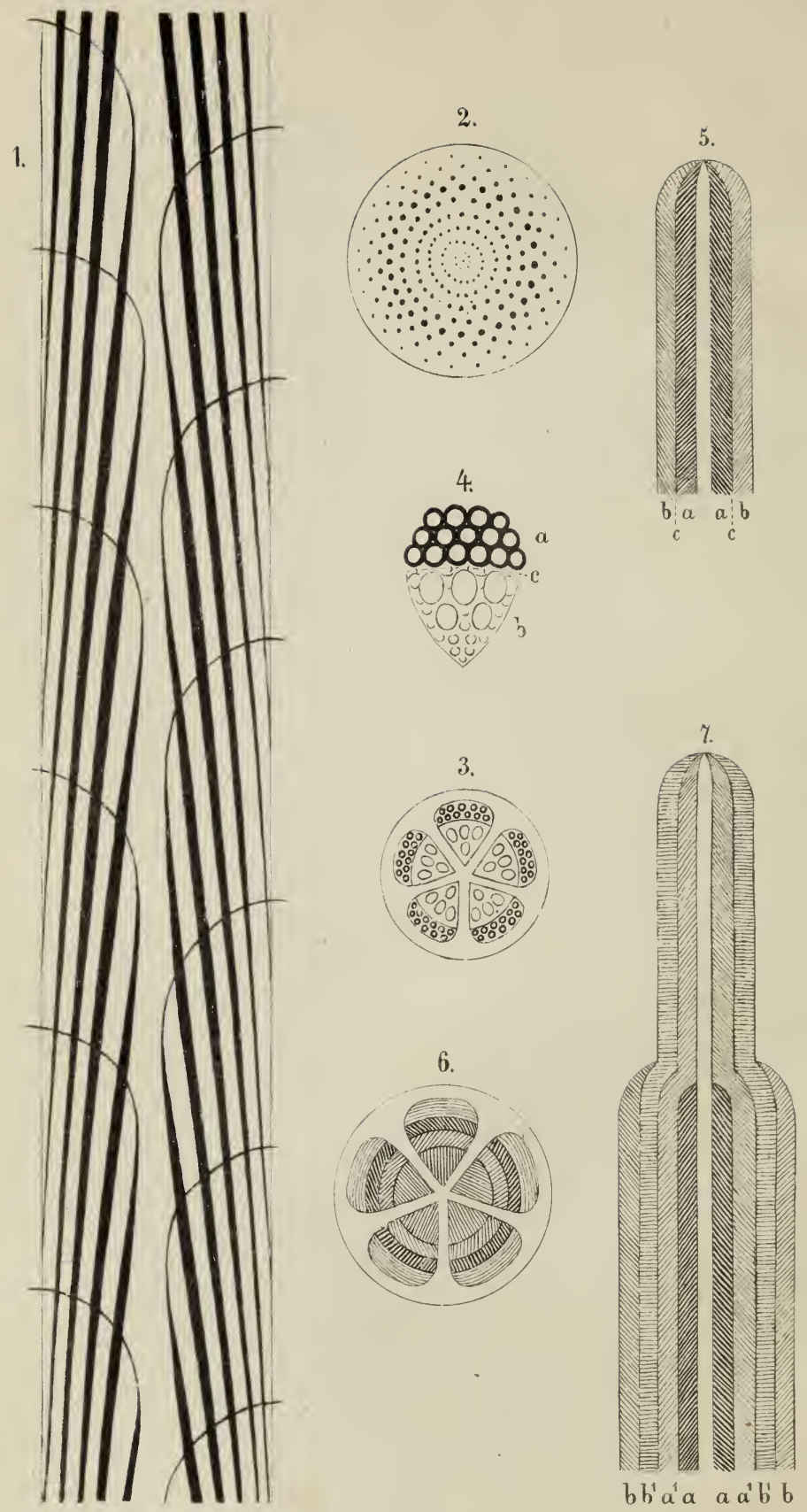
$-$ 
15.
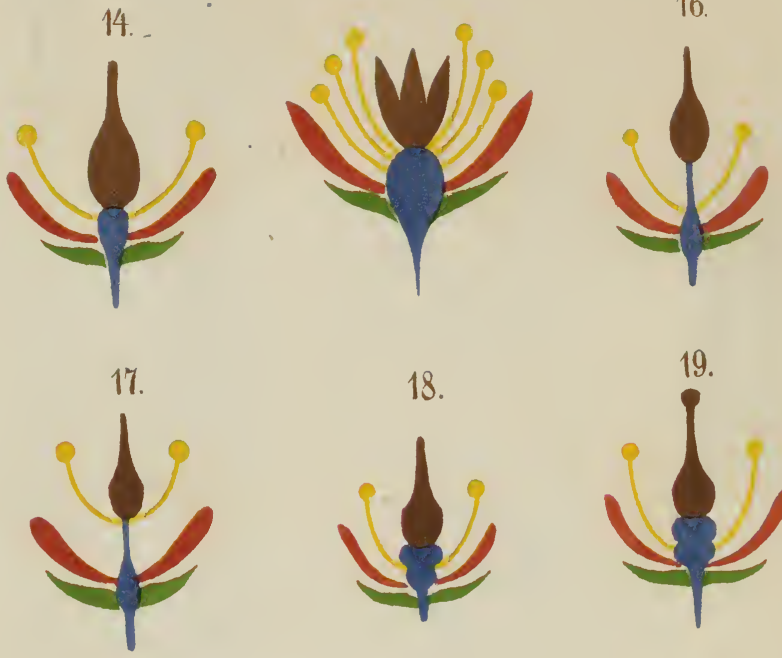

19.
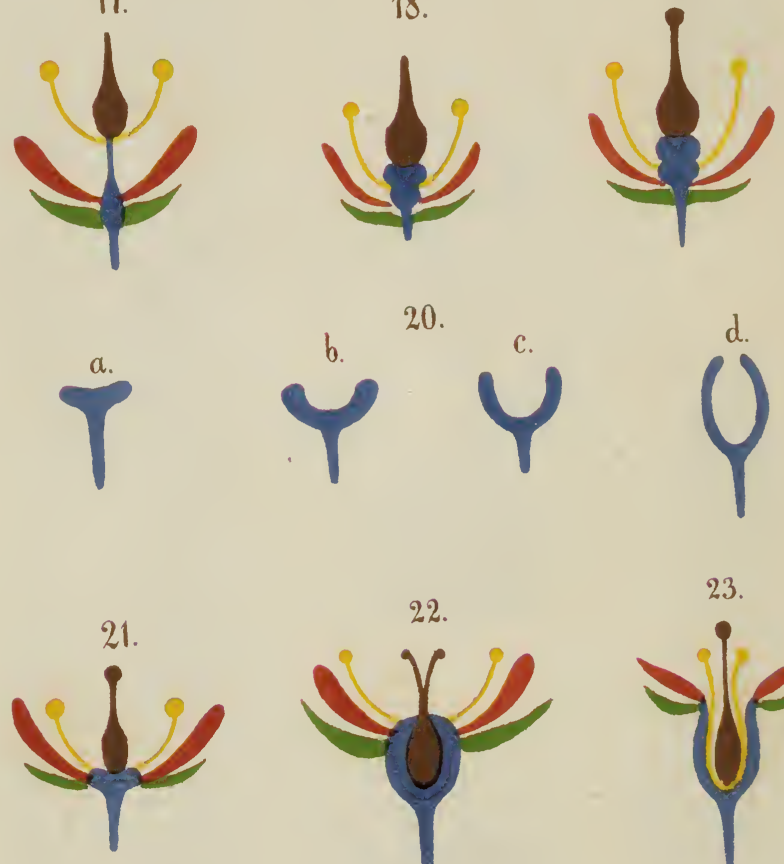

22.

23.
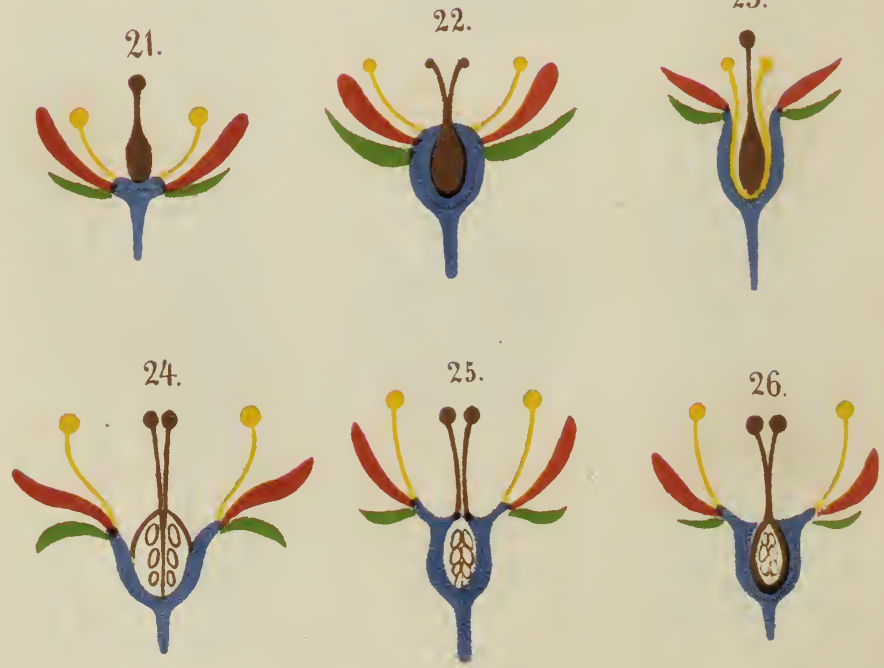

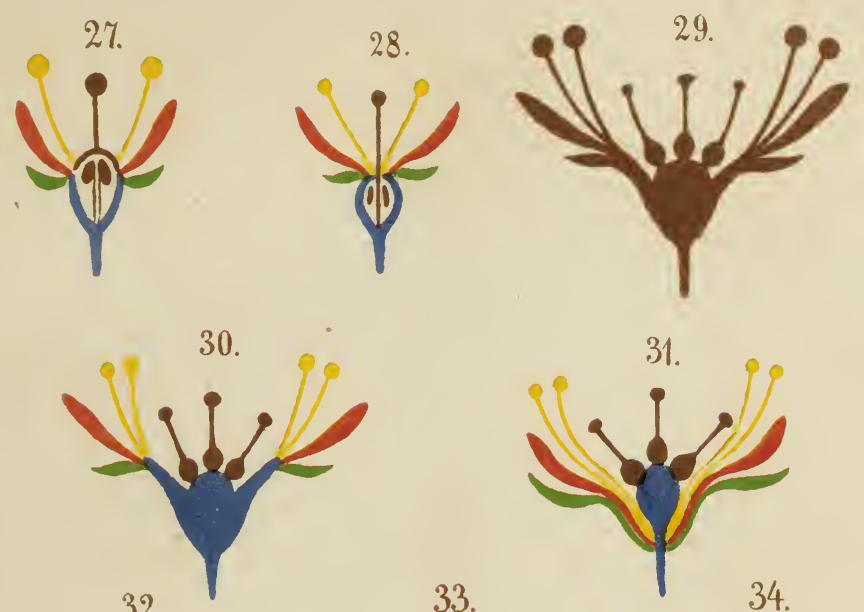

33.
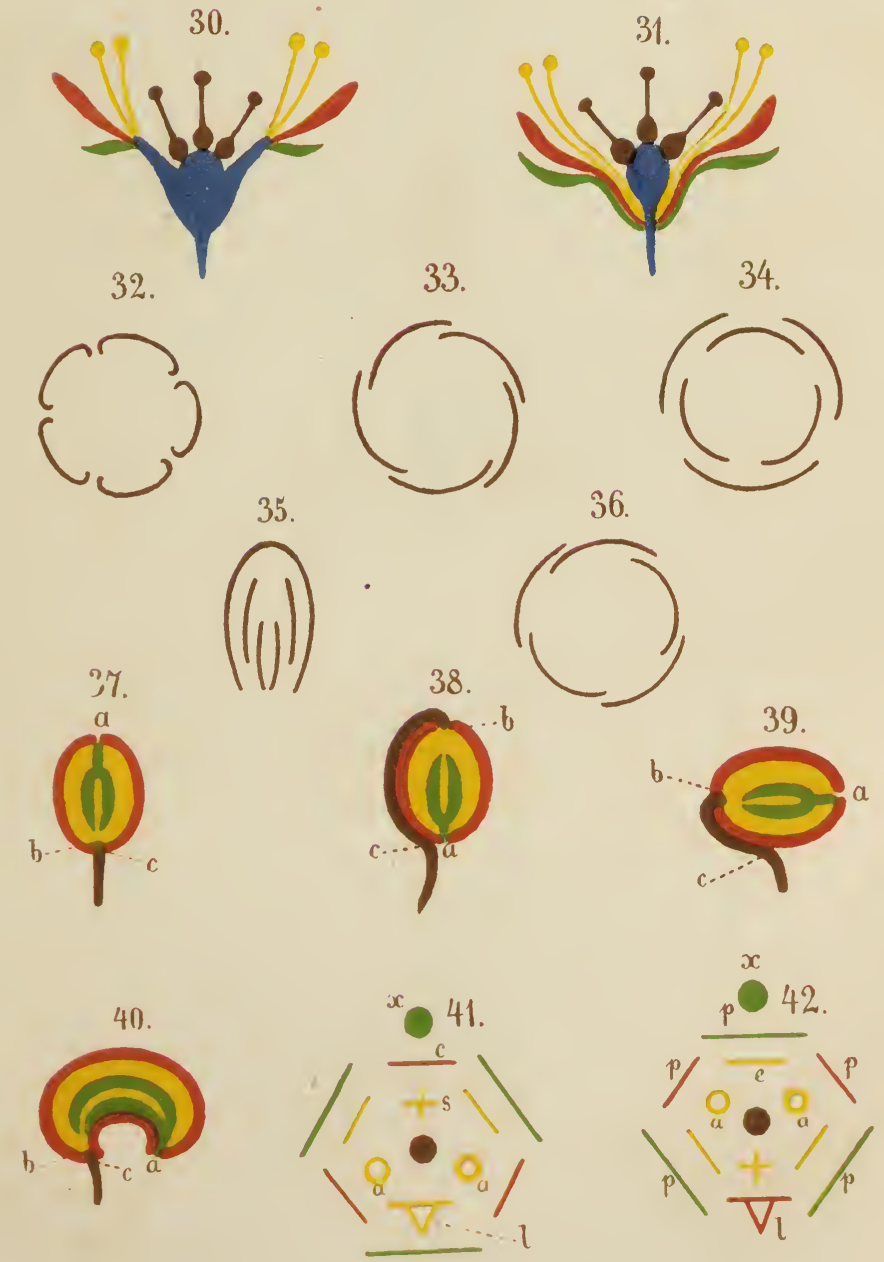



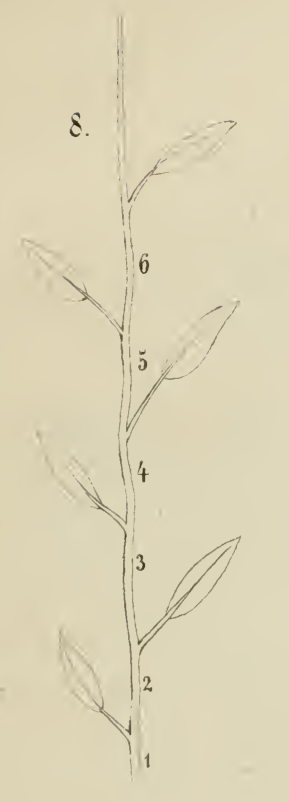

10.

12.
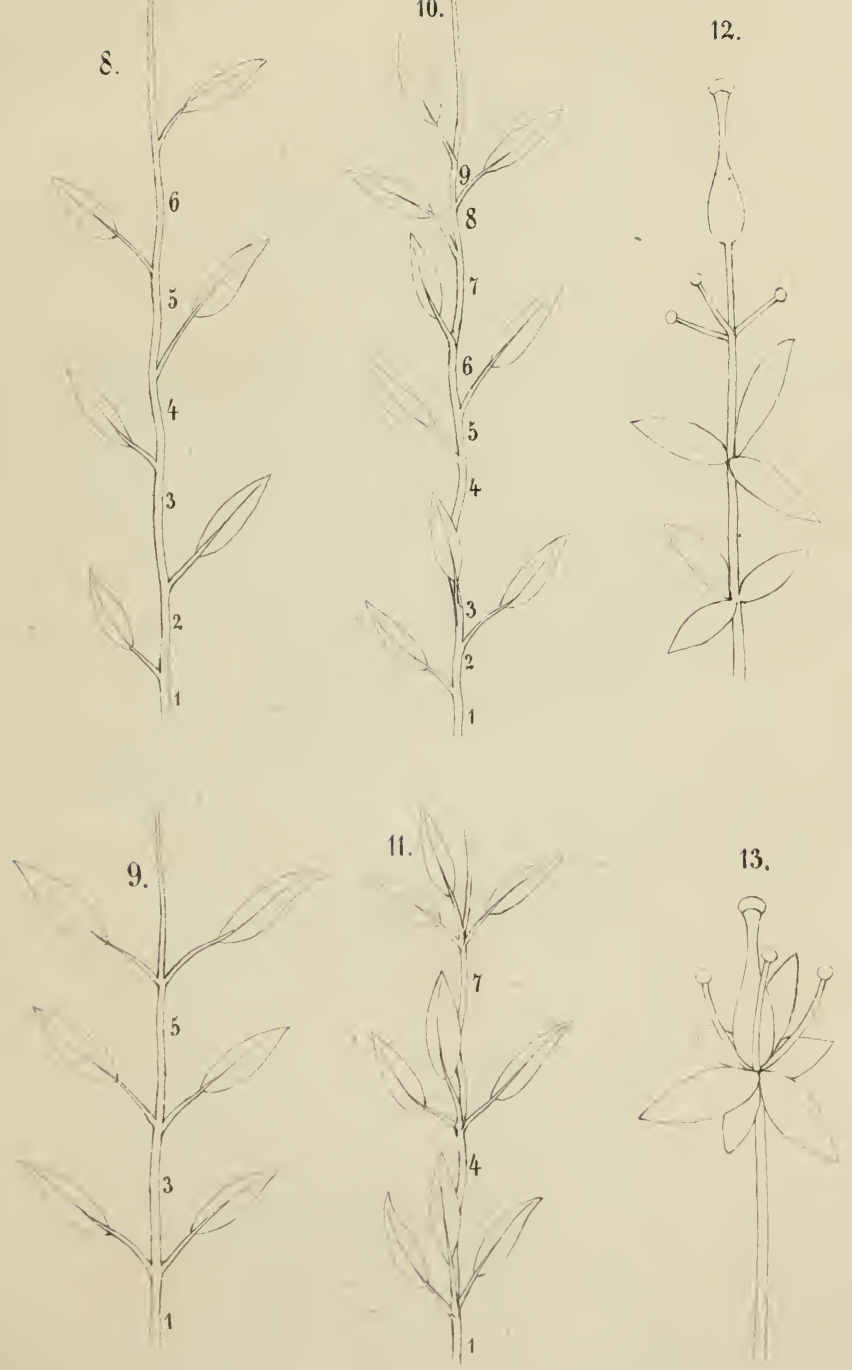



\section{E i I l e it II II g.}

Gleichzeitig mit der Entwicklung der Botanik zu einer besonderen Wissenschaft wurden auch schon Versuche zu einer systematischen Anordnung der Pflanzen gemacht, denn je mehr die Anzahl der Pflanzenarten durch genauere Untersuchungen und grössere Reisen, auch in entferntere Welttheile, vermehrt wurden, um so dringender fühlte man das Bedürfniss, dieselben in irgend eine Ordnung zu bringen, wodurch ihre Auffindung erleichtert würde. Das erste eigentliche Pflanzensystem wurde am Ende des 17. Jahrhunderts von Tournefort, einem französischen Botaniker, aufgestellt. Dieses System gründet sich auf die Beschaffenheit der Blumenkrone unter gleichzeitiger Berücksichtigung der Consistenz des Stengels und der Lebensdauer der Pflanzen. Dieselben zerfallen in krautartige und Holzpflanzen, jede dieser Abtheilungen wieder in Pflanzen mit und ohne Corolle, dann mit einblättriger, vielblättriger, regelmässiger und unregelmässiger Corolle u. s. w. Trotz seiner Mängel, und obwohl von späteren Botanikern verschiedene andere Klassificationsmethoden vorgeschlagen wurden, blieb Tournefort's System immer noch das beste, bis un das Jahr 1734 Linné mit seinem eben so scharfsinnigen als einfachen Pflanzensystem hervortrat, durch welches die Auffindung der Gewächse ausserordentlich erleichtert wurde, und welches bis auf die neueste Zeit in dieser letzteren Hinsicht seinen grossen Werth behalten hat. Zugleich war Linné der Erste, welcher jeder Pflanzengattung einen eigenen Namen, und jeder Pflanzenart ebenfalls einen eigenen 
Namen gab, so dass von Linné an jede Pflanze zwei Namen erhielt, wovon der Name für die Art oder Species dem Gattungs- oder Genus-Namen nachgesetzt wurde. Neben den grossen Vorzügen des Linné'schen Systems, die heute noch anerkannt werden müsșen, und wodurch es besonders zum Auffinden der Pflanzen dem Anfänger unentbehrlich ist, sind auf der anderen Seite doch auch die Mängel, von denen dieses System keineswegs frei ist, nicht zu übersehen.

Ein Pflanzensystem hat nicht allein den Zweck, das Auffinden einer Pflanze nach einer gegebenen Beschreibung zu erleichtern, sondern es sollen darin auch gleiche und ähnliche Pflanzen zusammen gestellt werden. Dieser letzteren Anforderung genügt nun Linné's System in vielen Fällen nicht, und auch der erstere Zweck wird nicht immer erreicht. Da nemlich die Charaktere der Klassen nur auf ein einziges Pflanzenorgan - die männlichen Befruchtungswerkzeuge - gegründet sind, so kommt es oft vor, dass Pflanzengattungen, die sonst in allen Beziehungen die grösste Aehnlichkeit mit einander haben, wegen eines oder einiger Staubgefässe mehr oder weniger von einander getrennt werden. Selbst bei einer und derselben Species ist bisweilen die Zahl der Staubgefässe veränderlich und eine solche anomale Pflanze lässt sich dann im System gar nicht auffinden. Linné's System heisst ein künstliches, weil bei der Bildung der Klassen und der Ordnungen nur ein einziges Pflanzenorgan in Betracht gezogen wurde, im Gegensatz zu denjenigen Klassificationsmethoden, bei welchen die Aehnlichkeit aller wichtigeren Pflanzenorgane berücksichtigt werden, und welche man natürliche Pflanzensysteme oder natürliche Methoden nennt. Erst die Anordnung der Gewächse nach der natürlichen Methode verschafft uns einen klaren Ueberblick über das ganze Gewächsreich, und schon Linné bezeichnete dieselbe als das letzte Ziel der Botanik. Das erste natürliche Pflanzensystem wurde von Jussieu zu Ende des vorigen Jahrhunderts aufgestellt und später von Richard verbessert. Von weiteren Systemen, welche sich dem von Jussieu mehr oder weniger anschliessen, haben das von DeCandolle und das neueste von Endlicher die meiste Ver- 
breitung gefunden, daher dieselben specieller betrachtet.werden sollen.

Bei der Klassification der Pflanzen nach dem natürlichen System werden diejenigen Gattungen, welche in der Beschaffenheit ihrer wichtigeren Organe eine grosse Uebereinstimmung zeigen zu einer Familie oder natürlichen Ordnung vereinigt. Diese Uebereinstimmung erstreckt sich bald nur auf wenige Pflanzenorgane, bald auf eine grössere Anzahl derselben. Es fragt sich nul, welches diejenigen Organe sind, auf welche es bei Bildung der Familien besonders ankommt, oder worin die Gattungen hauptsächlich übereinstimmen müssen, um zu einer Familie oder natürlichen Ordnung gerechnet $\mathrm{zu}$ werden? Diese Frage lässt sich im Allgemeinen dahin beantworten, dass je wichtiger ein Organ in physiologischer Beziehung, um so grösser auch seine Bedeutung ist für dịe Aufstellung der Pflanzenfamilien. Es sind also die Fructificationsorgane von grösserer Wichtigkeit als die Vegetationsorgane, welch letztere einen melrr untergeordneten Werth haben, obwohl sie in vielen Fällen auch entscheidend sind. Jedenfalls ist von ihnen der allgemeine Habitus einer Pflanze abhängig, der immer auch mehr oder weniger in die Wagschale fällt.

In Betreff der Rangordnung, in welcher die Organe nach dem Grad ihrer Bedeutung für die Familien auf einander folgen, stehen die Samen, zumal hinsichtlich der Beschaffenheit des Embryo, oben an, dann folgen das Ovarium, die Fruchthüllen, die Blüthenhüllen; weniger wichtig ist der Blüthenstand, der häufig selbst in den Gattungen verschieden ist. Von den Vegetationsorganen sind besonders die Blätter und Nebenblätter zu beachten. Indessen lassen sich hierüber keine festen Regeln aufstellen, denn es kommen oft Fälle vor, wo ein sonst sehr wichtiges Organ gar keine Berücksichtigung verdient.

Von den Verschiedenheiten, welche ein und dasselbe Organ zeigen kann, ist besonders wichtig das Vorbandensein oder Fehlen eines Organs, wenn es mit einer Verschiedenheit anderer Organe zugleich vorkommt, während es oft bei sonst gleicher Beschaffenheit anderer Organe nicht in Betracht kommt. Das 
Vorhandensein oder Fehlen des Eiweisskörpers der Samen z. B. bildet eines der wichtigsten Unterscheidungsmerkmale vieler Familien; bei den Leguminosen aber, einer durch Uebereinstimmung der meisten Organe ganz besonders ausgezeichneten Familie, kommen Arten mit eiweisshaltigem und eiweisslosem Samen vor, welcher Unterschied aber in diesen Falle nicht berücksichtigt wird. Anders ist es mit den Dipsaceen und Compositen. Beide Familien stehen einander sehr nahe und stimmen in mehreren Punkten ganz mit einander überein, ohne dass jedoch ihre Aehnlichkeit so gross wäre, wie bei den Leguminosen. Hier gibt nun vollends das Eiweiss den Ausschlag, indem es bei den einen (Compositae) fehlt, bei den andern (Dipsaceae) vorhanden ist, daher diese zwei Familien nicht in eine vereinigt werden, sondern getrennt bleiben. Die Form der Organe, sowie die Anzahl derselben ist im Ganzen von untergeordneter Bedeutung: sind aber diese Verhältnisse sehr constant, so können sie auch wichtig werden, so z. B. die lippenförmige Corolle bei den Lobiaten. Die relative Stellung der Organe ist ebenfalls von Wichtigkeit, z. B. ob die Staubgefässe mit den Blumenblättern abwechseln, oder denselben opponnirt sind, ebenso die Verwachsung ungleichartiger Organe, während die Verwachsung gleichartiger Organe unter sich, z. B. der Staubgefässe, weniger wichtig ist.

Die einzelnen Pflanzenfamilien werden nun so aneinander gereiht, dass die einander am ähnlichsten neben einander zu stehen kommen; wobei gewöhnlich mit den niedersten angefangen, mit den am höchsten organisirten geschlossen wird. So einfach und leicht es scheint, eine solche Anordnung der Familien zu treffen, so schwierig ist die genaue Durchführung dieses Grundsatzes. Gesetzt auch, es hätte darüber, welche Familie als die am höchsten organisirte zu betrachten sei, Jedermann einerlei Ansicht, wie es aber in der That nicht der Fall ist, so entsteht eine weitere Schwierigkeit dadurch, dass eine Familie nicht allein mit der vorhergehenden und folgenden, sondern nach mehr als zwei Seiten hin Aehnlichkeit hat. Man müsste also, um die Familien auf eine naturgemässe Weise nach ihren allseitigen Verwandtschaften $\mathrm{zu}$ ordnen, dieselbe 
nicht in eine lineare Reihe stellen, sondern in der Form eines Kreises um einen gemeinschaftlichen Mittelpunkt, oder nach Art einer Landkarte gruppiren, wo ein Land auch nach allen Seiten hin an die benachbarten Länder angrenzt. In der Praxis lässt sich selbstverständlich eine solche Anordnung nicht durchführen, sondern man ist genöthigt, die lineare Reihenfolge beizubehalten, wobei nun darauf $\mathrm{zu}$ sehen ist, dass die Familien, welche einander am ähnlichsten sind, zusammenkommen. Welches aber die wichtigsten Aehnlichkeitsverhältnisse zwischen zwei Familien sind, diese Frage ist in vielen Fällen noch nicht entschieden und es gehen in dieser Hinsicht die Ansichten der Botaniker oft weit auseinander. So sind nun von Jussieu bis auf unsere Zeit verschiedene natürliche Pflanzensysteme aufgestellt worden, wovon die meisten in ihrer allgemeinen Anordnung einander mehr oder weniger ähnlich, aber in der Stellung der einzelnen Familien doch von einander verschieden sind. Welches dieser Systeme das beste ist, lässt sich nicht so unbedingt entscheiden; jedes hat seine Schattenseiten, welche eben nicht ganz zu vermeiden sind, jedes aber auch seine Vorzüge. Jussieu's System hat freilich unverkennbare Mängel, welche in den neueren Systemen vermieden sind.

Der Umfang der Familien ist in den neueren Systemen so ziemlich derselbe; man ist bei den allermeisten Familien vollkommen darïber einig, welche Gattungen dazu gerechnet werden sollen, jedoch nicht bei allen, denn es gibt manche Gattungen, deren Charaktere von der Art sind, dass sie nicht unbedingt in eine bestimmte Familie gestellt werden müssen, sondern je nach dem Werth, der dem einen oder andern ihrer Organe beigelegt wird, dieser oder jener Familie zugetheilt werden können.

Bei der grossen Anzahl von Familien, die sich auf ungefähr 260 belauft, ist es zur besseren Uebersicht nöthig, dieselben in weitere Gruppen (Sectionen, Klassen) zu bringen und diese wieder zu grösseren Abtheilungen zu vereinigen, welche auf die Beschaffenheit nur weniger Organe gegründet werden. Es ist dabei aber nicht $\mathrm{zu}$ übersehen, dass gerade dadurch, dass 
nicht alle oder die meisten, sondern nur wenige Organe berücksichtigt werden, die Eintheilung auch den Charakter einer natürlichen verliert und mehr künstlich wird.

Es sind nun zunächst die wichtigeren Modificationen zu betrachten, welchen die zur Bildung der Familien, Klassen und grösseren Abtheilungen des Gewächsreichs benützten Vegetationsund Fructificationsorgane unterliegen.

\section{Vegetationsorgane.}

Bei den meisten Pflanzen sind die Vegetationsorgane in Achsen- und Seitenorgane, in Stamm und Blätter getrennt, bei den niedersten Pflanzen aber zu einem gemeinschaftlichen Gebilde von verschiedener Form, dem Lager, thallus, verschmolzen. Es lassen sich daher sämmtliche Pflanzen in La ger- und St engelp flanzen, Thallophyla und Cormophyla eintheilen. Berücksichtigt man den anatomischen Bau der Pflanzen, so findet man, dass ein Theil derselben nur aus Zellen besteht, während bei dem anderen, grösseren Theil neben den Zellen auch Gefässe sich finden. Nach dieser Verschiedenheit der Elementarorgane kann man also Zellenpflanzen, plantae cellulares und Gefässpflanzen, plantae vasculares unterscheiden. Die Lagerund Zellenpflanzen eịnerseits und die Stengel- und Gefässpflanzen andererseits kommen nahezu mit einander überein; sämmtliche Lagerpflanzen sind auch Zellenpflanzen, der bei weitem grösste Theil der Stengelpflanzen sind Gefässpflanzen, ein kleiner Theil jedoch, nemlich die Moose und Lebermoose, enthalten keine Gefässe, sondern höchtens Andeutungen davon.

\section{Der Stamm.}

Die Stengelpflanzen, welche mit Gefässen versehen sind, zeigen in ihrem Wahsthum und im anatomischen Bau der Gefässbündel wesentliche Verschiedenheiten, auf welche die weitere Eintheilung der Gefässpflanzen gegründet wird. 
A. Die Gefässbündel bestehen grösstentheils aus Gefässen, hauptsächlich Treppengängen, zwischen welchen sich verlängerte Parenchymzellen befinden. Der Stamm enthält entweder nur ein einziges Gefässbündel, oder mehrere, in welchem Falle sie durch seitliche Verzweigungen mit einander in Verbindung stehen, und ein regelmässiges Netz bilden, welches den ganzen Stamm durchzieht, so dass ein einziges zusammenhängendes Gefässbündelsystem gebildet wird. Das Wachsthum dieses Gefässbündels erfolgt immer nur an der Spitze; es ist ein endsprossendes Wachsthum, vegetatio terminalis; den Pflanzen, welchen dieses Wachsthum zukommt, gab Endlicher den Namen Endsprosser, Acrobrya, oder plantae acrobryae.

B. Die Gefässbündel enthalten verhältnissmässig wenige Gefässe, dagegen viele Zellen mit dicken Wandungen; sie bestehen aus zwei Schichten, von welcher die eine gegen die Peripherie, die andere gegen das Centrum des Stamınes gerichtet ist. Die äussere dieser Schichten besteht blos aus verlängerten Prosenchymzellen und zeichnet sich durch eine bedeutende Zähigkeit aus; es ist die sogenannte Bastschichte. Die innere Schichte bildet das aus Gefässen und Zellen bestehende Holzbündel, welches allein den Gefässen der Endsprosser entspricht. Die Anordnung dieser Gefässbündel im Stamm, und ihr Wachsthum findet aber auf zweierlei Weise statt, wonach die betreffenden Pflanzen wieder in zwei Abtheilungen zerfallen.

a) Bei der einen Abtheilung haben die Gefässbündel in ihrem Wachsthum mit den der Endsprosser darin Aehnlichkeit, dass sie nach der ersten Entwicklung nicht mehr in die Dicke wachsen, sondern auf ihrer ursprünglichen Entwicklungsstufe stehen bleiben. Dagegen ist ihre Anordnung im Stamm eine verschiedene, indem sie nicht ein geschlossenes Gefässbüindelsystem bilden, sondern durch das parenchymatose Zellgewebe des Stamines zerstreut sind, eine verschieden grosse Strecke des Stamms hindurch isolirt verlaufen und zuletzt nach aussen in die Blätter übertreten. Verfolgt man ein solches Gefässbündel von aussen nach innen, vom Blatt aus durch den Stamm abwärts, so findet man, dass es beim Eintritt in den Stamm zuerst 
gegen die Mitte desselben verlauft, sich hierauf in absteigender Richtung der Achse des Stammes ziemlich parallel, dann aber allmählig wieder nach aussen wendet, so dass sein unteres Ende (Fig. 1), welches sich entweder zerschlitzt oder mit tiefer liegenden Gefässbündeln verbindet, unter die Epidermis des Stammes zu liegen kommt. Da also, um wieder die Richtung der Gefässbündel von unten nach oben fest zu halten, jedes Gefässbündel von der Peripherie des Stammes gegen das Centrum verlauft, von hier aber wieder nach aussen tritt, so müssen sich dieselben kreuzen. Endlicher nennt dieses Wachsthum ein ums prossendes, vegetatio peripherica, und die Pflanzen, welche dieses Wảchsthum zeigen, Ums prosser, Amphibrya, plantae amphibryae. Die Gefässbündel selbst wachsen hier nicht unendlich fort wie bei den Endsprossern, sondern endigen in den Blättern, aber es entstehen vom Umfange des Stammes gegen die Mitte der Stammesspitze immer neue Gefässbündel. Eine weitere Eigenthümlichkeit derselben besteht darin, dass sie an ihrem unteren Ende dünn sind, weiter nach oben bei fester Consistenz dicker werden, in der Nähe der Blätter und gegen das Centrum des Stammes aber wieder dünner und von weicher Beschaffenheit sind. Der Stanm zeigt deshalb auf dem Querschnitt unter der Epidermis (Fig. 2) eine Schicht haardünner Fasern, weiter nach innen eine Anzahl Gefässbündel von bedeutender Dicke und Härte, in der Mitte wieder dünne und weiche Gefässbündel. Die äusseren sind die Jüngeren, die des Centrums obwohl weicher als die mehr gegen die Peripherie gelegenen, doch älter, was leicht aus dem Umstand zu erklären ist, dass sie sich nach oben kreuzen. DeCandolle glaubte, die Gefässbündel verlaufen einander parallel, hielt deshalb die inneren, weicheren, für die jüngeren, während sie nur die oberen Enden der älteren Gefässbündel sind, und schrieb irrthümlicher Weise diesen Pflanzen ein Wachsthum von innen nach aussen $z u$, daher er ihnen den Namen Endogenae beilegte.

b) Bei einer anderen, grösseren Abtheilung der Pflanzen haben die Gefässbündel nicht eine zerstreute Stellung im Stamm, sondern sie sind in einen einfachen Kreis geordnet (Fig. 3), 
welcher das Mark einschliesst und von der Epidermis bedeckt wird. Ihr ursprünglicher Bau ist dem der vorigen, der Umsprosser ganz ähnlich (Fig. 4); sie bestehen aus einer äusseren Bastschichte a, welche aụs dickwandigen Prosenchymzellen besteht, und aus einem inneren Holzkörper b, der aus Treppengängen, Spiral- und Ringgefässen und Zellen zusammengesetzt ist. Zwischen Bast- und Holzkörper befindet sich eine schmale, durchscheinende Schichte von sehr dünnen Zellen c, welche die Reproductionsschichte oder das Cambium heisst. Fig. 5 zeigt einen solchen Stamm im senkrechten Durchschnitt, a die Holz-, b die Bast-, c die Cambiumschichte; das Centrum besteht aus Mark. Mit der weiteren Entwicklung der Gefässbündel, schon einige Wochen nach ihrer Entstehung, tritt nun eine wesentliche Veränderung in ihrem Bau ein: sie haben nämlich ein ununterbrochenes Wachsthum in die Dicke und zwar in der Art, dass sich von der Cambiumschichte aus einerseits neue Bastschichten, andererseits neue Holzschichten erzeugen, welche sich den frïheren Schichten anlegen, also die neuen Bastschichten auf der Innenfläche des ursprünglichen Bastes, die Holzschichten auf der Aussenfläche des ursprünglichen Holzkörpers. Diese Ablagerung der Bast- und Holzschichten dauert den ganzen Sommer hindurch fort, wobei sich die Holzschichten durch seitliche Verzweigungen mit einander verbinden und so schon im ersten Jahre einen zusammenhängenden Holzcylinder bilden. Es inag hier noch erwähnt werden, dass die Zellen und Gefässe, welche am Anfang der Vegetationsperiode, im Frühjahr, ziemlich weit und dünnwandig sind, gegen den Herbst hin immer enger und dickwandiger werden, wodurch das gebildete Holz an Festigkeit zunimmt. Es beruht hierauf die Bildung der sogenannten Jahresringe.

Um nun nochmals auf die Gefässbündel zurückzukommen, so zeigen dieselben also abweichend von denen der Endsprosser und Umsprosser ein Wachsthum in die Dicke; zugleich aber wachsen sie auch in die Länge, und wenn dieses Längenwachsthum über den Winter aufhört, so ist für die weitere Verlängerung der Hauptachse, ode wenn diese verkümmert, wenigstens 
deren Seitenachsen durch die Bildung von Knospen gesorgt, welche sich im nächsten Jahre gerade so wie der einjährige Stamm entwickeln, wobei die Bast- und Holzschicht nicht mit ihrer Basis aufhört, sondern zwischen den Bast und das Holz des vorjährigen Stammes eintritt (Fig. 6. 7). Dieser Vorgang wiederholt sich jedes Jahr regelmässig, so dass also immer die älteren Bastschichten nach aussen, die älteren Holzschichten nach innen zu liegen kommen.

Es sind hier also gleichsam zwei Gefässbündelsysteme vorhanden, ein centrales und ein peripherisches, daher heisst diese Art des Wachsthums endumsprossend, vegetatio peripherico-terminalis, und die betreffenden Pflanzen: Endum s prosser, Acramphibrya, plantae acramphibryae. De Candolle nennt diese Pflanzen im Gegensatz zu seinen Endogenen: Exogenae.

\section{Die Blätter.}

Die verschiedenen Formen der Blätter eignen sich nicht zur Bildung grösserer Abtheilungen im Pflanzenreich, wohl aber sind sie für manche Familien charakteristisch. Es kommen hiebei folgende Verhältnisse in Betracht:

a) Das Vorhandensein von Nebenblättern. Dieselben finden sich oft constant durch mehrere Familien nach einander, wie z. B. den Papilionaceen, Mimoseen, Caesalpineen, dann den Amygdaleen, Rosaceen, Sanguisorbeen, Pomaceen, während sie bei anderen diesen nahe stehenden Familien fehlen. Bei den Polygoneen sind sie zu einer tutenförmigen Scheide verwachsen.

b) Die Theilung der Blätter. Manche Familien zeichnen sich durch gefiederte Blätter aus, so die Papilionaceen, Mimoseen, Caesalpineen, die meisten Anacardiaceen, Burseraceen und andere.

c) Die Aderung der Blätter ist oft sehr charakteristisch. So haben z. B. die Myrtaceen eine dem Rande parallel laufende Ader, welche den nahe stehenden Philadelpheen fehlt. Selbst die grösseren Abtheilungen des Pflanzenreichs, die Endsprosser und Endumsprosser sind durch die Aderung der Blätter verschieden; bei den ersteren sind die Adern in der Regel ein- 
fach und verlaufen parallel, bei den letzteren gewöhnlich netzförmig verzweigt.

d) Drüsen und Haare, mit welchen die Blätter besetzt sind, sind für manche Familien charakteristisch, so zeichnen sich die Myrtaceen, Burseraceen, Aurantiaceen, durch drüsig punktirte, die Boragineen durch sehr rauhe Blätter aus.

e) Auch eine besondere Consistenz der Blätter ist manchen Familien eigenthümlich, wie z. B. bei den Crassulaceen die Blätter sehr fleischig und saftig, bei den Laurineen, Aurantiaceen lederartig sind.

f) Eine besondere Beschaffenheit des Blattstiels findet sich z. B. bei den Aurantiaceen, wo derselbe geflügelt, bei den Ranunculaceen, wo dessen Basis scheidenartig verbreitert ist.

g) Die Stellung der Blätter am Stengel ist für viele Familien sehr charakteristisch. Manche Familien enthalten nur gegenständige Blätter, wie die Labiaten, Valerianeen, oder zugleich auch quirlförmige, z. B. Rubiaceen; bei anderen Familien kommen nur alternirende oder zerstreute Blätter vor.

Die Vegetationsorgane, obgleich für die Klassification der Pflanzen nicht so wichtig, als die Fructificationsorgane, bieten dennoch für diesen $Z$ weck sehr werthvolle Charaktere dar, und zwar lassen sich, wie aus Obigem hervorgeht, die Modificationen der Blätter besonders zur Unterscheidung der Familien benützen, während auf die Unterschiede im anatomischen Bau des Stengels und dessen Wachsthum die grösseren Abtheilungen des Pflanzenreichs gegriindet werden. Mit diesen Verschiedenheiten des Stamms gehen, wie wir später sehen werden, gewisse Modificationen der Fortpflanzungsorgane Hand in Hand, so dass also die - auf jene Charaktere basirte Eintheilung der Pflanzen auch von dieser Seite bestätigt wird.

\section{Fructificationsorgane.}

Für die Charakteristik der Familien sind die Fructificationsorgane, also die Blüthentheile mit der daraus hervorgehenden Frucht, ungleich wichtiger, als die Vegetationsorgane. Auch 
für Bildung der grösseren Abtheilungen finden wir unter jenen sehr werthvolle Anhaltspunkte. Wie die Vegetationsorgane bei den meisten Pflanzen in Achsen und Seitenorgane, in Wurzel und Stamm mit seinen Verzweigungen, und in die Blätter eingetheilt werden, so lassen sich auch bei den Organen der Befruchtung, welche überhaupt nur als modificirte Vegetationsorgane zu betrachten sind, Achsen- und Seitenorgane unterscheiden.

Bekanntlich betrachtet man die alternirende Stellung der Blätter am Stengel als die normale; stehen sie einander gegenüber, so nimint man an, dass ein zwischen zwei Blättern befindliches Stengelglied nicht zur Entwicklung gekommen sei. Wenn sich die abwechselnden Internodien 2, 4, 6 u. s. f. bei Fig. 8 nicht entwickeln, so werden die Blätter opponirt, Fig. 9. Ganz auf die gleiche Art lässt sich die quirlförmige Stellung der Blätter ableiten, und es entsteht z. B. ein 3blättriger Quirl (Fig. 11), wenn die Stengelglieder 2, 3, 5, 6, 8, 9 u. s. w. (Fig. 10) verkürzt sind. So stehen nun auch die Seitenorgane der Blüthe, deren sich hauptsächlich dreierlei Hauptformen, nämlich Blüthendecken, Staubgefässe und der aus den Fruchtblättern gebildete Stempel unterscheiden lassen, in Quirlen oder Kreisen an einem gemeinschaftlichen Achsenorgan - der Blüthenachse. Allein hier sind nicht nur die Internodien zwischen den einzelnen Gliedern eines und desselben Kreises, also zwischen den einzelnen Kelchund Blumenblättern, Staubfäden u. s. w. unentwickelt (Fig. 12), sondern auch die zwischen diesen Kreisen der Blüthenorgane stehenden Stengelglieder sind in den meisten Fällen alle, oder fast alle nicht zur Entwicklung gekommen (Fig. 13); sie stehen daher in concentrischen Kreisen oder einer Spirale in einander, so dass die Kelchblätter immer den äussersten, die Fruchtblätter den innersten Kreis bilden. Der Achsentheil, welcher die seitlichen Blüthenorgane trägt, heisst $B l$ ü the $n \mathrm{~b}$ od en, receptaculum. Die Blüthenorgane selbst zerfallen, wie schon bemerkt, in Blüthendecken, Staubgefässe und Stempel, jedoch sind nicht immer alle entwickelt. 


\section{Der Blüthenboden.}

Der Blüthenboden ist eine aus verkürzten Internodien bestehende Blüthenachse, welche die Bestimmung hat, den Blüthenorganen als Träger zu dienen. Derselbe zeigt, je nachdem alle oder nur einzelne Internodien verkürzt, oder einzelne in die Breite ausgedehnt sind, in seiner Form oft so bedeutende Verschiedenheiten, dass dadurch die Stellung der Blüthentheile zu einander ganz verändert wird und dass hierauf die wichtigsten Unterschiede nicht blos einzelner Familien, sondern auch grösserer Abtheilungen gegründet werden. Hauptsächlich ist es die relative Stellung der Blüthendecken und Staubgefässe zum Stempel, oder ihre Insertion, welche in den meisten Fällen von der verschiedenen Entwicklung der Internodien der Blüthenachse abhängig ist und es wird in dieser Beziehung zwischen hyp ogynischer, perigynischer und epigynischer Insertion unterschieden. *

A. Wenn sämmtliche Internodien der Blüthenachse verkürzt sind, so ist ihr Ende gewöhnlich angeschwollen oder kegelförmig verdickt und die Blüthentheile stehen alle in concentrischen Kreisen oder einer Spirale bei einander, ohne dass in ihrer gegenseitigen Stellung etwas verändert wird; die Blüthendecken nehınen die äusserste oder unterste, der Fruchtblätterkreis, welcher den Stempel bildet, die innerste oder oberste Stelle ein; erstere stehen also unter den weiblichen Befruchtungswerkzeugen, sie haben eine unterweibige Stellung, insertio hypogyna. Das Ovarium ist in diesem Fall ein oberständiges, ovarium superum. Dieselbe unterweibige Stellung haben auch die Staubgefässe (Fig. 14. 15). Die einzelnen Theile der Blüthendeckenkreise, also Kelchblätter, Blumenblätter, können dabei unter sich verwachsen sein, ohne dass an ihrem Verhältniss zum Stempel etwas geändert wird; selbst die Staubgefässe können mit den Blumenblättern, welche in diesen Fall gewöhnlich mit einander

* Bei den Figuren, welche die nachstehende Beschreibung der Insertion erläutern sollen, sind die zur Blüthenachse und Blüthenboden gehörigen Theile mit blauer Farbe bezeichnet, der Kelch grün, Corolle roth, Staubgefässe orange, Pistill braun. 
verwachsen sind, verbunden sein, ihre Stellung zum Stempel bleibt dennoch eine hypogyne; es sind unterweibige, auf den Blumenblättern sizende Staubgefässe, stamina hypogyna epipetala.

Von dieser normalen hypogynischen Stellung der Blüthendecken und Staubgefässe kommen vielfache Abweichungen vor, welche davon herrühren, entweder dass nicht alle Interнodien des Blüthenbodens verkürzt sind, oder dass einzelne oder alle in die Breite auswachsen. Der erste Fall, dass nicht alle Internodien verkürzt sind, also zur Entwicklung kommen, kann beim obersten Internodium, das den Stempel trägt, eintreten (Fig. 16), wodurch der Stempelträger, gynophorum entsteht, wie diess z. B. bei Saponaria, Capparis, stattfindet. Auch das Internodium, welches die Staubgefässe trägt, hat sich bisweilen nicht verkürzt (Fig. 16), wodurch der S taubgefässträger, androphorum, gebildet wird, was bei Passiflora beobachtet werden kann. In beiden Fällen wird an der hypogynischen Insertion der Blüthentheile nichts verändert. Ungleich häufiger kommt es vor, dass eines oder alle Internodien in die Breite auswachsen, wodurch die Insertion der Blüthentheile perigynisch oder hypogynisch werden kann. Wenn sich das oberste, den Stempel tragende Glied der Blüthenachse statt in die Länge - in die Breite ausdehnt, so entsteht eine unterweibige Scheibe, discus hypogynus (Fig. 18), wie z. B. bei den Labiaten, bei Citrus und vielen anderen Pflanzen. Wenn die Corolle verwachsenblättrig ist, so stehen die Staubgefässe auf der Corolle selbst. Auch das nächste Internodium, das der Staubgefässe, kann sich gemeinschaftlich mit dem Internodium des Stengels in die Breite ausdehnen, ebenfalls eine hypogynische Scheibe bildend, welche am Rande die Staubgefässe trägt, wie bei Reseda, Acer (Fig. 19). Die Stellung der Blüthentheile zum Ovarium bleibt auch jetzt noch hypogynisch. Es können sich aber auch alle Internodien des Blüthenbodens mit einander zu einer verschieden gestalteten, - flächen, concaven, becherförmigen oder röhrenförmigen Scheibe ausbreiten (Fig. 20 a b c), auf welcher die Blüthentheile auf gar mannigfaltige Weise angeordnet sind; ihre Stel- 
lung wird nun entweder perigynisch oder epigynisch. Diese Modification des Bluthenbodens wird von Link Unterkelch, hypanthium, genannt.

B. Wenn die Blüthendecken und Staubgefässe auf dem Rand des Unterkelchs, die Fruchtblätter aber, welche das Ovarium bilden, in deutlichem Abstand davon mehr gegen die Mitte des Unterkelchs entspringen, so nennt man diess die perigynische Stellung, insertio perigyna. Das Ovarium ist dabei entweder ein oberständiges oder ein unterständiges.

a) Bei der perigynischen Insertion mit oberständigem Ovarium bleibt der Unterkelch entweder ein schmaler Ring, der die Blüthendecken und Staubgefässe trägt, wie z. B. bei den Laurineen, Papilionaceen (Fig. 21), oder er bildet eine deutliche Röhre, aus welcher die Blüthendecken und Staubgefässe entspringen und zwar gewöhnlich ohne Unterbrechung über einander, z. B. bei den Rosaceen (Fig. 22), bisweilen aber auch die Staubgefässe entfernt von den Blüthendecken, mehr in Grunde des Unterkelchs (Fig. 23). Nicht selten erhebt sich der zwischen Staubgefässen und Ovarium gelegene Theil zu einem Wulst und bildet einen Ring, annulus oder eine perigy is che $\mathrm{S}$ cheibe, discus perigynus. Bei wenigen Familien mit perigynischer Insertion, z. B. den Pomaceen, verwachst der anfangs freie Stempel mit dem Unterkelch.

b) Die perigynische Insertion mit unterständigem Ovarium entsteht dadurch, dass sich der Unterkelch über letzteres hinaus zu einer Röhre verlängert, aus welcher die Blüthendecken und Staubgefässe hervortreten. Die Fruchtblätter bilden bei ihrer Verwachsung zum Ovarium entweder eine Wölbung, wodurch die Eier bedeckt werden, die im Grunde des Unterkelchs entspringen, und gehen nach oben in den Griffel und die Narbe über, in welchem Falle das Ovarium halbunterständig, seminiferum ist (Fig. 24); oder die Eier sind ganz von dem Unterkelch, der sich oben verengt, eingeschlossen, und die Fruchtblätter bilden nur den Griffel und die Narbe (Fig. 25).

Diese Verhältnisse könnten übrigens auch, - und vielleicht auf naturgemässere Weise, so erklärt werden, dass die Eier auf 
normale Weise von den Fruchtblättern eingeschlossen sind, dass aber die Röhre, welche der Unterkelch bildet, mit dem Ovarium ganz oder zur Hälfte verwachsen ist (Fig. 26).

C. Die epigynische Insertion, insertio epigyna entsteht dadurch, dass sämmtliche Blüthentheile über einem unterständigen Ovarium olnne deutlichen Abstand von einander auf dem Unterkelch entspringen, dessen Rand nicht, über das Ovarium hinaus verlängert ist. Dabei kann Letzteres, wie bei der perigynischen Stellung, halbunterständig (Fig. 27) oder ganz unterständig sein (Fig. 28). Da der Unterschied zwischen der insertio perigyna ovario infero und hypogyna eigentlich nur in der beim ersten Fall entfernteren Stellung der Bliithentheile vom Pistill liegt, so ist leicht einzusehen, dass auch Uebergänge von der einen in die andere Stellung vorkommen. Im folgenden Abschnitt werden wir sehen, dass sich die verschiedenen von đer normalen hypogynischen Insertion abweichenden Stellungen der Blüthentheile auch noch auf andere Art erklären lassen.

\section{Die Blüthendecken.}

Bei den meisten Pflanzen sind die Blüthendecken von zweierlei Art und bestehen aus einem äusseren Kreise von derberen, meist grün gefärbten Blättern, dem Kelch, calyx, und einem inneren Kreise zarter Blätter von gewöhnlich anderer als grüner Farbe, der Blumenkrone, corolla. Die normale Stellung beider ist die, dass die Kelch- und Corollenblätter mit einander abwechseln. Diese Regel erleidet dann eine scheinbare Ausnahme, wenn zwei Kelchblattkreise und zwei Blumenblattkreise vorhanden sind, wodurch die Blumenblätter den Kelchblättern opponirt erscheinen. Sodann kommt eine Abweichung von der normalen Stellung durch Fehlschlagen einzelner Kelchoder Blumenblätter vor, was dann gewöhnlich eine unregelmässige Form derselben zur Folge hat. Bei vielen Pflanzen fehlt die Corolle ganz und es ist nur eine einfache Blüthendecke vorhanden, welche Perigon, perigonium heisst. Dieser Ausdruck Perigon wird auch dann gebraucht, wenn zwar 2 Kreise von 
Blüthendecken vorhanden sind, aber beide eine gleichartige Beschaffenheit, sei es die eines Kelchs oder einer Corolle angenommen haben, wie diess bei den Amphibryen der Fall ist.

Sowohl die Blätter des Kel chs, sepala, als die der C orolle, petala, sind häufig unter sich verwachsen; Kelch und Corolle heissen dann einblättrig, calyx monosepalus oder monophyllus, corolla monopetala, richtiger aber verwach senblättrig, calyx gamosepalus, corolla gamopetala. Das Verwachsensein findet sehr häufig niclıt der ganzen Länge nàch, sondern, von der Basis der Kelch- und Blumenblätter aus, auf verschiedene Höhe derselben statt, und ihre freien oberen Enden erscheinen als Abschnitte, Zipfel, Lappen, segmenta, laciniae, lobi. Bei Pflanzen mit seitenständigen Blüthen ist die Stellung, welche die Kelchzipfel bei ungerader Zahl zur Hauptachse einnehmen, oft eine ganz bestimmte, und für einzelne Familien charakteristisch; bei den Leguminosen z. B. ist der unpaare Kelchzahn nach vorne, bei den diesen nahe stehenden Rosaceen nach hinten oder oben gestellt.

Nicht nur die Kelch- und Blumenblätter unter sich können verwachsen sein, sondern es kommt auch eine Verwachsung der Kelchröhre mit den unteren Theilen der Blumenblätter, der Staubgefässe und selbst des Ovariums vor, wodurch nun die sonst hypogynische Stellung der Blüthentheile zu einer perigynischen oder epigynis chen wird, und das Ovarium nicht mehr frei oder oberständig, sondern halbunterständig oder unterständig erscheint.

Nach dem Vorstehenden ist es klar, dass die perigynische und epigynische Insertion der Blüthentheile, das halbunterständige und unterständige Ovarium auf zweierlei Weise erklärt werden, und entweder von einer besonderen Bildung des Blïthenbodens oder von einem Verwachsensein der verschiedenen Kreise der Blüthentheile abgeleitet werden kann. Welche von beiden Ansichten die richtige ist, kann nicht immer entschieden werden; immerhin aber gibt es Fälle, wo ganz sicher die eine, und andere Fälle, wo unzweifelhaft die andere Erklärungsweise anzuwenden ist. Oft werden wir durch anomale Bildungen der 
Blüthen auf die richtige Ansicht geleitet; so findet man zuweilen Umbelliferen mit epigynischer Corolle und hypogynischem Kelch, was darauf hinweist, dass die sonst ebenfalls epigynische Insertion des Kelchs von der Verwachsung der Kelchröhre mit dem Ovarium herrührt. Ueberhaupt ist diese letztere Ansicht immer als die richtige anzunehmen, wenn die Mittelnerven der Kelchblätter oder -Zipfel sich über das Ovarium herab verfolgen lassen. Mag man sich übrigens die Sache erklären wie man will, - auf die Unterscheidung der Familien, Klassen u. s. w. sind selbstverständlich die verschiedenen Ansichten von keinem Einfluss; denn es ist für diesen Zweck gleichgiltig, ob z. B. die Fig. 29 nach Art von Fig. 30 oder Fig. 31 erklärt wird.

Die Knospenlage ist häufig ein sehr sicheres Merkmal zu Unterscheidung der Familien und bietet bei sehr nahe verwandten Pflanzen oft das einzige Unterscheidungsmerkmal, so dass also bei Pflanzen, von denen es ungewiss ist, ob sie in dieselbe, oder zwei verschiedene Familien zu stellen sind, die Knospenlage entscheidet.

Man versteht unter Knospenlage, aestivatio, oder, da dieser Ausdruck auch für die Vegetationsblätter gilt, unter Blüthendeckenlage, praefloratio, die Art und Weise, wie die Blätter der Blüthendecken in der Knospe gegenseitig liegen, und die Art, wie sie gefaltet sind. Es lassen sich hiebei folgende Arten unterscheiden:

A. Klappige Knospenlage, aestivatio valvularis. Die Blätter sind in der Knospe nicht übereinander gelegt, sondern berühren sich nur mit ihren Rändern, wie bei Malva, Tilia.

Eine besondere Art der klappigen Knospenlage ist die eingefaltete, aestiv. induplicativa, wo die Ränder nach innen umgerollt sind, so dass sie sich mit ihren Rückenflächen berühren, z. B. Clematis (Fig. 32).

B. Gedrehte Knospenlage, aestiv. contorta. Der eine Rand eines Blatts bedeckt den ihm zunächst gelegenen Rand des auf seiner Seite liegenden Blatts, so dass also von jedem Blatt ein Rand bedeckt, der andere unbedeckt ist, z. B. Phlox (Fig. 33.). 
C. Dachziegelförmige Knospenlage, aestiv. imbricativa. Die Ränder der äusseren Blätter sind über die Ränder der inneren Blätter hergedeckt; es sind also bei den inneren Blättern beide Ränder bedeckt, bei den äusseren beide frei, dazwischen stehen dann Blätter, deren einer Rand bedeckt, der andere frei ist. Als besondere Arten dieser Knospenlage unterscheidet man:

a. Abwechselnde Knospenlage, aest. alternativa. Zwei Reihen von Blüthenhüllen wechseln regelmässig mit einander $a b$ und bedecken einander, z. B. Tulipa (Fig. 34).

b. Fahnenförmige Knospenlage, aest. vexillaris, die Knospenlage der Papilionaceen, wo das eine Blüthenblatt bedeutend grösser ist, als die übrigen, welche von ihm eingeschlossen werden (Fig. 35).

c. Fünfschichtige Knospenlage, aestivatio quincuncialis. Es sind hier immer 5 Blumenblätter vorhanden; die zwei äusseren haben unbedeckte Ränder, das nächste einen bedeckten und einen freien Rand, und bei den beiden innersten sind beide Ränder bedeckt. Diese Stellung rührt daher, dass in einer fünfblättrigen Spirale die Blätter um ${ }^{2}, 5$ des Kreises von einander entfernt sind, und findet sich z. B. bei den Rosaceen und vielen anderen Familien (Fig. 36).

Häufig lässt sich die dachziegelförmige Knospenlage nicht unter diese drei Fälle zurückführen.

D. Ge fal t e te Knospen lage, aestivatio plicativa. Eine verwachsenblättrige Corolle ist der Länge nach eingefaltet, wie z. B. bei Campanula. Wenn die Blumenblätter ganz unregelmässig gefaltet sind, so nennt man diess - zerknitterte Knospenlage, aestiv. corrugativa, was bei Papaver vorkommt.

\section{Die Staubgefässe.}

Wie die Blumenblätter mit den Kelchblättern, so wechseln unter normalen Verhältnissen die Staubgefässe mit den Blumenblättern ab. Ausnahmen kommen auch hier häufig vor. Stehen die Staubgefässe den Blumenblättern gegenüber, so erklärt sich diess leicht dadurc,h dass man das Vorhandensein zweier Staub- 
gefässkreise annimmt, wovon aber auch bisweilen ein Kreis $\mathrm{nicht}$ entwickelt sein kann. Durch Fehlschlagen einzelner Staubgefässe aus einem Kreis wird die Blüthe unregelmässig.

Die Art des Aufspringens der Staubbeutel ist bisweilen charakteristisch. Bei den meisten Pflanzen erfolgt das Aufspringen in Längsfurchen, gewöhnlich nach innen; dann aber kommt es vor, dass die Antheren nach aussen gewendet sind und sich daher nach dieser Seite hin öffnen; das Aufspringen selbst findet bei gewissen Pflanzen, oder ganzen Familien auch in Poren, Klappen, Deckeln, kürzeren Spalten statt.

\section{Der Stempel.}

Gleich den übrigen Blüthentheilen besteht auch der Stempel, pistillum, aus metamorphosirten Blättern, welche man Fruch tblät ter oder Carpell arblätter, carpophylla, folia carpellaria nennt. Dieselben bieten, je nachdem sie einzeln oder $\mathrm{zu}$ mehreren in einer Blüthe vorhanden und je nachdem sie unter sich mit einander verbunden sind, so mannigfaltige Formen dar, dass sie zur Unterscheidung der Familien unstreitig die besten und wichtigsten Anhaltspunkte abgeben. Die Fruchtblätter unıschliessen die Anfänge der Samen - Eier -, welche auf einem eigenthümlichen Gebilde, dem Sam enträger, spermophorum, oder Mutterkuchen, placenta, befestigt sind. Dieselben stehen in selteneren Fällen frei in der Höhlung, welche durch die verwachsenen Fruchtblätter gebildet wird; viel häufiger aber sind sie mit den letzteren verwachsen und erscheinen als wulstförmige Erhöhungen, welche die Höhlung des Pistills von unten bis oben durchziehen, indem sie sich an dessen Wandungen, oder an die Scheidewände, wenn solche vorhanden, anlegen. Der Stempel ist entweder einfach, d. h. nur aus einem Carpellarblatt gebildet, pistillum simplex, carpellum; oder er besteht aus mehreren Carpellarblättern, ist also $\mathrm{z}$ u s ammeng e s etzt, pistillum compositum.

A. Der einfachste Fall ist der, dass der Stempel aus einem einzigen Carpellarblatt besteht. Bei sehr wenigen Familien, 
Coniferen, Cycadeen, ist dasselbe offen und trägt dann die Eier entweder an seiner Basis oder an Rande. Man nennt die Pflanzen mit offenem Carpellarblatt: Nacktsamige, Gymnospermae, was nicht zu verwechseln ist mit der Linnésschen Ordnung $D i$ dynamia gymnospermia für die Labiaten. Bei weitem am häufigsten aber ist das Carpellarblatt geschlossen, d. h. es ist zusammengelegt und seine Ränder sind verwachsen; es besteht. dann aus einem unteren, hohlen Theil, dem Fruchtknoten, germen, ovarium, der die Placenta mit den Eiern einschliesst, nach oben in eine dünne Röhre übergeht, welche Griffel, stylus genannt wird, und an seiner Spitze ein sehr lockeres, Feuchtigkeit ausschwitzendes Zellgewebe, die $\mathrm{N}$ a rb e, stigma, trägt. Der Griffel ist als Verlängerung der Mittelrippe des Carpellarblattes zu betrachten, kann aber auch fehlen, so dass die Narbe unmittelbar auf dem Ovarium sitzt. Am Ovarium unterscheidet man die R ückennaht, sulura dorsalis, der Mittelrippe des Fruchtblatts entsprechend, und die Bauchnaht, sutura ventralis, welche durch die Verwachsung der Fruchtblattränder gebildet wird. Der Samenträger oder die Placenta ist in der Regel mit der Bauchnaht verbunden, kann aber auch in der Rückennaht liegen. Eine Blüthe enthält entweder nur ein einziges Carpell, in welchem Fall es immer seitlich, nie auf der Spitze der Blüthenachse, und zwar so gestellt ist, dass die Rückennaht gegen die Peripherie, die Bauchnaht gegen das Centrum der Blüthe gewendet ist; oder es stehen in einer Blüthe mehrere einfache Carpelle in einem Kreis oder einer Spirale beisammen.

B. Wenn zwei oder mehrere Carpellarblätter mit einander verwachsen, so kann diess auf doppelte Art geschehen.

a. Der rechte Rand des einen verwachst mit dem linken Rand des ilım zunächst stehenden Carpellarblatts und es wird auf diese Art ein einfächeriges Ovarium gebildet. Die Placenten sind hier gewöhnlich aus den verwachsenen Rändern zweier Carpellarblätter gebildet, sie können aber auch in der Mittelrippe jedes einzelnen Carpellarblatts auftreten; die Eier stehen also an der äusseren Wand des Ovariums in Längsreihen. 
b. Es können aber auch geschlossene Carpelle mit einander verwachsen, und zwar geschieht diess immer an der - der Achse zugekehrten Seite. Die Placenten, welche in der Bauchnaht der einzelnen Carpelle liegen, verschmelzen dann zu einer gemeinschaftlichen Säule, die der ganzen Länge nach durch das Ovarium verlauft. Es entstehen dann gerade so viele Fächer im Ovarium, als die Anzahl der Carpellarblätter beträgt, aus welchen es besteht.

Oft kommt es aber auch vor, dass die Ränder der Carpellarblätter noch einmal zurückgeschlagen und gegen die Peripherie des Ovariums gewendet sind, wo dann oft die Placenta mit dessen äusserer Wandung verwachst. Die Zahl der Fächer wird dadurch verdoppelt, aber nicht alle, sondern jedesmal nur die abwechselnden Scheidewände tragen Samen. Cucurbitaceae.

Die Scheidewände, dissepimenta, welche durch die Verwachsung der Carpelle gebildet werden, haben begreiflicher Weise eine doppelte Wandung. Es gibt aber auch falsche Scheidewände, mit nur einfacher Wandung sowohl in senkrechter, als transversaler Richtung, von denen die ersteren centrifugal, oder centripetal sind, indem sie entweder aus der centralen Placenta gegen die Peripherie vorspringen, und sich an die Rückennähte des Ovariums anschliessen, Datura; oder umgekehrt aus dieser hervorkommen und gegen das Centrum hin verlaufen, ohne jedoch immer ganz zur Placenta zu gelangen, Aronia. Die falschen $Q$ u erscheidewände bilden sich erst nach der Blüthe aus und entstehen durch eine Wucherung des Zellgewebes in den Wandungen der Carpelle; sie finden sich z. B. bei vielen Leguminosen, wie Phaseolus, Cassia fistula, Ceratonia u. S. w.

Es wurde schon oben erwähnt, dass die Samenträger oder Placenten gewöhnlich durch die Verdickung zweier, mit einander verwachsener Carpellarblattränder entstehen, dass letztere also vorzugsweise es sind, welche die Fähigkeit haben, Samenknospen oder Eier zu erzeugen. Da immer je zwei Carpellarblätter zusammenstossen, so stehen auch die Eier in der Regel in zwei Reihen geordnet. Aber auch die Mittelrippen der Carpellarblätter 
und in einzelnen Fällen die ganze Innenseite des Ovariums kann mit Eiern besetzt sein. Ein analoges Beispiel haben wir bei den Vegetationsblättern mancher Pflanzen, z. B. Bryophyllum, Begonia, welche unter günstigen Unständen nicht allein an ihren Rändern, sondern auch auf der Blattfläche selbst Knospen hervorzubringen vermögen. Bei wenigen Familien entspringt die Placenta aus der Basis des Ovariums und ragt frei in dessen Höhlung hinein, Primulaceae; sie ist als Fortsetzung der Blüthenachse zu betrachten, welche bisweilen noch über das Ovarium hinaus verlängert ist, Geraniaceae. Es werden desshalb von manchen Botanikern alle Placenten als die Enden der Blüthenachsen betrachtet und bei den wandständigen Placenten eine von ihrer Basis ausgehende Theilung dieser Achsen angenommen. Es scheint jedoch naturgemässer zu sein, die wandständigen und diejenigen centralen Placenten, welche mit den Scheidewänden zusammenhängen, als aus den Carpellarblatträndern hervorgegangen anzusehen.

Die Samenknospen, gemmulae oder Eier* ovula entstehen auf der Oberfläche der Placenta, und zwar immer vor der Blüthezeit. Zuerst erscheint eine warzenförmige Erhöhung, welche zu einem eiförmigen Sack auswächst, dèm späteren Eikern, nucleus. An seiner Basis entwickelt sich eine Hautfalte, die gegen die Spitze fortwächst, ohne jedoch sich oben zu schliessen, und welcher bei den meisten Pflanzen eine zweite folgt. Die Oeffnung dieser Eihäute heisst Keimmund, micropyle, die der äusseren Eihaut: exostomium, die der inneren: endostomium. Als Spitze des Eikerns ist der gegen den Keimmund gekehrte Theil zu betrachten, als Basis der auf der Placenta befestigte Theil; die Stelle, wo der Eikern mit den Eihäuten zusammenmündet, heisst $\mathrm{Hag}$ elfleck, in nerer $\mathrm{Nabel}$, chalazd. Das Ei sitzt entweder unmittelbar auf der Placenta, oder ist darauf mittelst eines Fadens, welcher $\mathrm{Nab}$ els c hnur,

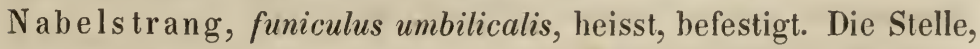

* Ich bediene mich dieses Wortes statt des schlecht klingenden Diminutivums „Eichen ". 
wo das Ei an der Nabelschnur, oder wenn diese fehlt, an der Placenta sitzt, heisst $\mathrm{N}$ ab e 1, umbilicus, hilum. *

Ein Ei, dessen Achse gerade ist, an dessen höchster Spitze der Keimmund und an der demselben gerade entgegengesetzten Basis der Nabel und der Hagelfleck sich befindet, heisst ein gerades, geradläufiges, ungewendetes Ei, ovulum orthotropum s. atropum (Fig. 37). Der Nabelstrang ist hier in der Regel so kurz, dass er zu fehlen scheint. Solche Eier kommen bei verhältnissmässig nicht vielen Pflanzen vor. Weit häufiger unterliegen die Eier im Verlaufe ihrer Entwicklung verschiedenen Modifikationen, deren Folge die ist, dass der Keimmund eine andere, als die dem Nabel entgegengesetzte Stelle einnimmt. Diess kann auf zweierlei Art stattfinden. Einmal bleibt das Ei selbst gerade, es wendet sich aber auf der Spitze der Nabelschnur um, legt sich mit seiner Seite an dieselbe an und verwachst mit ihr entweder seiner ganzen Länge nach - gegenläufiges Ei, ovulum anatropum (Fig. 38), der häufigste Fall, oder nur zur Hälfte, halbgegenläufiges Ei, ovuhım hemianatropum (Fig. 39), z. B. Primulaceae. Der mit dem Ei verwachsene Theil der Nabelschnur heisst $\mathrm{Naht}$, raphe. Beim anatropen Ei liegt der Nabel neben dem Keimmund, bei halbgegenläufigen zwischen diesem und dem Hagelfleck.

Es kann sich aber auch die Achse des Ei's krümmen, indem die eine Seite desselben, gewöhnlich die von der Placenta abgewendete, sich stärker entwickelt; dann kommt nicht allein der Nabel, sondern auch der Hagelfleck neben den Keimmund zu liegen; ein solches Ei heisst krummläufig, ovulum cam. pylotropum (Fig. 40). Wenn ein langgestrecktes Ei sich in

* In den zum Ei und Embryo gehörigen Figuren ist der Nabelstrang durch braune, die Eihäute durch rothe, der Eikern durch gelbe und der Embryo durch grüne Farbe bezeichnet. Der Eikern verwandelt sich entweder in den Eiweisskörper, oder wenn dieser fehlt, so nehmen die fleischig gewordenen. Cotyledonen des Embryo dessen Stelle ein.

a) Der Keimmund, micropyle.

b) Der innere Nabel, chalaza.

c) Der äussere Nabel, hilum, umbilicus. 
der Mitte umbiegt und seine beiden Schenkel parallel neben einander verlaufen, so entsteht ein hufeisenförmig gebogenes Ei, ovulum camptotropum, z. B. Menispermum.

Gegen die Zeit der Blüthe entwickelt sich im Zellkern eine seiner Zellen zu bedeutender Grösse und stellt so den Keimsack, sacculus embryonalis dar, innerhalb welchem in Folge der Befruchtung der Keim, embryo, entsteht, d. h. derjenige Theil des Samens, welcher die Fähigkeit hat, zu einer Pflanze sich zu entwickeln.

\section{Der Samen.}

Der Samen, semen, ist das zur Reife gekommene Ei. Gleichzeitig mit der Entstehung des Embryo verwachsen die Eihäute mit einander und erscheinen beim reifen Samen als Samenhaut; der Eikern verschmilzt entweder mit derselben oder er wächst zu einer fleischigen Masse aus, in welcher Nahrungsstoffe abgelagert werden. Man nennt dieselbe den Eiweisskörper, Albumen. Auch im Innern des Keimsacks kann sich ein Eiweisskörper bilden; das Eiweiss kann also einen doppelten Ursprung haben und entweder aus dem Eikern oder innerhalb des Keimsacks entstanden seyn; Ersteres wird perispermium, Letzteres endospermium, genannt, gewöhnlich ist nur Eines von Beiden, in seltenen Fällen perispermiun und endospermium vorhanden, wie bei den Piperaceen, Zingiberaceen. Die Bildung eines Eiweisskörpers findet jedoch nicht immer statl, sondern häufig eilt der Embryo in seiner Entwicklung dem Albunen voraus und die Nahrungsstoffe werden voin Embryo selbst aufgenommen. Man unterscheidet daher eiweisshaltige und eiweisslose Samen, semina albuminosa und exalbuminosa

Der Einbryo bildet die Anlage zu einer neuen Pflanze und besteht aus der künftigen absteigenden Achse, dem Würzelchen, radicula, welches im Samen immer gegen den Keimmund gerichtet ist, und dem Federchen, plumula, der Anlage zu den Blätterm, unterhalb welchen die $\mathrm{S}$ am enblätter, Samenlappen oder $\mathrm{C}_{0-}$ t yledonen, colyledones, cotylae, entspringen, welche schon mehr ausgebildet sind als die Blättchen des Federchens, und auch in 
ihrer Form von derselben abweichen. Zwischen beiden befindet sich das Stengelchen, cauliculus, das aber gewöhnlich zu dem Würzelchen gerechnet wird, weil sich keine feste Grenze zwischen den beiden Achsenorganen wahrnehmen lässt. Bei manchen Samen ist der Embryo in seiner Entwicklung noch nicht bis zu dem Grad fortgeschritten, dass sich die einzelnen Theile unterscheiden lassen, sondern er stellt eine gleichförmige, fleischige Masse dar, er ist ein embryo homogenius, z. B. Bertholletia, Utricularia, Orchideen. Bei den meisten Embryonen aber kann man die Samenlappen mehr oder weniger deutlich unterscheiden.

Ein Drittheil des Pflanzenreichs hat nur e in en Samenlappen, welcher die Spitze des Stengelchens wie eine Mütze bedeckt und das Federchen einhüllt; diese Pflanzèn heissen einsamenla ppige, Plantae monocotyledoneae, Monocotyledones. Bei diesen Pflanzen ist zugleich das Würzelchen wenig ausgebildet, und entwickelt sich auch nicht bei der Keimung, oder wenn diess doch der Fall ist, so stirbt es bald ab. Dafür entwickeln sich in beiden Fällen am unteren Ende des Stengelchens Nebenwurzeln. Richard nennt diese Pflanzen Plantae endorhizae. Bei den übrigen Pflanzen finden sich in der Regel zwei Cotyledonen, welche einander gegenüber stehen, selten mehrere, quirlförmig gestellte; sie heissen zweis am en lappige Pflanzen, Plantae dicotyledoneae, Dicotyledones. Das Würzelchen ist bei diesen Pflanzen mehr ausgebildet und wächst unmittelbar zur Pfahlwurzel aus; sie heissen nach Richard Plantae exorhizae.

Die einsamenlappigen Pflanzen sind zugleich diejenigen, deren Stamm den oben beschriebenen Bau der Umsprosser hat, während dem Stamm der Dicotyledonen der Bau der Endumsprosser zukommt. Es bezeichnen also: Amphibrya, Monocotyledones, Endorhizae einerseits, und Acramphibrya, Dicotyledones, Exorhizae andererseits dieselben Abtheilungen des Pflanzenreichs.

Für die Unterscheidung der Familien noch besonders wichtig ist die Lage des Embryo in Beziehung auf den Eiweisskörper und die Richtung des Würzelchens gegen den Nabel und das Fruchtgehäuse. 
Das Eiweiss bildet bei normaler Entwicklung einen Sack, in welchem der Embryo eingeschlossan ist; er liegt entweder in der Achse des Eiweisses, e mbryo axilis, und zwar oben, unten, oder in der Mitte; oder er befindet sich mehr gegen seine Seite hin, embryo extraaxillaris. Allein öfters tritt der Fall ein, dass sich das Eiweiss einseitig entwickelt, wodurch der Embryo zur Seite geschoben wird und ausserhalb desselben zu liegen kommt; er befindet sich dann entweder an der Seite, e mbryo la teralis, oder an einem Ende des Eiweisskörpers embryo albumini accumbens, oder schliesst das Albumen ein, embryo periphericus. Als Basis des Embryo wird das Würzelchen betrachtet, als Spitze das Federchen; bei einem Samen, der aus einem geradläufigen Ei entstanden ist, muss also, da das Würzelchen immer gegen die Micropyle sieht, der Keim umgekehrt sein, embryo inversus (Fig. 37), wogegen er bei einem anatropen Ei aufrecht ist, embr. erectus (Fig. 38). Das Würzelchen des umgekehrten Embryo's ist vom Nabel abgewendet, radicula ab hilo remonta, das des aufrechten Embryo's gegen den Nabel gerichtet, radicula ad hilum versa, rad. hilum spectans. Bei einem ovulum hemianatropum ist das Würzelchen gegen die Seitenflächen des Samens gerichtet, und heisst radicula la teralis (Fig: 39). Beim ovulum campylotropum und camptotropum ist der Keim gekrümmt, embryo curvatus.

Hinsichtlich der Lage des Würzelchens zum Fruchtgehäuse unterscheidet man das nach der Fruchtspitze gerichtete, radicula supera, und das nach deren Basis sehende Würzelchen, rad. infera; dieselbe hängt nothwendig davon ab, welche Richtung das Ei und der Samen im Fruchtgehäuse hat, und ob er aus einem geraden oder gegenläufigen Ei hervorgegangen ist. Ein aus einem geraden aufrechten $\mathrm{Ei}$ entstandener Samen muss nothwendig ein gegen die Fruchtspitze gerichtetes Würzelchen haben, ebenso ein Samen der sich aus einem gegenläufigen, hängenden $\mathrm{Ei}$ gebildet hat; ferner entspricht dem ovulum orthotropum pendulum und dem ov. anatropum crectum eine radicula infera. Wenn die Eicr (Samen) wagrecht von der Placenta abstehen, so hat das Würzelchen ebenfalls eine horizontale 
Richtung, beim ovulum orthotropum ist dann das Würzelchen centrifugal, rad. centrifuga, beim anatropen Ei gegen das Centrum des Fruchtgehäuses gerichtet, rad. centripeta.

\section{- 6. Die Frucht.}

Unter der Frucht, fructus, werden im Allgemeinen sämmitliche Blüthentheile nach der Periode der Samenreife begriffen, also ausser dem zur Reife gekommenen Ovarium auch minder wesentliche Theile der Blüthe, wie bei manchen Pflanzen der Blumenboden, das Perigon, oder selbst die Bracteen, besonders wenn dieselben eine fleischige oder holzige Beschaffenheit angenommen haben. Demnach bilden die Samen, deren Entwicklung aus den Eiern wir bereits verfolgt haben, einen Theil der Frucht und es bleibt also noch übrig zu untersuchen, welchen Veränderungen die anderen Blüthentheile besonders die Carpellarblätter bei der Fruchtbildung unterliegen. Wenn eine Frucht nur allein aus einem Stempel hervorgegangen ist, heisst sie wahre Frucht, haben sich aber noch andere, ausserwesentliche Blüthentheile dabei betheiligt, namentlich Kelch und Bracteen, wird sie falsche Frucht genannt.

Das einfachste Verhältniss bei der Entwicklung der wahren Frucht ist das, dass die Carpellarblätter und Placenten sich vergrössern und fest werden, so dass man. also schon rom Ovarium aus auf die Beschaffenheit der Fruclt schliessen kann. Dieses Verhältniss findet jedoch bei weitem nicht bei allen Pflanzen statt, sondern bei vielen ist der Bau der_Frucht von dem des Ovariums ganz verschieden und zwar hängt diess hauptsächlich von zwei Ursachen ab.

Einmal entwickeln sich häufig einzelne Theile des Ovariums nicht weiter, sondern verkümmern, so dass sie an der reifen Frucht oft gar nicht mehr bemerkt werden können. Am häufigsten ist das Fehlschlagen einzelner Eier, und in Folge dessen das Verschwinden einzelner Fächer. Bei Corylus z. B. ist das Ovarium dreifächerig und enthält in jedem Fach ein Ei, die Frucht ist einfächerig, einsamig, bei Quercus findet sich ein dreifächeriges Ovarium mit je zwei Eiern, die Frucht aber ist ebenfalls einfächerig, einsamig. 
Bisweilen reissen die Scheidewände ein, wodurch aus einem mehrfächrigen Ovarium eine einfächerige Frucht entsteht. Bei einsamigen Früchten verwächst häufig der Samen mit der Fruchthülle, wodurch scheinbar nackte Samen entstehen z. B. bei den Gramineen, Umbelliferen.

Sodann können sich auch an der Frucht Theile ausbilden, die im Ovarium nicht vorhanden waren, wie z. B. Scheidewände und Nähte, beide nicht nur der Länge nach, sondern auch in die Quere. Eine weitere Veränderung, welche das Ovarium bei seiner Ausbildnng zur Frucht erleidet, ist die, dass die Fruchthülle fleischig wird. Übrigens ist dieser Umstand für die Unterscheidung der Familien von untergeordneter Bedeutung, denn es können von sehr nahe verwandten Pflanzen, welche sogar zu einer und derselben Gattung gehören, die einen trokene, die anderen fleischige Früchte haben.

Das Aufspringen der Früchte, oder die Art wie sich die einzelnen Carpellarblätter nach der Fruchtreife wieder trennen, bietet sehr wichtige Unterscheidungsmerkmale dar. In der Regel springen einsamige Früchte nicht auf, vielsamige Früchte dagegen, wenn sie trocken sind, springen auf; doch gibt es beiderseits Ausnahmen. Das Aufspringen der Früchte erfolgt in ihren Nähten, entweder der Länge nach oder in querer Richtung, im letzteren Fall haben sich die Nähte erst im Verlauf der Fruchtreife gebildet; ist nur eine Quernaht vorhanden, so heisst der obere Theil, welcher abfällt, De ckel, operculus, und diese Art des Aufspringens dehiscentia circumscissa. Bei mehreren Quernähten zerfällt die Frucht in einzelne Theile, welche Glieder, articuli, genannt werden; dehiscentia articularis.

Wenn eine Frucht der Länge nach aufspringt, so spaltet sie sich entweder in einzelne Theile, - Aufspringen in Kn̈̈pfe $\mathrm{n}$, dehiscentia in coccis, oder sie öffnet sich in Klappen, dehiscentià valvaris, wobei die einzelnen Theile der Frucht noch mit einander im Zusammenhang bleiben. Die Knöpfe, cocci, mericarpia, öffnen sich entweder in ihren Nähten, Euphorbiaceae, Geraniaceae, oder sie bleiben geschlossen, Umbelliferae, Rubiaceae. Beim Aufspringen in Klappen können folgende Ver- 
schiedenheiten stattfinden: Zwei oder mehrere Carpelle, welche zu einem zusammengesetzten Ovarium verwachsen sind, lösen sich bei der Fruchtreife wieder von einander ab; die Frucht löst sich in ihre Theile auf, aus denen sie entstanden ist, indem die Scheidewände gespalten werden; scheidewandspaltiges Aufspringen, dehisc. septicida. Die einzelnen Theile sind die Klappen mit ungebogenen Rändern, an welchen die Samen befestigt sind, Colchicum; oder die Samenträger können auch als centrale Säule stehen bleiben, Verbascum. In anderen Fällen bleiben die Carpellarblätter mit einander in Verbindung und die Frucht springt in den Rückennähten derselben auf; es findet diess bei Früchten mit einfachen, centripetalen Scheidewänden statt, wo die Carpellarblätter mit ihren Rändern verwachsen sind und sich von hier aus nach innen $\mathrm{zu}$ falsche Scheidewände ausgebildet haben. Diess ist das fachspaltige A ufspringen, dehisc. loculicida; Tulipa, Lilium. Haben sich aber diese Scheidewände in centrifugaler Richtung, von innen nach aussen ausgebildet, so trennen sich die Carpellarblätter von einander und von den Scheidewänden, die dann für sich stehen bleiben; scheidewandbrüchiges Aufspringen, dehisc. septifraga; Datura. Bei einfächerigen, aus melır als einem Carpellarblatt gebildeten Früchten geschieht es bisweilen, dass die Nähte oder Placenten für sich stehen bleiben, was g efenstertes Aufspringen, dehisc. fenestralis genannt wird; Chelidonium.

Bei den bisherigen Arten des Aufspringens öffnet sich die Kapsel ihrer ganzen Länge nach; bei manchen Früchten aber erfolgt die Trennung der Klappen nur zur Hälfte, halbklappiges Aufspring en, deh. semivalvularis, entweder von oben nach unten, oder von unten-nach oben; oder sie erfolgt nur auf eine kurze Strecke, Aufspringen in Zähnen, deh. dentalis; oder die Klappen bleiben oben und unten verwachsen und trennen sich in der Mitte - deh. fissuralis; endlich findet bisweilen ein Aufspringen der Kapsel in Pore $\mathbf{n}$ oder Löchern statt, deh. in poris.

Man unterscheidet einfache Früchte, zusammengesetzte Früchte 
und Fruclitstände; jede dieser Gruppen enthält trockene und fleischige oder saftige Früchte. Die einfache Frucht ist aus einem einzigen Stempel hervorgegangen; bei der zusammengesetzten Frucht haben sich mehrere Stempel, welche aber einer einzigen Blüthe angehören, vereinigt, z. B. Fragaria, Rubus, wo zugleich bei der ersteren der Fruchtboden, bei der letzteren die Samenhülle fleischig oder saftig wurde. Der Fruchtstand oder die Sammelfrucht ist aus mehreren, sehr nahe beisammen stehenden Blüthen hervorgegangen, wie z. B. die Zapfen der Coniferen, die Maulbeere.

Von verschiedenen Fruchtarten, welche besondere Namen erhalten haben, sind die wichtigsten folgende:

a. Die S c h al e $\mathrm{nfru}$ ch t, caryopsis, aus einem oberständigen Stempel entstanden, einsamig, nicht aufspringend. Die Fruchthülle ist entweder dünn und mit dem Samen verwachsen, wie bei den Gramineen, oder vom Samen getrennt, z. B. Ranunculus. Bisweilen ist die Fruchtschale hart, wie beim Hanf, dann heisst sie nussartig, caryopsis nucacea. Häufig vereinigen sich zwei oder mehrere Caryopsen zu zusammengesetzten Früchten, wie bei den Alismaceen, vielen Rosaceen, ferner bei den Labiaten, Boragineen, bei welchen die einzelnen Früchtchen, weil ihre Fruchtschale hart ist, Nüsschen, nuculae, heissen.

b. Die Schliessfrucht, achaenium, ist eine einsamige, nicht aufspringende Frucht, welche aus einem unterständigen Ovarium hervorgegangen ist; sie findet sich bei den Valerianeen, Compositen, und mit lederartiger Fruchthülle bei der Buche, Eiche u. S. w. Zwei Achänien können zu einem D op pelachänium, diachaenium, vereinigt sein, welches bei der Reife entweder verbunden bleibt, Galium, Asperula, oder sich in zwei, je einen Samen enthaltende Stücke zertheilt. Dergleichen Früchte, welche aus zwei oder mehreren Schliessfrüchten zusanmengesetzt sind, sich aber bei der Reife wieder trennen, begreift man unter dem gemeinschaftlichen Namen - Spaltfrüchte, schizocarpia, und die einzelnen Theile heissen Kn öpfe, mericarpia oder cocci. Mericarpien heissen vorzugsweise die Spaltfrüchte der Umbelliferen. Bei den Knöpfen kommt es bisweilen 
vor, dass sie aufspringen, also eigentlich nicht in die Kategorie der Schliessfrüchte gehören (pag. 29).

c. Flüge lf rucht, samara, eine ein- oder wenigsamige nicht aufspringende Trockenfrucht, deren Fruchthülle zu einem häutigen Flügel ausgebreitet ist. Sie kommt einflügelig vor bei der Ulme, Esche, zweiflügelig bei der Birke, dreiflügelig bei der Rhabarber; findet sich auch zusammengesetzt, in welchem Falle sie bei der Reife in zwei Hälften zerfällt, z. B. Ahorn.

d. Die Balgfrucht, Balgkapsel, folliculus, eine trockenhäutige, mehrsamige, aus ein em oberständigen Carpell bestehende Frucht, welche an der Bauchnaht die Samen trägt und hier aufspringt. Selten finden sich die Balgfrüchte einzeln wie beim Gartenrittersporn, gewöhnlich stehen mehrere beisammen, z. B. Aconitum, Paeonia.

e. Die Hüls e, legumen, die Frucht der Leguminosen, ist wie die Balgkapsel aus einem Fruchtblatt gebildet und unterscheidet sich von derselben nur dadurch, dass sie nicht allein in der Bauchnaht, sondern auch in der Rückennaht aufspringt. Die Hülse hat bisweilen falsche Querscheidewände, welche dadurch entstehen, dass sich zwischen den Samen die Fruchthülle zusammenzieht, oder das Parenchym sich daselbst ausbreitet, wie bei Ceratonia, Tamarindus u. A.; eine solche Hülse heisst legumen septatum. In diesen Querscheidewänden bilden sich oft wirkliche Nähte aus, in welchen die Hülse bei der Fruchtreife auseinander fällt, - Gliederhüls e, lomentum; findet sich z. B. bei Hippocrepis, Coronilla, Hedysarum. Selten ist die Hülse in zwei Längsfächer getheilt, legumen biloculare, subbiloculare, indem die Rückennaht nach innen mehr oder weniger vorspringt z. B. bei Astragalus. Die einsamigen Hülsen und die fleischigen, z. B. Ceratonia, springen nicht auf.

f. Schotenfrucht, Schote, siliqua, Schötchen, silicula, heissen die Früchte der Cruciferen. Sie sind aus zwei Carpellarblättern gebildet, zweifächerig, mit zwei wandständigen Placenten, zwischen welchen eine dünne (falsche) Scheidewand ausgespannt ist; sie öffnen sich durch die beiden, von unten her sich ablösenden Klappen. Schötchen, silicula heisst die Schotenfrucht dann, wenn sie höchstens zwei- bis dreimal länger 
als breit ist. Sie kann einsamig werden und nicht aufspringen, auch die Scheidewand kann sich unvollständig entwickeln oder fehlen. - Gliederschote, siliqua lomeniacea heisst eine Schotenfrucht, in welcher sich falsche Querscheidewände entwickelt haben. Man unterscheidet Schoten mit breiter Scheidewand, siliquae und siliculae latiseptae, deren Klappen flach oder leicht gebogen sind, Cardamine, Camelina u. A., und Schoten mit schmaler Sclieidewand, sil. angustisepiae, bei welchen die Klappen eine mehr oder weniger kalınförmige Gestalt angenommen haben, z. B. Capsella, Brassica u. s. w.

g. Kapselfrucht, capsula, heisst jede aus einem zusammengesetzten Ovarium hervorgegangene trockenhäutige Frucht.

h. Ste in frucht, drupa, ist eine Frucht, deren Fruchthülle aus zwei deutlich getrennten Schichten besteht. Die innere ist steinartig hart und heisst Schale, pulamen, die äussere ist fleischig, saftig, Prunus, oder trocken und faserig, Amygdalus. Sie kann aus einem ober- oder unterständigen Ovarium entstanden sein, und kommt auch zusammengesetzt vor, Rubus.

i. Die Beere, bacca ist eine fleischige oder saftige Frucht ohne Steinschale, deren innere Höhlungen oder Fächer von einer haut- oder pergamentartigen Fruchthaut ausgekleidet sind. Auch die Beere findet sich ebensowolıl ober- als unterständig. Besendere Arten derselben sind die Kürbisfrucht, die Apfelfrucht, die Pomeranzenfrucht.

k. Die Haufenfrucht, sorosus, ist ein ähren- oder kätzchenförmiger Fruchtstand, bei welcher das Perigon der einzelnen Blüthen, aus denen die Frucht entstand, saftig geworden ist, wie bei der Maulbeere.

1. Feigenfrucht, sycone, heisst eine Sammelfrucht, bei welcher der gemeinschaftliche Blüthenboden fleischig geworden ist.

m. Z apfenfrucht, conus, strobilus, ist die Frucht der Nadelhölzer, wo die offenen Carpellarblätter sammt den Deckblättern eine holzige Beschaffenheit angenommen haben; in seltenen Fällen werden dieselben auch fleischig, wodurch eine der Beere äusserlich ähnliche Frucht, der Beerenzapfen, galbulus entsteht. 


\section{P flanzens ysteme.}

Von den verschiedenen natürlichen Pflanzensystemen, welche seit Jussieu bis auf unsere Zeit von Richard, DeCandolle, Bartling, Lindley, Endlicher und Anderen aufgestellt wurden, sind die von DeCandolle und Endlicher die am meisten verbreiteten, daher sie jetzt nebst dem von Jussieu speciell betrachtet werden sollen. Es wurde schon bemerkt, dass in diesen Systemen die Familien nach ihren Aehnlichkeiten geordnet und mit der niedersten begonnen, mit der höchsten geschlossen werde. Als die niedersten Pflanzen gelten natürlich die Kryptogamen und von diesen ziemlich allgemein die Algen. Für die am höchsten organisirten Pflanzen werden gewöhnlich diejenigen angesehen, bei welchen die Anzahl der Organe am grössten ist, bei welchen diese Organe nicht verwachsen sind, und bei welchen kein Fehlschlagen derselben stattfindet. Es sind hauptsächlich zwei Familien, bei welchen diese Bedingungen zutreffen, nämlich die Leguminosen * und Ranunculaceen. Die Leguminosen haben meistens zusammengesetzte, mit Nebenblättern versehene Blätter, also die Seitenorgane sind gleichsam vervielfältigt, zugleich sind die Achsenorgane sehr entwickelt, indem unter ihnen viele baumartige Pflanzen sich finden. Dagegen sind ihre Staubgefässe zwar nicht immer, aber doch häufig mit einander verwachsen, es ist nur ein einziges, einfaches Pistill vorhanden, während bei den Ranunculaceen die Blüthentheile mehr ausgebildet sind. Hier sind die zahlreichen Staubgefässe frei, die Kelch- und Blumenblätter ebenfalls; Pistille finden sich in jeder Blüthe gewöhnlich mehrere, oft viele, währer aber die Blätter nicht zusammengesetzt, sondern nur geth silt sind. Von einigen werden die Aurantiaceen, von Einigen die Rosaceen als die höchste Familie angesehen, die meisten Botaniker aber stellen die Leguminosen

* Die Leguminosen bilden jetzt eigentlich keine Familie mehr, sondern eine Klasse oder Section, und enthält die Familien der Papilionaceen, Mimoseen etc. 
oder Ranunculaceen an die Spitze. $\mathrm{Zu}$ den Letzteren gehört DeCandolle, dessen System zugleich die Eigenthümlichkeit hat, dass er die Familien in umgekehrter Reiheniolge aufführt, also mit den Ranunculaceen anfängt und mit den Algen aufhört. *

Jussieu gründet sein System auf die Verschiedenheit der Fructificationsorgane und theilt das ganze Pflanzenreich zunächst nach der Beschaffenheit des Embryo in drei grosse Abtheilungen, je nachdem der Embryo ohne Samenlappen, oder mit einem oder 2 Samenlappen versehen ist, und unterscheidet also:

A cotyled onen - ohne Samenlappen,

Monocotyledonen - mit e in em Samenlappen,

Dicotyledonen - mit zwei oder mehreren Samenlappen.

Der Ausdruck "Acotyledonen ", unter welchen die 24. Klasse Linné's, die Kryptogamen, verstandan sind, ist aber nicht gut gewählt, denn die Keimkörner der Kryptogamen enthalten nicht nur keine Samenlappen, sondern gar keinen Embryo; sie stellen vielmehr einzelne Zellen dar, in welchen eine Flüssigkeit eingeschlossen ist. Daher suchte Richard diese Ausdrücke zu verbessern und brachte das Pflanzenreich zunächst in zwei Abtheilungen; Plantae exembryonatae, ohne Embryo, entsprechend den Acotyledonen Jussieu's, und in Plantae embryon a tae, Pflanzen mit wahrem Samen, der einen Keim enthält. Diese theilte er nun wieder in Endorhizae, welche Jussieu's Monocotyledonen, und in Exorhizae, welche seinen Dicotyledonen entsprechen (siehe pag. 26). Uebrigens sind die Ausdrücke von Jussieu allgemeiner angenommen als die von Richard.

$\mathrm{DeC}$ andolle benützt für die Bildung der grösseren $\mathrm{Ab}$ theilungen im Pflanzenreich die Elementarorgane und berücksichtigt dabei die anatomische Beschaffenheit des Stamms und die Art und Weise seines Wachsthums. Nach ihm zerfallen sämmtliche Pflanzen in Z ellenpflanzen, pl. cellulares, und Gefässpflanzen, pl. vasculares, und diese letzteren wieder in $p l$. endogenae und exogenae (pag. 8. 10). Die Zellenpflan-

* Wegen der Vergleichung mit den, anderen Systemen nehmen wir vorerst von diesem Umstand keine Notiz. 
zen entsprechen den Kryptogamen oder Acotyledonen, die Endogenen den Monocotyledonen, die Exogenen den Dicotyledonen, aber nicht genau, denn es gibt unter den Monocotyledonen Pflanzen ohne Gefässe, welche also nach DeCandolle zu den Kryptogamen gestellt werden müssten, - und andererseits ist ein grosser Theil der Kryptogamen, nämlich die Farrenkräuter und ihre Verwandten, mit Gefässen versehen, daher sie mit den Monocotyledonen vereinigt wurden, was offenbar unpassend ist. DeCandolle änderte desshalb, um wenigstens diesen letzteren Uebelstand zu beseitigen, diese Eintheilung später selbst dahin ab, dass er aus den Gefässkryptogamen eine besondere Abtheilung mit dem Namen Plantae semivasculares bildet. Wir bekommen also:

Plantae cellulares

$$
\begin{aligned}
& \text { semivasculares }\}=\text { Acotyledonen. } \\
& \text { vasc. endogenae }=\text { Monocotyledonen. } \\
& \text { exogenae = Dicotyledonen. }
\end{aligned}
$$

Die Ausdrücke "Endogenae und Exogenae" sind übrigens unrichtig, weil dabei von einer ganz irrigen Ansicht über die Entwicklung des Stammes der Mono- und Dicotyledonen ausgegangen wurde (siehe oben p. 8.). Trotz dem hat DeCandolle's System eine grosse Verbreitung gefunden; es wurde von $\mathrm{Koch}$ seiner Synopsis florae germanicae et helveticae, sodann den meisten Localfloren zu Grunde gelegt, woher es kommt, dass es das in Deutschland am meisten benützte System ist.

Endlicher theilt sämmtliche Pflanzen nach der Beschaffenheit der Achsen- und Seitenorgane, je nachdem dieselben in Stamm und Blätter geschieden, oder zu einem gemeinschaftlichen Gebilde, dem Lager, thallus, zusammengeschmolzen sind, in

Thall o phyta, Lagerpflanzen, und

Cormophyta, Stengelpflanzen, letztere wieder in

A crobrya,

Amphibrya und

Acramphibrya (siehe pag. 7. 8. 10). 
Diese Gruppen stimmen annähernd, nicht ganz genau mit den vorigen überein, wie folgende Uebersicht zeigt.

\begin{tabular}{|c|c|c|}
\hline Jussieu. & DeCandolle. & Endlicher. \\
\hline \multirow{4}{*}{$\begin{array}{c}\text { A cotyledoneae. } \\
\text { (Exembryonatae RICH.) } \\
\text { Sämmtliche } \\
\text { Kryptogamen. }\end{array}$} & \multirow{2}{*}{$\begin{array}{l}\text { Cellulares. } \\
\text { Algen, Flechten, Pilze, }\end{array}$} & $\begin{array}{l}\text { Thallophyta. } \\
\text { Algen, Flechten, Pilze. }\end{array}$ \\
\hline & & \multirow{3}{*}{$\begin{array}{c}\text { Cormop hyta a cro- } \\
\text { brya. } \\
\text { Lebermoose, Laubmoose, } \\
\text { Gefässkryptogamen. }\end{array}$} \\
\hline & Lebermoose, Laubmoose. & \\
\hline & $\begin{array}{l}\text { Semivasculares seu } \\
\text { Endogenae cryptogamae. } \\
\text { Die Gefässkryptogamen. }\end{array}$ & \\
\hline $\begin{array}{c}\text { Mo nocotyled oneae. } \\
\text { (Endorhizae RICH.) }\end{array}$ & $\begin{array}{c}\text { Vasculares end o- } \\
\text { genae s. Endogenae } \\
\text { phanerogamae. }\end{array}$ & $\begin{array}{c}\text { Cormophyta amphi- } \\
\text { brya. }\end{array}$ \\
\hline $\begin{array}{l}\text { Dicotyledoneae. } \\
\text { (Exorhizae RICH.) }\end{array}$ & $\begin{array}{c}\text { Vasculares exo- } \\
\text { genae. }\end{array}$ & $\begin{array}{c}\text { Cormophyta } \\
\text { acramphibrya. }\end{array}$ \\
\hline
\end{tabular}

Diese Hauptabtheilungen werden nun weiter eingetheilt und in Klassen gebracht. Hiebei ist zunächst zu bemerken, dass der Ausdruck "Klasse" in verschiedenem Sinne gebraucht wird. DeCandolle nennt obige Hauptabtheilungen des Pflanzenreichs Klassen, deren er also nur drei, beziehungsweise vier aufstellt, wenn die spätere Trennung der kryptogamischen Gefässpflanzen berücksichtigt wird, wie es in obiger Tabelle geschehen ist. Von diesen zerfällt die I. Klasse in zwei Unterklassen, näılich B I a t tlos e, Algen, Pilze, Flechten, und Beblätterte, Lebermoose und Laubmoose; die II. und III. Klasse haben keine, dagegen die IV. Klasse 4 Unterklassen, wie folgt:

Class. I. Cellulares.

\section{Subclass. 1. Aphyllae.}

2. Foliosae.

II. Semivasculares.

III. Vasculares endogenae.

IV. "exogenae. 
Subclass. 1. Monochlamydeae.

2. Corolliflorae.

3. Calyciflorae.

4. Thalamiflorae.

Von diesen letzteren 4 Unterklassen haben die Monochlamydeen nur ein e Blüthendecke, die drei anderen vollständige Blüthen mit Kelch und Corolle, und zwar ist diese bei den Corollifloren verwachsenblättrig und hypogynisch; bei den Calycifloren verwachsen- oder getrennthlättrig und epi- oder perigynisch und bei den Thalamifloren getrenntblättrig und hypogynisch.

Ju s s i e u fasst sämıntliche Kryptogamen in eine einzige Klasse zusammen, theilt aber die Mionocotyledonen nach der Insertion ihres Perigons in 3 Klassen, nämlich in solche mit hypogynischer, perigynischer und epigynischer Insertion, welches Eintheilungsprincip auch bei den Dicotyledonen befolgt ist. Diese letzteren zerfallen zunächst in Pflanzen ohne Corolle, dann in solche mit verwachsenblättriger, (einblättriger) und in solche mit getrenntblättriger Corolle; jede dieser drei Unterabtheilungen werden dann nach der Insertion wie bei den Monocotyledonen in 3 Klassen abgetheilt. Die Pflanzen mit einblättriger Corolle und epigynischer Insertion theilen sich aber noch in 2 Klassen, je nachdem die Antheren verwachsen oder frei sind. Endlich werden die diclinischen Pflanzen in eine Klasse zusammengestellt und auf diese Art nachfolgende 15 Klassen erhalten.

\section{A. Acotyledoneae.}

B. Monocotyledoneae.

Classis I. Acotyledonia.
a. insertio hypogyna.
b. " perigyna.
II. Monohypogynia.
c. " epigyna.
III. Monoperigynia.
IV. Monoepigynia.

C. Dicotyledoneae.

I. Flores hermaphroditi.

1. apetalae.
a. insert. epigyna.
b. " perigyna.
V. Epistaminia.
c. " hypogyna. "
VI. Peristaminia.
VII. Hypostaminia. 
2. monopetalae.

a. insert. hypogyna. Classis VIII. Hypocorollia.

b. " perigyna. " IX. Pericorollia

c. " epigyna.

aa. antherae connatae." $\quad X$. Synantheria.

bb. " liberae. "X XI. Corisantheria.

3. polypetalae.
a. insert. epigyna.
XII. Epipetalia.
b. " hypogyna.
XIII. Hypopetalia.
c. " perigyna.
XIV. Peripetalia.
XV. Diclinia.

II. Flores diclini.

Die fünfzehnte Klasse ist keine natürliche; jedenfalls steht sie am Ende des Systems ganz am unrechten Ort, sondern viel naturgemässer zwischen der 4. und 5. Klasse bei den Apetalen, weil die meisten diclinischen Pflanzen zu den letzteren gehören. Nur die Cucurbitaceen müssten dann wegen ihrer vollständigen Blütheń von den Apetalen getrennt werden und würden in die 14. Klasse, Peripetalia, zu stellen sein.

Jede dieser 15 Klassen enthält nun eine kleinere oder grössere Reihe von Familien oder natürlichen Ordnungen, ohne weitere Abtheilung innerhalb dieser Klassen. Jussieu führt in seinem System 100 Familien auf. Im Verlauf der Zeit aber hat sich die Anzahl der Familien bedeutend vermehrt, theils durch Entdeckung neuer Pflanzen, theils dadurch, dass die bisherigen Familien in zwei oder mehrere gespalten wurden, so dass ihre Zahl bei DeCandolle auf nahezu das Doppelte, bei Endlicher auf fast das Dreifache (275) gestiegen ist.

Endlicher nennt diejenigen Abtheilungen seines Systems, welche etwa den Klassen bei Jussieu oder DeCandolle entsprechen, Cohorten, und theilt diese dann erst in Klassen, welche natürlich einen viel kleineren Umfang haben, als die Klassen der beiden anderen Systeme, daher ihre Anzahl auch weit grösser ist. Vielmehr kommen dieselben theilweise mit den natürlichen Ordnungen Jussieu's überein, und werden wohl auch S e c ti on e n genannt. Wie schon oben p. 5 bemerkt, sind sie nicht immer als natürliche Gruppen zu betrachten; da sie aber die 
Uebersicht in System erleichtern, so können sie wohl beibehalten werden. Endlicher theilt die Lagerpflanzen, Thallophyta, in Protophyta, welche in Medium des Wassers, Algen, oder der Luft, Flechten, leben, und in Hysterophyta, welche auf - in Verwesung begriffenen organischen Körpern wohnen, die Pilze. Die Acrobrya zerfallen in Anophyta, ohne Gefässe, Lebermoose und Laubmoose, Protophyta, die kryptoganischen Gefässpflanzen, und in Hysterophyta, eigenthümliche Schmarotzergewächse, welche sich in mancher Beziehung den Phanerogamen anschliessen. Die Amphibrya (Monocotyledonen) werden in keine Cohorten abgetheilt, wie auch DeCandolle die dazu gehörigen Familien in keine weiteren Abtheilungen bringt. Die Acramphibrya (Dicotyledonen) zerfallen in vier Cohorten, nämlich in Gymnospermae, Nacktsamige, deren Carpellarblätter nicht geschlossen sind, nämlich die Coniferen, und in Apetalae, Gamopetalae (Nonopetalae) und Dialypetalae (Polypetalae) wie bei Jussieu. Diese Colorten werden dann also, wie schon bemerkt, in Klassen (Sectionen) abgetheilt.

Wenn wir Endlicher's System mit dem von DeCandolle vergleichen und dabei an den niedersten Fanilien beginnen, so finden wir, dass beide Systeme so ziemlich mit einander gehen bis zu den Dicotyledonen init vollständiger Blüthe. Hier tritt nun eine Verschiedenheit ein. Endlicher unterscheidet blos zwischen Pflanzen mit einblättriger und inehrblättriger Corolle, Gamopetalae und Dialypetalae, während DeCandolle zugleich auch die Insertion der Blüthentheile beriicksichtigt, wie diess bereits auseinandergesetzt wurde. Endlicher's Gamopetalae umfassen DeCandolle's Corolliflorae und einen Theil seiner Calyciflorae; die Dialypetalae correspondiren mit einen anderen Theil von DeCandolle's Calyciflorae und seinen Thalaniflorae. Eine weitere Verschiedenheit zwischen beiden Systemen entsteht dadurch, dass DeCandolle die Ranunculaceen, Endlicher (wie auch Jussieu) die Leguminosen für die höchste Familie ansieht. Will man daher diese Systeme mit einander in Einklang bringen, so kommt ein Theil der Calycifloren über die Thalamifloren zu stehen, wie aus nachstehender Tabelle ersichtlich ist, welche eine Uebersicht 
über die gegenseitigen Verhältnisse geben soll, in welchen die drei Systeme zu einander stehen. Aus den oben entwickelten Gründen ist die 15. Klasse Jussieu's in dieser Tabelle zwischen die 4. und 5. eingeschoben.

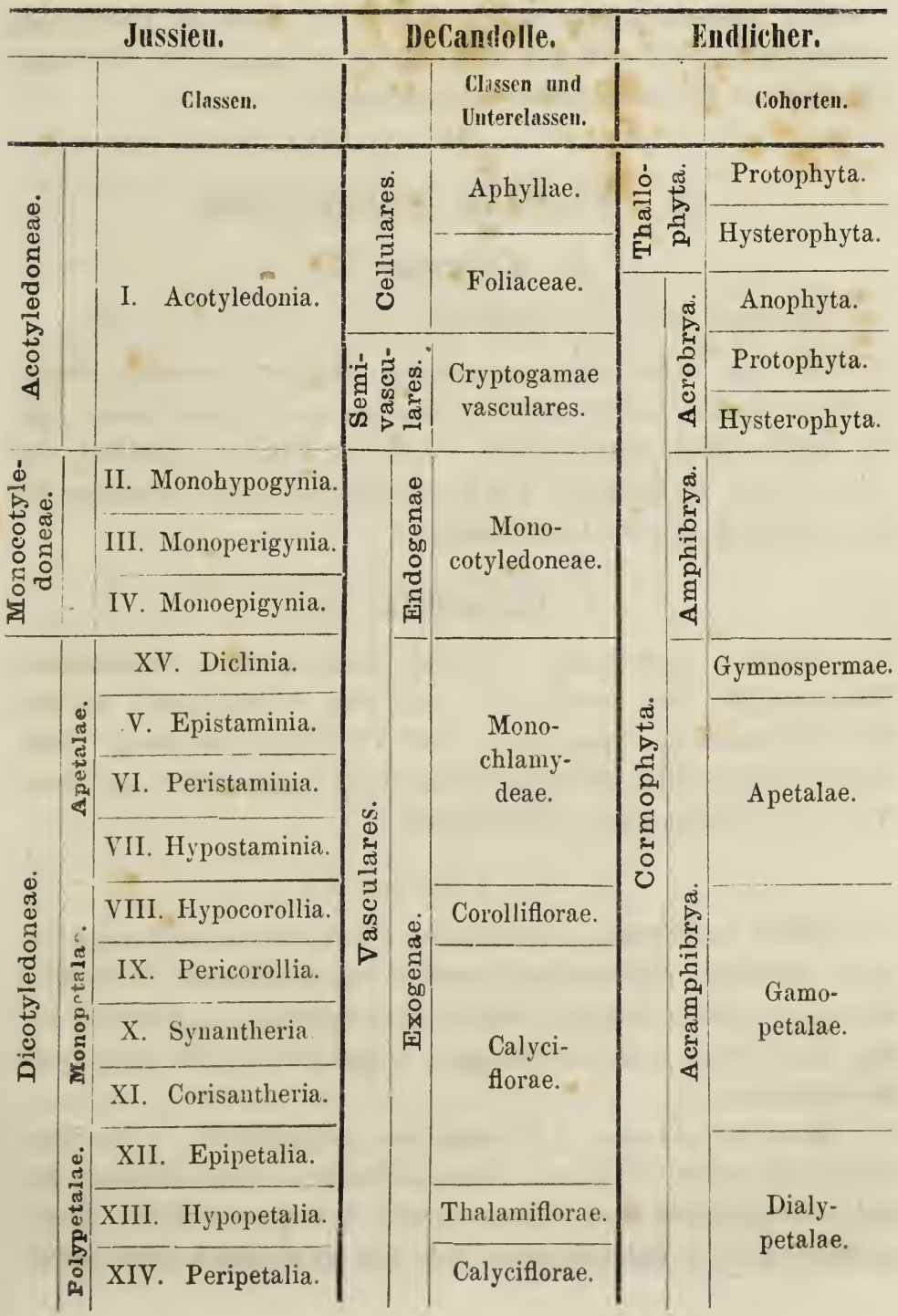


Indem wir zur Betrachtung der einzelnen Familien übergehen, sei hier bemerkt, dass nur die wichtigsten derselben hervorgehoben werden sollen, und zwar in der Reihenfolge, wie sie im DeCandolle'schen Systeme aufgeführt sind, mit einigen wenigen Abänderungen, welche durch die damit in Verbindung gebrachten, von späteren Botanikern aufgestellten Sectionen (Endlichers Klassen) nothwendig wurden.

\section{Plantae vasculares.}

A. Exogenae DC.

Exorhizae RICH. Dicotyledoneae Juss. Acramphibrya ENDL.

$\mathrm{Zu}$ der schon oben gegebenen näheren Definition dieser Abtheilung des Gewächsreichs ist etwa noch beizufügen, dass die Blüthentheile sehr häufig nach der Fünfzahl gebildet sind und bei den meisten ein Kelch und eine Corolle vorhanden ist. Sie zerfallen in vier Unterklassen.

\section{Thalamiflorae DC.}

Blüthen vollständig. Corolle mehrblättrig. Kelchblätter, Blumenblätter und Staubgefässe auf dem Blumenboden inserirt. Die Thalamifloren entsprechen der 13. Klasse Jussieu's. Endlicher's Dialypetalae umfassen sämmtliche Thalamifloren und einen Theil von DeCandolle's Calycifloren.

\section{Sect. Polycarpicae.}

Kelch und Corolle mehrblättrig, Staubgefässe zahlreich; Carpelle ebenfalls, mit wenigen Ausnahmen in Mehrzahl vorhanden. Eier gewöhnlich anatrop, Samen eiweisshaltig. Es gehören hieher die Familien: Ranunculaceen, Magnoliaceen, Menispermeen, Berberideen.

Ranunculaceae. Kelchblätter gewöhnlich 5, bisweilen 3 oder 6, meist abfallend. Blumenblätter in verschiedener Anzahl, die Fünfzahl aber vorherrschend, bisweilen fehlend. Staubgefässe frei, in unbestimmter Zahl mit gewöhnlich nach aussen 
gewendeten, angewachsenen Antheren (bei welchen sich der Staubfaden unmittelbar in's Connectiv fortsetzt). Die meist in Mehrzahl vorhandenen Carpelle, aus je einem Fruchtblatt gebildet, sind frei und tragen an der Bauchnaht die Placenta, an welcher ein oder mehrere anatrope Eier befestigt sind, selten sind sie mit einander verwachsen. Sie bilden zahlreiche trockene nicht aufspringende Caryopsen oder eine mehrfächerige, aufspringende Kapsel, sehr selten eine Beere. Krautartige, seltener halbstrauchartige Pflanzen mit alternirenden, häufig getheilten Blättern, deren Blattstiel an der Basis verbreitert und halbstengelumfassend ist; Nebenblätter fehlen.

Magnoliaceae. Diese Familie unterscheidet sich von den Ranunculaceen dadurch, dass die Blüthentheile, welche gewöhnlich in zwei oder mehreren Kreisen stehen, nach der Dreizahl gebildet, und dass die Blätter mit Nebenblättern versehen sind. Es sind Bäume oder Sträucher mit abwechselnden, meist ungetheilten Blättern mit grossen schönen Blüthen.

Menispermeae. Auch hier sind die Blüthentheile nach der Drei- bisweilen auch nach der Vierzahl gebildet, aber durch Fehlschlagen diclinisch. Der Kelch wie bei den zwei vorigen Familien abfallend. Die Anzahl der Staubgefässe hat abgenommen und beträgt nur noch soviel als die der Blumenblätter oder das Doppelte; sie stehen denselben opponirt. Ovarien sind noch mehrere vorhanden, welche entweder frei, oder mit einander verwachsen sind; sie bilden eine Beere oder Steinfrucht. Der Embryo ist, abweichend von den anderen Familien dieser Section, gross und gekrümmt, weil aus einem campylotropen Ei entstanden, aber das Eiweiss sehr klein oder fehlend. Windende Sträucher mit alternirenden Blättern ohne Nebenblätter.

Berberideae. Von den zahlreichen Pistillen, welche die Section charakterisirt, sind alle, bis auf eines fehlgeschlagen, welches mehrere oder viele anatrope Eier enthält, von denen aber auch nur wenige oder eines sich zum Samen entwickelt. Auch hier stehen die Blunnenblätter in 2 Kreisen, und eine gleiche Anzahl von Staubgefüssen sind denselben opponirt. Die Antheren öffnen sich in Klappen. Die Frucht ist gewöhnlich 
beerenartig. Kraut- oder strauchartige Pflanzen, oft mit Dornen besetzt, mit alternirenden Blättern.

\section{Sect. Nelumbia.}

Kelch mehrblättrig, Corolle vielblättrig, Staubgefässe und Pistille zahlreich, wodurch sie mit den Polycorpicae übereinstimmen. Von diesen unterscheiden sie sich besonders dadurch, dass die zahlreichen Blumenblätter gewöhnlich auf einer hypogynischen Scheibe (torus) stehen, welche die Pistille ungibt und theilweise einschliesst. Es sind lauter Wassergewächse. Von den wenigen Familien, welche zu dieser Section gehören, ist die grösste die der

Nymphaeaceae. Die Blumenblätter stehen in mehreren Reihen, sind auf verschiedener Höhe des torus inserirt, und gehen nach innen zu in die Staubgefässe über, welche ebenfalls mehrreihig angeordnet sind und nach innen gewendete Antheren tragen. Narben strahlenförmig ausgebreitet. Frucht beerenartig, aus den quirlförmig unter sich, und mit dem torus verwachsenen Carpellen gebildet. Embryo ausserhalb des Albumens, an der Basis des Samens liegend.

\section{Sect Rhoeades.}

Kelch mehrblättrig, abfallend, mit Ausnahme der Resedaceen. Ovarium aus 2 oder mehreren Carpellarblättern gebildet, deren Ränder zu einem einfächerigen Ovarium mit wandständigen Placenten verwachsen sind, welches aber durch falsche Scheidewände auch inehrächerig werden kann. Abweichend von der Regel, dass die Griffel mit den Narben die Verlängerung der Mittelrippe der Carpellarblätter bilden, also mit den Placenten, welche an der Verwachsungsstelle der Carpellarblattränder stehen, abwechseln, stehen hier die Narben über den Placenten, was so erklärt wird, dass jede Narbe sich gespalten und die eine Hälfte mit der anderen Hälfte der benachbarten Narbe sich verbunden hat. Die Papaveraceen, Fumariaceen, Cruciferen, Capparideen, Resedaceen gehören zu dieser Section.

Papaveraceae. Kelch- und Blumenblätter in bestimmter 
Anzahl vorhanden, und zwar ein Kreis von zwei Kelchblättern, und zwei Kreise von je zwei Blumenblättern. Staubgefässe zahlreich. Durch die strahlenförmig ausgebreitete Narbe bei Papaver schliessen sie sich den Nymphaeaceen an. Ovarium gewöhnlich einfächerig. Frucht eine nicht, oder in Fächern aufspringende Kapsel, oder eine zweiklappige Schote. Samen eiweisshaltig. Krautartige Pflanzen mit weissem oder gelbem Milchsaft.

Fumariaceae. Diese sind den Papaveraceen so ähnlich, dass Endlicher sie nur als Unterfamilie derselben betrachtet, und haben besonders den zweiblätterigen, hinfälligen Kelch und die schotenartigen Früchte mit ihnen gemein, unterscheiden sich aber durch eine unregelmässige Corolle und die öfters in zwei Bündel verwachsenen Staubgefässe. Die beiden Kelchblätter stehen in der Knospe nach oben und unten, dann folgen zwei Blumenblätter rechts und links, hierauf wieder zwei Blumenblätter nach oben und unten, welche an ihrer Spitze etwas verwachsen sind. Von den rechts und links stehenden Blumenblättern, welche dem äusseren Kreis angehören, sind entweder beide oder nur eines gespornt. Beim Aufblühen dreht sich die Blüthe, die Sporne stehen dann nach oben und unten, die Kelchblätter rechts und links. Mit den inneren Blumenblättern abwechselnd, also den äusseren opponirt, steht je ein Staubfaden, und zu beiden Seiten derselben je ein halbes Staubgefäss mit einfächeriger Anthere. Die auf jeder Seite stehenden Staubfäden sind verwachsen. Die beiden Carpellarblätter des Ovariums stehen rechts und links, die Placenten also oben und unten. Krautartige Pflanzen mit weichem, saftigem Stengel.

Cruc if erae. Kelch und Corolle vierblättrig. Von den vier Kelchblältern stehen zwei rechts und links und sind an der Basis meist etwas gespornt; zwei andere, ungespornte, von denen angenommen wird, dass sie einem besonderen Kreis angehören, stehen oben und unten. Die vier Blumenblätter, gewöhnlich mit langen Nägeln versehen, gehören nur einem Kreis an, da sie mit den Kelchblättern abwechseln; würden sie zwei Kreisen angehören, so müssten sie den Kelchblättern opponirt 
sein. Staubgefässe sollten es acht sein, vier äussere und vier innere; von den äusseren haben sich aber diejenigen, welche vor den Placenten stehen, nicht entwickelt; der äussere Kreis hat also nur zwei Staubfäden, welche kürzer sind als die vier des inneren Kreises. Die Staubgefässe sind also gleichsam eine Wiederholung der Blüthendecken. Es sind:

$2+2$ Kelchblätter -4 Blumenblätter.

2 (kürzere) +2 (nicht entwickelte) Staubgefässe - und dann noch 4 Staubgefässe.

Antheren nach innen gewendet. Zwischen den Staubgefässen, im Grunde der Blüthen finden sich zwei bis vier Drüsen. Die Carpellarblätter stehen rechts und links, die Placenten, zwischen denen eine falsche Scheidewand ausgespannt ist, oben und unten. Eier krummläufig. Frucht eine zweiklappige Schote, welche zwei oder mehrere, gewöhnlich hängende, eiweisslose Samen enthält. Embryo gekrümmt. Krautartige Pflanzen mit alternirenden Blättern ohne Nebenblätter.

Cap parideae. Durch die Stellung und Anzahl der Blüthendecken, einwärts gekehrte Antheren, krummläufige Eier und wandständige Placenten stimmen sie ganz mit den Cruciferen überein, unterscheiden sich aber durch die niemals viermächtigen, häufig sehr zahlreichen Staubgefässe, das Fehlen der Scheidewand im Ovarium, welches daher einfächerig, öfters aber aus mehr als zwei Carpellarblättern gebildet, und entweder gestielt ist, oder auf einer hypogynischen Scheibe sitzt. Die Frucht ist eine Kapsel oder Beere. Kraut- oder strauchartige Pflanzen.

Resedaceae. Diese kleine, Familie ist durch ihr Ovarium mit wandständigen Placenten, eiweisslose Samen, gekrümmten Embryo den vorigen Familien ähnlich, schliesst sich insbesondere durch die hypogynische Scheibe, welche sich zwischen Corollenblättern und Staubgefässen ausbreitet, den Capparideen an, zeichnet sich aber vor jenen aus durch einen unregelmässigen, vier- bis sechsblättrigen, nicht abfallenden Kelch und die sehr ungleichen, mit breitem Nagel und gefranzter Lamina ver- 
sehenen Blumenblätter. Ovarium oben geöffnet. Meistens krautartige Pflanzen.

\section{Sect. Parietales.}

Kelchblätter frei oder an der Basis etwas verwachsen. Ovarium gewöhnlich einfächerig, aus mehreren Carpellarblättern gebildet. Placenten nicht am Rande, sondern in der Mittellinie der Carpellarblätter. Embryo eiweisshaltig. Von den hieher gehörigen Familien sind die Bixineen, Cistineen, Violarieen, Droseraceen hervorzuheben.

Bixine a e. Kelchblätter vier bis sieben, in der Knospenlage dachziegelförmig, Blumenblätter fünf, mit ebenfalls dachziegelförmiger A estivation. Staubgefässe sehr zahlreich. Eier zahlreich, anatrop. Frucht eine Kapsel oder Beere. Samen in einen fleischigen Arillus eingeschlossen. Bäume oder Sträucher mit alternirenden einfachen, bisweilen durchscheinend punktirten Blättern und hinfälligen Nebenblättern.

$\mathrm{C}$ istineae. Unterscheiden sich von den Bixineen durch die Knospenlage, welche beim Kelch links, bei der Corolle rechts gedreht ist und durch die geradläufigen Eier. Staubgefässe wie bei jenen zahlreich. Kräuter, Halbsträucher oder Sträucher mit gewöhnlich gegenständigen, nie durchscheinend punktirten, bisweilen mit Nebenblättern versehenen Blättern.

Violarieae. Den Cistineen durch gedrehte Knospenlage der Corolle und einwärts gewendete Antheren ähnlich, unterscheiden sie sich durch den dachziegelförmigen Kelch, unregelmässige Corolle, bestimmte Anzahl der Staubgefässe, und anatrope Eier. Kraut- oder strauchartige Pflanzen mit meist alternirenden Blättern, welche mit Nebenblättern versehen und in der Knospenlage zusammengerollt sind.

Droseraceae. Diese Familie zeichnet sich von den vorigen, mit welchen sie in den meisten Charakteren übereinstimmt, hauptsächlich aus durch die dachziegelförmige Knospenlage des Kelchs und der Corolle, die schneckenförmig eingerollten Blüthenähren, die bestimmte Anzahl der Staubgefässe, nach aussen gewendete Antheren und anatrope Eier. Es sind 
kleine, zarte Kräuter, deren Blätter mit gestielten Drüsen besetzt und in der Knospe von der Basis gegen die Spitze aufgerollt sind.

\section{Sect. Polygalinae.}

Kelch und Corolle gewöhnlich unregelmässig, und dann die Staubgefässe mit der Corolle rerwachsen. Antheren an der Spitze in einer Pore sich öffnend. Ovarium zweifächerig, wenigsamig. Frucht gewöhnlich eine Kapsel, selten eine Steinfrucht. Die Section ist repräsentirt durch die Familie der

Polygaleae. Die Verwandtschaft dieser - übrigens sehr natürlichen Familie ist nach keiner Seite hin gross. Durch die Form ihrer Narbe und die unregelmässigen Blüthen ist sie den Violarieen ähnlich, erinnert eben durch die Forn der letzteren an die Fumariaceen und Leguminosen, während aber Frucht und Samen ganz verschieden sind.

Kelch fünfblättrig, unregelmässig, 3 äussere Kelchblätter kleiner, 3 innere zu beiden Seiten gestellte grössere häufig gefärbt, heissen dann Flügel, alae. Von den drei bis vier Blumenblättern, welche durch Vermittlung der Staubgefäss-Röhre zusammenhängen, ist das vordere grösser und dreilappig oder kammförmig und heisst carina. Staubgefässe monadelphisch, mit den Blumenblättern rerwachsen, aber in zwei gleiche, gegenständige Flügel getheilt. Antheren acht, einfächerig, oben in einer Pore aufspringend. Ovarium durch zwei Fruchtblätter gebildet, welche die gleiche Stellung haben, wie bei den Cruciferen, aber die falsche Scheidewand geht quer von der Mitte des-einen Carpellarblatts zur Mitte des anderen. Die Kapsel springt fachspaltig aus. Bei dem anomalen Genus Krameria ist die Scheidewand verkümmert, es ist nur ein Ei zur Entwicklung gekommen, die Kapsel springt nicht auf. Kraut- oder strauchartige, Milchsaft führende Pflanzen mit gewöhnlich alternirenden, ganzrandigen Blättern.

\section{Sect. Caryophyllinae.}

Kelch fünftheilig, Corolle fünfblättrig, Staubgefässe gewöhnlich zehn, wovon die fünf des inneren Kreises an ihrer Basis 
mit den Blumenblättern verwachsen sind. Ovarium einfächerig, mit centraler Placenta, welche dadurch entstanden ist, dass die ursprünglichen Scheidewände vor Entwicklung der Blüthe sich von der Wand des Ovariums abgelöst haben. Samen mit mehligem Eiweiss und gewöhnlich peripherischem Embryo.

Es gehören hieher die Familien der Sileneen und Alsimeen, welche man in andern botanischen Schriften wohl auch unter dem Namen der Canyophylleen vereinigt findet; so auch bei Endlicher, welcher zugleich die Paronychieen und Sclerantheen wegen ihres mehligen Eiweisses und peripherischen Embryo's hieher zieht, während DeCandolle sie wegen der perigynischen Insertion ihrer Blüthentheile in die Klasse der Calycifloren versetzt. Ferner stellt Endlicher in diese Section aus demselben Grunde die Portulaceen (nach DC. zu den Calycifloren gehörig) und die Phytolacceen (Monochlamydeen DC.).

Sil e n e ae. Kelch verwachsenblättrig, 5zähnig, ausdauernd. Blumenblätter mit den Staubgefässen unterhalb einer Verlängerung der Blüthenachse, Gynophorum, inserirt, welche auf ihrer Spitze das Ovarium trägt. Blumenblätter mit langem Nagel, 5 an der Zahl, zuweilen fehlend. Von den 10 Staubgefässen sind 5 mit den Nägeln der Corolle an ihrer Basis verwachsen, 5 andere nicht. Ovarium in der Knospe zwei- bis fünffächerig, später einfächerig mit freier centraler Placenta. Griffel so viel als Fächer: Eier zahlreich, krummläufig. Frucht eine in Zähnen aufspringende Kapsel, selten eine Beere. Strauch- oder krautartige Pflanzen mit opponirten, ganzrandigen Blättern und knotigen Stengeln.

Alsineae. Unterscheiden sich von den Sileneen dadurch, dass der Kelch sehr tief gespalten, die Blumenblätter ohne Nagel, das Ovarium nicht von einen Gynophorum getragen, sondern von einer hypogynischen, mit dem Kelch verwachsenen Scheibe umgeben ist, auf welchem die Staubgefässe inserirt sind. Die Verwandtschaft dieser beiden Familien mit anderen erhellt schon daraus, dass die oben angegebenen Familien sonst auch hieher gezogen werden. In ihren Blüthen haben sie auch mit den Lineen, Geraniaceen, Oxalideen einige Aelnlichkeit. Eine 
grosse Verwandtschaft zu den unmittelbar vorhergehenden und folgenden Familien lässt sich. nicht nachweisen.

\section{Sect. Columniferae.}

Kelch frei mit klappiger Knospenlage. Blumenblätter so viel als Kelchblätter, mit diesen alternirend, in der Knospenlage gedreht. Ovarium zwar nicht bei allen, aber einem grossen Theile dieser Pflanzen aus mehreren Carpellen zusammengesetzt, welche um eine gemeinschaftliche Säule gestellt (daher der Name) und zu einem mehrfächerigen Ovarium verwachsen sind. Alle haben alternirende Blätter mit Nebenblättern. Die Malvaceen, Tiliaceen, Sterculiaceen, Büttneriaceen sind die wichtigsten Familien dieser Section.

M a lv a ceae. Kelch verwach senblättrig mit klappiger Knospenlage, häufig mit einem sogen. äusseren Kelch, - einer einoder mehrblättrigen Hülle versehen. Staubfäden zahlreich, unter sich zu einer Röhre und an ihrer Basis mit den Blumenblättern verwachsen, wodurch das Ovarium bedeckt wird. Antheren einfächerig, in einer Querspalte aufspringend. Ovarium aus melreren Carpellen gebildet, welche um eine centrale Achse gestellt (oder in spiraler Richtung zu einem Köpfchen vereinigt) sind, und entweder frei bleiben, oder verwachsen, sich aber bei der Fruchtreife wieder trennen, - oder èndlich zu einer mehrfächerigen Kapsel mit dehiscentia loculicida verbunden bleiben. Eier krummläufig oder gegenläufig. Samen mit in einander gefalteten Cotyledonen. Eiweiss dünn oder fehlend. Kräuter, Sträucher oder Bäume mit zerstreuten, einfachen Blättern und Nebenblättern. Haare, wenn sie vorhanden sind, sternförmig gestellt.

Tiliace a e. Durch klappige Knospenlage des Kelchs, gedrehte Knospenlage der Corolle den Malvaceen ähnlich, unterscheiden sie sich durch mehrblättrigen oft corollinisch gefärbten Kelch, freie oder polyadelphische Staubgefässe mit zweifächerigen Antheren, welche theils quer, theils der Länge nach aufspringen. Die Frucht ist eine mehrfächerige Kapsel, welche entweder nicht, oder scheidewandspaltig oder fachspaltig auf- 
springt, oder sie ist in seltenen Fällen steinfrucht- oder beeren= artig. Bäume oder Sträucher, selten krautartige Pflanzen mit zerstreuten einfachen Blättern und abfallenden Nebenblättern.

Zwischen diesen beiden Familien stehen die früher vereinigten Familien der Sterculiaceen und Büttneriaceer, sich in ihren Characteren bald mehr den Malvaceen, bald mehr den Tiliaceen nähernd.

Der Kelch ist noch verwachsenblättrig, die Staubgefässe meist monadelphisch, bei den Sterculiaceen in unbestimmter, den Büttneriaceen oft in bestimmter Anzahl, entweder so viel als Blumenblätter und diesen opponirt, oder doppelt so viel, oder ein Mehrfaches von der Anzahl der Blumenblätter, und von diesen die den Kelchzipfeln opponirten steril. Die Antheren sind bei den Sterculiaceen zum Theil noch unvollkommen, zun Theil vollkommen zweifächerig, bei den Büttneriaceen zweifächerig. Strauch- oder baumartige Pflanzen mit einfachen, zerstreuten Blättern und Nebenblättern. Behaarung wie bei den Malvaceen sternförmig.

\section{Sect. Guttiferae.}

Kelch mit dachziegelförmiger, Blumenblätter mit gedrehter Knospenlage. Staubgefässe gewöhnlich zahlreich, polyadëlphisch. Samen gewöhnlich eiweisslos. Diese Section, welche meist ausländische Familien umfasst, schliesst sich eng an die vorige an. Wir heben die Camelliaceen, Clusiaceen und die auch bei uns vertretene Familie der Hypericineen hervor.

- Hy per i cin e a e. Kelch bleibend, 4-5́blättrig oder -theilig. Blumenblätter so viel als Kelchblätter, welkend. Staubgefässe zahlreich, in der Regel wenigstens an der Basis in 3-5 Bündel verwachsen. Antheren beweglich. Ovarium aus 3-5 (selten mehr) Carpellarblättern gebildet, deren eingelogene Ränder mehr oder weniger gegen das Centrum vorspringen, ein- oder mehrfächerig mit gewöhnlich mehreren anatropen Eiern in jedem Fach. Samen eiweisslos. Kräuter, Sträucher oder Bäume. Blätter ohne Nebenblätter, einfach, opponirt oder quirlförmig, mit Harzdrüsen besetzt oder durchsichtig punktirt. 
Clusiaceae. Eine den Hypericineen sehr ähnliche Familie der Tropengegenden unterscheidet sich von diesen dadurch, dass die Blüthendecken nach der 2-4-6Zahl angeordnet, die Antheren angewachsen (nicht beweglich), das 0varium wenigsamig und die Samen mit einem Arillus versehen, die Aeste und Blüthenstiele gegliedert sind. Blätter opponirt.

Camelliaceae. Theaceae. Diese und noch einige andere ähnliche Familien werden in neuerer Zeit unter dem gemeinschaftlichen Namen Ternstroemiaceen vereinigt, und die einzelnen Familien als Tribus betrachtet. Die Camelliaceen zeichnen sich vor den Clusiaceen und Hypericineen aus durch 5 bis 9blättrigen Kelch, 5-7blättrige Corolle, bewegliche Antheren, $3-5$ fächeriges, wenigsamiges Ovarium. Sträucher oder Bäume mit alternirenden, lederartigen, immergrünen Blättern. -

\section{Sect. Hesperides.}

Kelchblätter an der Basis verwachsen mit dachziegelförmiger Knospenlage. Blumenblätter so viel als Kelchabschnitte, mit diesen alternirend, in der Knospenlage klappig oder zusammengerollt. Staubgefässe 2 oder 4 mal so viel als Blumenblätter, frei, monadelphisch oder polyadelphisch. Ovarium mehrfächerig. Embryo gewöhnlich eiweisslos mit fleischigen, häufig zusammengelötheten (leichtverwachsenen) Cotyledonen. Die wichtigste Familie ist die der

Aurantiaceae. Kelch becher- oder glockenförmig, 3 bis 5zähnig oder -spaltig. Blumenblätter frei oder mit einander etwas verwachsen, auf einer hypogynischen Scheibe oder einem stielförmigen Blüthenpolster eingefügt. Staubgefässe ebensoviel oder doppelt oder mehrmals so viel als Blumenblätter. Staubfäden an der Basis abgeplattet, frei, oder in ein oder mehrere Bündel verwachsen, an der Spitze immer frei, pfriemenförmig. Ovarium frei, 5 bis mehrfächerig, Eier im inneren Winkel der Fächer, gegen das Centrum, angeheftet. Die Frucht ist eine sogenannte Pomeranzenfrucht, Aurantium, Hesperidium, und besteht aus mehreren häutigen Carpellın, welche quirlförmig um eine Achse gestellt und verwachsen sind, aber leicht getrennt 
werden können, entweder nur die Samen oder zugleich ein saftiges Fleisch oder Mark enthalten, und in eine nicht aufspringende lederartige Hülle eingeschlossen sind, auf deren Oberfläche eine Menge kleiner Oeldrüsen eingesenkt sind. Diese Hülle kann als Fortsetzung der hypogynischen Scheibe, auf welcher das Ovarium sitzt und auf der die Staubgefässe inserirt sind, betrachtet werden. Die Aurantiaceen schliessen sich durch ihre polyadelphischen Staubgefässe, Zahl und Knospenlage der Blüthentheile und eiweisslosen Samen den vorigen Familien an, sind aber sonst sehr verschieden. Bäume oder Sträucher mit alternirenden einfachen oder zusammengesetzten lederartigen Blättern ohne Nebenblätter, überall mit Oeldrüsen bedeckt. Die

Meliaceae sind den Aurantiaceen nahe verwandt, und zeichnen sich hauptsächlich dadurch aus, dass die Staubfäden fast bis zu ihrer Spitze zu einem Cylinder verwachen sind. Die Frucht ist theils beerenartig, theils eine trockene, aufspringende Kapsel; die Oeldrüsen fehlen.

\section{Sect. A c e ra.}

Kelch frei, mit dachziegelförmiger oder fast klappiger Knospenlage. Blumenblätter ebenso viel als Kelchblätter mit diesen abwechselnd, oder eines weniger, Staubgefässe mit den Blumenblättern auf einer hypogynischen Scheibe inserirt, so viel oder doppelt so viel als Blumenblätter, höchst selten ein Mehrfaches davon. Ovarium aus 2 bis 5 Carpellen gebildet. Samen gewöhulich eiweisslos, Embryo gekrümmt. Diese Section schliesst sich durch die Sapindaceen, welche den Meliaceen nahe verwandt sind, an die vorige an, und hat mit dieser die dachziegelförmige Aestivation des Kelchs, Zahl und Insertion der Blüthentheile und eiweisslose Samen gemein. Die Sapindaceen, Acerineen, Malpighiaceen nebst ein paar kleineren Familien gehören zu dieser Section.

S a p in dac eae. Kelch 4-5̃blättrig, oft unregelmässig. Blumenblätter gewöhnlich nur 4, mit drüsigem Nagel, und meist noch mit einer Honigschuppe versehen, auf einer oft unregelmässigen, hypogynischen Scheibe eingefügt. Staubgefässe dop- 
pelt so viel als Kelchblätter, zum Theil fehlschlagend und einseitig gestellt, frei oder an der Basis verwaclisen. Ovarium oft excentrisch, 3-, seltener 2-4fächerig mit wenigen Eiern. Frucht durch Fehlschlagen oft einfächerig, wenigsamig. Samen häufig mit Arillus oder sehr grossem Nabel, eiweisslos. Cotyledonen oft zu einer fleischigen Masse verwachsen. Bäume, Sträucher oder Halbsträucher, bisweilen klimmend und mit Ranken versehen, mit abwechselnden zusammengesetzten Blättern.

Acerin e a . Kelch 5-, bisweilen 4-9blättrig, drüsig. Blumenblätter so viel als Kelchblätter, bisweilen fehlend. Staubgefässe ausnahmsweise 8 , nicht 5 oder 10 , wie man erwarten sollte. Ovarium, 2fächerig, aus 2 Carpellen gebildet, welche mit einander verwachsen sind, sich aber bei der Fruchtreife wieder trennen. Von den 2 hängenden Eiern in jedem Fach kommt gewöhnlich nur eines zur Entwicklung, es findet also, wie bei der vorigen Familie ein theilweises Fehlschlagen der Eier statt. Frucht eine doppelte Flügelfrucht. Samen init blattartigen Cotyledonen. Bäume mit opponirten, lıäufig handförnig getheilten oder gefiederten Blättern ohne Nebenblätter. Durch drüsigen Kelch, zweigliedriges Ovarium und handförmig getheilte Blätter ist diese Familie von der vorigen unterschieden.

Malpighiacea e. Kelch wie bei den Acerineen uit Drüsen besetzt, aber die Blumenblätter mit langen Nägeln versehen. Die Staubgefässe monadelphisch, das Ovariun gewöhnlich aus drei Carpellen mit je einem Ei gebildet. Bäume oder Sträucher mit opponirten, einfachen, federnervigen Blättern.

Hip pocastaneae. Diese kleine Familie, welche auch zur Section der Acera gehört, ist durch die Unregelmässigkeit der Blüthen und die zusammengesetzten Blätter den Sapindaceen ähnlich, unterscheidet sich aber durch constant 2eiige Fächer des 3fächerigen Ovariums, lederartige 3fächerige oder durch Fehlschlagen 2 bis einfächerige, fachspaltig aufspringende, gुewöhnlich nur einsamige Kapsel. Samen mit grossem Nabel, ohne Arillus, Cotyledonen verwachsen. Bäume mit opponirten, fingerförmig zusammengesetzten oder getheilten Blättern ohne Nebenblätter: 


\section{Sect. Sarmentaceae.}

Blumenkrone mit klappiger Knospenlage. Blumenblätter mit breiter Basis. Staubfäden den Blumenblättern opponirt. Diese Section stellt Barthling zwischen die Acera und Gruinales und rechnet dazu die Ampelideen, Canellaceen, Méliaceen, Cedrelaceen; allein ihre Verwandtschaft ist noch nicht endgültig festgestellt. Endlicher stellt die Ampelideen wegen ihrer Aehnlichkeit mit den Araliaceen sammt diesen in die Section der Discanthae zu den Umbelliferen u. s. w. Die Meliaceen und Cedrelaceen gehören zu den Hesperiden, die Canellaceen zu den Guttiferen.

A in p elide a e. Blüthen theils Zwitter, theils diclinisch. Kelch verwachsenblättrig, 4-5zähnig. Blumenblätter auf einer hypogynischen Scheibe inserirt 4-5, mit den Kelchzähnen abwechselnd, Staubgefässe ebensoviel, den Blumenblättern opponirt. Ovarium zweifächerig mit je zwei anatropen, aufsteigenden Eiern. Frucht eine durch Fehlschlagen der Scheidewand oft einfächerige Beere mit 4 oder weniger Samen. Embryo gerade, in der Achse des knorpligen Eiweisses. Strauchartige Pflanzen mit klimmendeın Stengel und alternirenden Blättern, welchen meist eine Ranke oder Traube entgegengesetzt ist.

Die Ampelideen sind durch die kleinen unscheinbaren Blüthen, die handförınig getheilten Blätter den Acerineen ähnlich, unterscheiden sich aber durch die beerenartige Frucht, die albuminosen Samen und die Lage der Eier. Sie grenzen ferner durch den gegliederten Stengel an die Geraniaceen und durch diese an die Oxalideen, von welchen sie aber durch oberständiges Ovarium geschieden sind; auch sind sie durch die rankenlosen Arten mit den Meliaceen verwandt.

\section{Sect. Gruinales.}

Kelch 5tlıeilig, frei, Blumenblätter so viel als Kelchabschnitte, auf dem Fruchtboden eingefügt. Staubgefässe in bestimmter Anzahl. Ovarium aus ummittelbar verwachsenen oder einer centralen Achse angewachsenen Carpellen gebildet, wenigsamig. Die wichtigsten Familien dieser Section sind die Lineen, Gera- 
niaceen, Tropaeoleen, Balsamineen, Oxalideen, wovon sich die 3 mittleren Familien noch durch unregelmässige (gespornte) Blüthen auszeichnen.

L in ea e. Kelch mit dachziegelförmiger, Blumenblätter mit gedrehter Knospenlage, mit den Kelchblättern abwechselnd. Staubgefässe in 2 Kreisen, an der Basis zu einem Ring verwachsen, die 5 äusseren den Kelchblättern, die 5 inneren den Blumenblättern opponirt, diese unfruchtbar, bisweilen auch ganz fehlend. Ovarium aus 5 (selten 4) Carpellen gebildet, mit getrennten Griffeln und zwei hängenden anatropen Eiern in jedem Fach, welche neben einander gegen die Achse angeheftet, und durch eine unvollständige centripetale Scheidewand getrennt sind. Kapsel also unvollständig 10- (oder 8-) fächerig, in eben so vielen Klappen aufspringend. Samen eiweisslos. Krautartige, einjährige oder perennirende, oder halbstrauchartige Pflanzen mit einfachen linienförmigen, nervenlosen, sitzenden, gewöhnlich alternirenden Blättern ohne Nebenblätter. Diese Familie ist nahe mit der folgenden, auch mit den 0xalideen verwandt; entfernter mit den Caryophylleen in deren Nähe sie von DeCandolle gestellt wird, und mit welchen sie in der Blüthenbildung einigermassen übereinstimmt.

Geraniaceae. Durch Zahl und Knospenlage der Blüthendecken, Zahl der Staubgefässe, die am Grunde verwachsen und von welchen auch einige steril sind, den Lineen ganz nahe stehend, unterscheiden sie sich durch eine leichte Unregelmässigkeit des Kelchs und oft auch der Corolle. Das hintere Kelchblatt ist nämlich an seiner Basis zu einem Sporn verlängert, der an den Blüthenstiel angewachsen ist: die Blumenblätter bisweilen zweilippig gestellt. Die 5 Carpelle sind sammt ihren Griffeln an eine centrale Säule angewachsen und lösen sich bei der Fruchtreife wieder davon ab, indem sie zugleich an der Bauchnaht aufspringen. Von den zwei Eiern in jedemi Carpell kommt nur eines zur Entwicklung, daher die Frucht 5̌samig. Embryo eiweisslos. Cotyledonen gefaltet. Kräuter oder Halbsträucher mit knotigem Stengel nnd häufig handförmig getheilten Blättern, wovon die unteren gegenständig, die oberen abwechselnd sind, in 
welchem Falle aber dem Blatt ein Blüthenstiel gegenüber steht. Dadurch hat der Habitus grosse Aehnlichkeit mit dem der Ampelideen. An der Basis der Blattstiele sitzen je 2 Nebenblätter.

Tropa o lea e. Die Unregelmässigkeit des Kelches und der Corolle, welche in der vorigen Familie nur angedeutet war, hat sich hier entschieden entwickelt. Kelch corollinisch gefärbt, zweilippig, je-die 2 oberen und die 3 unteren Kelchblätter verwachsen, letztere zu einem freien Sporn verlängert, der sich gegen das Innere der Blüthe erweitert. Blumenblätter ungleich, auf deın Kelchsaum sitzend, also perigynisch. Staubgefässe 8, hypogynisch. Das Ovarium ist aus gewöhnlich 3 verwachsenen Carpellen gebildet, welche sich bei der Fruchtreife von einander ablösen (dehiscentia in coccis); bei den Geraniaceen bleiben auch noch die Griffel an den Knöpfen stehen, was hier nicht der Fall ist. Jedes Fach enthält ein hängendes anatropes Ei. Samen ohne Eiweiss. Cotyledonen verwachsen. 'Krautartige Pflanzen mit klimmenden Stengeln und alternirenden Blättern ohne Nebenblätter. Die Blätter haben schildförmig verzweigte Nerven, Blattstiele und Blüthenstiele sind rankend. Unterscheiden sich von den Geraniaceen hauptsächlich durch die freien Staubgefässe und die mit den Blumenblättern nicht ïbereinstimmende Zahl der Staubgefässe.

Bals amineae. Durch ihre unregelmässigen Blüthen mit corollinisch gefärbtem Kelch den Tropaeoleen ähnlich, nähern sie sich in der Bildung des Ovariums den Oxalideen. Von den 5 Kelchblättern entwickeln sich häufig die 2 oberen nicht; das untere Kelchblatt wie auch das obere Blüthenblatt ist gespornt; von den 4 übrigen Blüthenblättern sind je die zwei seitlichen verwachsen. Staubgefässe 5, init den Blumenblättern alternirend, Staubfäden an der Spitze zusainmenhängend. Ovarium aus j Carpellen gebildet, welche mit einer centralen Säule verwachsen sind, J̌fächerig, mit mehreren Eiern in jedem Fach. Frucht gewöhnlich eine elastisch aufspringende Kapsel. Embryo ohne Eiweiss. Zarte krantartige Pflanzen mit knotigen, saftigen Stengeh und einfachen Blättern ohne Nebenblätter. Nähern sich hin- 
sichtlich der Bildung des Embryo den Lineen. Von den Fumariaceen, mit denen sie in der Blüthenbildung einige Aehnlichkeit haben, sind sie im Uebrigen weit verschieden.

Oxalideae. Durch die Knospenlage des Kelchs und der Corolle und die Anzahl der Staubgefässe stehen sie den Geraniaceen näher als den beiden vorigen Familien, schliessen sich aber durch den albuminosen Embryo und die zusammengesetzten Blätter der folgenden Familie an.

Kelch 5blättrig oder -theilig, bleibend, in der Knospenlage dachziegelförmig; Blumenblätter 5, gleich, an der Basis zusaminenhängend, in der Knospenlage gedreht. Staubgefässe 10, häufig am Grunde verwachsen, die 5 äusseren, den Kelchblättern opponirten kürzer. Ovarium aus 5 Carpellen mit eben so vielen freien Griffeln zusammengesetzt, mit mehreren anatropen Eiern in jedem Fach. Frucht eine fünffächerige, fachspaltig aufspringende Kapsel, Samen mit elastischer Samenhaut, wodurch die Samen weggeschleudert werden. Embryo albuminos. Kräuter oder Halbsträucher mit meist alternirenden, zusammengesetzten, häufig reizbaren Blättern ohne Nebenblätter. Unterscheiden sich von den Geraniaceen durch den Mangel einer centralen Achse des Ovariuns, Mehrzahl ciêr Samen, die elastische Samenhaut und zusammengesetzte Blätter.

Es folgen nun ein paar Familien, welche Endlicher mit den zu den Calycifloren gehörigen Terebinthineen vereinigt, hier aber (nach DeCandolle) noch am Schluss der Thalamifloren aufzuführen sind, weil die Insertion ihrer Blüthentheile noch hypogynisch ist; es sind die Zygophylleen, Rutaceen und Simarubaceen.

Zyg ophylleae. Kelch und Corolle jblättrig, ersterer mit dachziegelförmiger, letztere mit gedrehter Knospenlage, wodurch sich diese Familie den Oxalideen anschliesst. Staubfäden wie. bei diesen 10, wovon die äusseren länger oder kürzer. Ovarium gewöhnlich aus 5 verwachsenen Carpellen bestehend, J̌fächerig mit 2 oder mehreren Eiern in jedem Fach. Griffel einfach. Kapsel gewöhnlich fachspaltig aufspringend. Samen 
mit knorpeligem Eiweiss und grünem Embryo. Kräuter, Sträucher oder Bäume mit zusammengesetzten opponirten Blättern und Nebenblättern. Die Familie steht zwischen den Oxalideen und Rutaceen in der Mitte und unterscheidet sich von den ersteren durch den einzigen Griffel, das Fehlen der elastischen Samenhaut und die opponirten, mit Nebenblättern versehenen Blätter, in welch letzterer Hinsicht sie auch von der folgenden Familie verschieden ist.

Rutaceae. Kelchzipfel und Blumenblätter wie bei der vorigen Familie in gleicher Anzahl 3, 4, 5, Staubgefässe doppelt oder 3mal so viel, darunter ein ganzer Kreis oder einzelne steril. Aestivation der Blüthendecken wie bei den Zygophylleen. Ovarium aus so vielen Carpellen gebildet, als Kelchzipfel vorhanden, mit eben so vielen Fäclıern und je 2 oder mehreren Eiern. Griffel einfach. Frucht eine fachspaltig oder scheidewandspaltig aufspringende Kapsel. Samen mit eiweisshaltigem Embryo. Sträucher oder perennirende krautartige Pflanzen mit alternirenden Blättern ohne Nebenblätter; fast alle mit Oeldrüsen versehen. Von dieser Familie werden wohl auch die Diosmeen, deren innere Fruchthaut von der Mittelschichte elastisch abspringt, als besondere Familie getrennt. Die Rutaceen bilden den Uebergang von den Thalamifloren zu den Calycifloren und grenzen einerseits an die Zygophylleen und Simarubaceen, andererseits an die Rlıamneen.

Sim arubaceae. Unterscheiden sich von den Rutaceen durch eineiige Fächer des Ovariums, nicht aufspringende Steinfrüchte und eiweisslose Samen.

\section{Calycillorae. DC.}

Kelchblätter an der Basis mehr oder weniger verwachsen und mit einer hypogynischen Seheibe, B lüthenpolster, torus, ausgekleidet, auf welchem die Blumenblätter und Staubgefässe eingefügt sind; bezielungsweise der Blüthenboden in einen Unterkelch umgewandelt: die Insertion der Blüthentheile also perigyniseh, oder, wenn das Ovarium auch mit der hypogynischen 
Scheibe oder dem Unterkelch verwachsen ist, epigynisch. Die Blumenblätter theils frei, theils unter sich verwachsen. Es gehören hieher ein Theil der Dialypetalae und ein Theil der Gamopetalae Endlicher's. Diese Abtheilung entspricht sodann Jussieu's Klassen 14. 12. 11. 10. 9. zum Theil, und zwar schliessen sich hier zunächst die Familien der 14. Klasse Jussieu's mit freiblättriger Corolle und perigynischer Insertion an.

\section{Sect. Frangulaceae.}

Blüthen regelmässig, Kelchabschnitte und Blumenblätter in gleicher Anzahl, Ovarium mehrfächerig, Sanen mit Eiweiss sind die gemeinschaftlichen Charaktere der hieher gehörigen Familien der Celastrineen und Rhanneen, worin sie auch mit den Rutaceen übereinstimmen, von welchen sie sich aber durch die geringere Anzahl der Staubgefässe und Eier und die perigynische Insertion der Blüthentheile unterscheiden.

Celastrineae. Kelch 4 bis 5 theilig oder -spaltig mit dachziegelförmiger Knospenlage. Corolle regelmässig. Blumenblätter so viel als Kelchabschnitte, mit diesen alternirend, mit dachziegelförıniger Knospenlage. Staubgefässe so viel als Blumenblätter, mit diesen alternirend, unterhalb des Scheibenrandes oder auf der Scheibe selbst sitzend oder die Fortsetzung des Scheibenrandes bildend. Ovarium frei, zwei- bis vierfächerig mit je einem oder mehreren aufrechten, selten hängenden Eiern. Frucht eine Beere, Steinfrucht, Flügelfrucht, Samen mit oder ohne Arillus, nach welchen Kennzeichen die Familie in zwei Unterfanilien oder Tribus zerfällt, Slaphyleaceae und Evonymeae, welche wohl auch als eigene Familien betrachtet werden. Sträucher oder Bäume mit einfachen oder zusammengesetzten Blättern und kleinen, sehr hinfälligen Nebenblättern.

Rhamneae. Von der vorigen Familie durch klappige Aestivation des Kelchs, abfallende Kelchzipfel, den Blumenblättern opponirte Staubgefässe und das mit der Kelchröhre verwachsene Ovarium verschieden, welches in jedem seiner 2 bis 4 Fächer nur ein Ei enthält. Durch dio Stellung der Staubgefässe sind die Rhamneen den Büttneriaceen ähnlich und un- 
terscheiden sich dadurch von den folgenden Familien. Sträucher oder kleine Bäume mit einfachen, alternirenden, häufig mit Nebenblättern versehenen Blättern und unscheinbaren, häufig grün gefärbten Blüthen.

\section{Sect. Terebin thineae.}

Kelch gewöhnlich frei, drei- bis fünf- oder mehrtheilig, bleibend. Blumenblätter so viel als Kelchabschnitte, auf dem Kelch oder einer perigynischen Scheibe eingefügt. Staubgefässe gewöhnlich doppelt so viel als Blumenblätter, selten mehr. Ovarium ein- bis fünffächerig, nicht aufspringend. Samen eiweisslos. Ausser den bereits erwähnten Familien pag. 58. 59. rechnet Endlicher hieher noch die Anacardiaceen, Burseraceen und andere, so auch die Juglandeen, welche von DeCandolle unter den Monochlamydeen aufgeführt werden.

Burse rac e a e. Kelch drei- bis vier- bis fünfspaltig. Blumenblätter mit den Kelchzipfeln alternirend und grösser als diese, unterhalb einer runden Scheibe eingefügt, mit meist klappiger Aestivation. Staubgefässe doppelt so viel als Blumenblätter, alle Antheren tragend, die abwechselnd den Blumenblättern opponirten gewöhnlich kürzer als die übrigen. Ovarium zwei- bis fünfächerig mit je zwei anatropen Eiern. Steinfrucht mit zweibis fünffächerigem Kern. Cotyledonen ungleich gefaltet. Harzführende Bäune und Sträucher mit alternirenden, läufig zusammengesetzten, öfters durchsichtig punktirten Blättern, bisweilen mit Nebenblättern. Durch zweifächeriges Ovarium mit je zwei hängenden Eiern und ungleich gefaltete Cotyledonen sich von den übrigen Familien dieser Section unterscheidend, erinnert diese Familie hinsichtlich der Zahl und Lage der Eier an die Euphorbiaceen. Das mehrfächerige Ovarium lıaben die Burseraceen auch mit den vorigen Familien gemein.

A nacardiaceae s. Terebinthaceae. Knospenlage des Kelchs dachziegelförmig, der Corolle klappig. Ovarium einfach, einfächerig, enthält nur ein $\mathrm{Ei}$, das an einem, vom Grunde des Ovariums aufsteigenden Nabelstrang befestigt ist. Durch dieses Kennzeichen ist diese Familie vor anderen älnlichen charakteri- 
sirt. Zwar kommt es vor, dass fünf bis sechs Ovarien vorhanden sind, aber in diesem Falle schlagen vier bis fünf fehI und es entwickelt sich immer nur eines. Bäune oder Sträucher mit guımösem oder harzigem Milchsaft und abwechselnden, häufig zusammengesetzten, nichtpunktirten Blättern ohne Nebenblätter. Der Unterschied der Anacardiaceen von den Rhamneen wurde schon oben angegeben; von den Rosaceen und Leguminosen, mit welchen die Anacardiaceen auch Aehnlichkeit haben, unterscheiden sie sich durch die Lage der Eier und das Fehlen der Nebenblätter.

\section{Sect. L e g u mino sa e.}

Kelch fünf-, seltener vierspaltig oder zähnig, in der Knospenlage gewöhnlich dachziegelförmig; der unpaare Kelchzahn nach unten gestellt. Blumenblättêr so viel als Kelchabschnitte, selten weniger, Staubfäden in der Regel doppelt so viel, bisweilen auclı mehr. Samen meist mit eiweisslosem, gekrümmtem Embryo. Frucht eine Hülse oder Gliederhülse. Diese Section, als deren wichtigste Familien wir die Papilionaceen, Caesalpineen und Mimoseen hier näher betrachten, schliesst sich durch ihr einzelnes, einfächeriges Ovarium, eiweisslose Samen und theilweise auch durch den Habitus an die Terebinthineen an und es sind besonders diejenigen Leguminosen, denen die Corolle fehlt, jenen selır ähnlich; dieselben unterscheiden sich aber durch die Befestigung der Eier, welche nicht an der Spitze oder der Basis des Ovariums, sondern seitlich an dessen Bauchnaht entspringen, und durch das Vorhandensein von Nebenblättern. Andererseits gehen die Leguminosen durch die Gattungen mit regelmässigen Blüthen, wobei es auch vorkommt, dass die Hülse fleischig und steinfruchtartig wird, in die Rosifloren über.

Papili on a c e e e. Kelch fünfzähnig, oft zweilippig. Corolle unregelmässig, schmetterlingsförmig. Staubfäden zehn, mit den Blumenblättern auf einem torus inserirt, welcher den Grund des Kelches auskleidet, gewöhnlich 9 verwachsen, der zehnte frei, oder alle verwachsen. Ovarium aus einem Carpellarblatt gebildet, einfächerig, mit mehreren Eiern an der gegen die Fahne ge- 
richteten Bauchnaht, selten findet sich nur e in Ei. Frucht eine in zwei Klappen aufspringende Hülse, gewöhnlich einfächerig, bisweilen durch die einwärts gestiilpte Rückennaht des Carpellarblatts zweifächerig, oder durch Zellgewebsbildung zwischen den Samen mehrfächerig, oder durch Zusammenziehen der Fruchthülle zwischen den Samen eine in mehrere Stïcke zerfallende Gliederhülse, selten eine nicht aufspringende Steinfrucht. Samen eiweisslos mit gekrümmtem Embryo.

Kräuter, Sträucher oder Bäume mit alternirenden, zusammengesetzten oft mit Ranken versehenen Blättern und Nebenblättern, welche sich bisweilen in Dornen umwandeln. Die Papilionaceen bilden eine der natürlichsten und zugleich zahlreichsten Familien des Gewächsreichs.

C a salpineae. Sie werden wohl auch als Unterfamilie der Papilionaceen betrachtet, und unterscheiden sich von denselben dadurch, dass die Corolle von der Schmetterlingsform abweicht und fast regelmässig wird, bisweilen aber auch fehlt, dass die zehn oder auch weniger Staubfäden häufig frei sind, und dass der Embryo gerade ist.

Mimoseae. In der Bildung der Frucht stimmen sie mil den Papilionaceen überein, unterscheiden sich aber von ilınen durch die klappige Aestivation des Kelchs und der Corolle, welch letztere regelmässig, häufig verwachsenblättrig ist, und durch die oft sehr zahlreichen Staubgefässe, welche bisweilen verwachsen, oft aber auch frei sind. Durch diese Charaktere nähern sie sich den Rosaceen. Meist Bäume oder Sträucher, mit häufig sehr zusammengesetzten, öfters reizbaren Blättern und bisweilen verkümmerten oft auch in Dornen umgewandelten Nebenblättern.

16. Sect. Rosiflorae.

Blüthen regelmässig. Kelch fünf-, selten viertheilig, der unpaare Kelchzahn nacl oben gestellt. Kelchröhre mit einer drüsigen Scheibe ausgekleidet. Knospenlage des Kelchs und der Corolle fünfschichtig. Blumenblätter frei, so viel als Kelchzipfel, dem Rande des Kelchs eingefügt. Staubgefässe mit den Blumenblättern inserirt, gewölnntich zahlreich, in der Knospenlage ein- 
wärts gekrümmt. Ovarium selten aus einem, meist aus mehreren Carpellen gebildet, welche entweder frei, oder mit einander, bisweilen auch noch mit dem Kelch, zu einem mehrfächerigen Ovarium verwachsen sind. Frucht verschieden, trocken oder fleischig, aufspringend oder nicht aufspringend. Samen mit eiweisslosem, geradem Embryo. Diese Section schliesst sich durch achsenständige Placenten, eiweisslose Samen, das Vorhandensein von Nebenblättern an die Leguminosen an, und es ist die an die vorige angrenzende Familie der Anıgdaleen jener auch durch ihr einfaches Ovarium und geraden Embryo ähnliclı; die Section unterscheidet sich aber von der vorigen durch die Stellung des Kelchs, regelmässige Corolle und das grösstentheils mehrächerige oder melırfache Ovarium. Wir heben die Familien der Amygdaleen, Rosaceen und Pomaceen hervor.

A mygdaleae. Wie schon bemerkt, besteht das Ovarium hier noch aus einem einzigen Carpell (wie bei den Leguminosen), ist frei, nicht mit dem Kelch verwachsen, verwandelt sich aber nicht in eine Hülse, sondern in eine nicht aufspringende Steinfrucht, indem sich die Mittelschichte der Fruchthülle in zwei Schichten sondert, von denen die innere steinhart, die äussere fleischig oder auch trocken wird; sie enthält einen bis zwei Samen mit fleiscligen Cotyledonen und nach oben gewendetem Würzelchen. Sträucher oder Bäume mit alternirenden einfachen Blättern und hinfälligen Nebenblättern.

R o s a ceae. Hinsichtlich der Zahl und Insertion der Blüthentheile schliesst sich diese Familie ganz der vorigen an, ist aber durch das Ovarium verschieden. Kelch fünftheilig, oft noch mit einer weiteren, äusseren Reihe von Kelchblättchen versehen, welche gewöhnlich kleiner sind und mit den äusseren alterniren. Blumenblätter fünf, auf dem Kelchrande stehend, wie auch die ungefähr zwanzig Staubfäden. Ovarien meistens zahlreich, frei, einfächerig, mit in der Regel ein e m anatropen Ei. Griffel endständig, öfters auch seitenständig. Frucht verschieden gebildet: sie besteht entweder aus zwei oder mehreren einsamigen Nüsschen, welche theils in die harte oder fleischig gewordene Kelchröhre eingeschlossen sind, theils frei auf dem trockenen oder 
saftigen Fruchtboden sitzen; oder es haben sich mehrere Steinfrüchtchen zu einer zusammengesetzten Beere vereinigt; oder endlich ist sie aus mehreren, an der Bauchnaht aufspringenden Balgkapseln zusammengesetzt. Die Familie zerfällt daher auch in mehrere Tribus, welche wohl auch als eigene Familien betrachtet werden. Die Rosaceen unterscheiden sich von den Anygdaleẹn wie schon bemerkt durch die Mehrzahl der Carpelle und von den folgenden Pomaceen dadurch, dass der Kelch nie mit dem Ovarium verwachsen ist. Die Rosaceen mit geschwänzten Caryopsen (Dryas, Geum) erinnern an gewisse Ranunculaceen, bei welchen aber die Insertion der Blïthentheile hypogynisch, nicht perigynisch ist. Die Rosaceen mit Balgkapseln (Spireae) stehen den Saxifrageen sehr nahe, unterscheiden sich aber durch eiweisslose Samen. Die Rosaceen sind krautartige Pflanzen, Sträucher oder Bäume mit meist gefiederten oder gefingerten Blättern und an die Blattstielbasis angewachsenen Nebenblättern.

Pomaceae. Hinsichtlich der Zahl und Bildung der Blïthentheile mit den übrigen Rosifloren übereinstimmend unterscheiden sie sich aufs Bestimnteste dadurch, dass die Kelchröhre mit dem Ovarium verwachsen ist, und nähern sich durch dieses Kennzeichen der folgenden Section. In der Regel sind fünf, seltener drei oder zwei Carpelle zu einem fünf-, drei-, zweifächerigen Ovarium vereinigt, selten besteht dasselbe nur aus e in e m Carpell, und ist daher einfächerig. Jedes Fach enthält gewölnnlich zwei, bisweilen auch mehr anatrope Eier. Die Frucht ist fleischig, die Fächer sind mit einer sehr dünnen oder pergamentartigen oder steinharten Haut ausgekleidet, daher die Frucht eine Beere, eine Apfelfrucht oder eine mehrsteinige Steinfrucht. Von den zwei Eiern schlägt oft eines fehl, dather die Fächer häufig einsamig. Bäume oder Sträucher, deren Zweige sich oft in Dornen verwandeln, mit einfachen oder zusanmengesetzten, alternirenden Blättern und freien, hinfailligen Nebenblättern.

17. Sect. Myrtiflorae.

Kelch mit dem Ovarium verwachsen, selten frei. Kelchlappen mit klappiger, Blumenblitter in gleicher Anzahl mit ge- 
drehter oder dachziegelförmiger Knospenlage. Staubgefässe doppelt so viel oder mehr als Blumenblätter, mit diesen auf dem Kelchschlund inserirt, frei oder in mehrere, selten ein Bündel verwachsen. Ovarium mehrfächerig, selten einfächerig mit gewöhnlich mehreren Eiern. Samen mit eiweisslosem, häufig gekrümmtem Embryo. Dèr Hauptunterschied zwischen dieser und der vorigen Section besteht darin, dass die Blätter nie zusammengesetzt sind und die Nebenblätter fehlen (oder doch wenigstens sehr klein und hinfällig sind). Die Myrtaceen, Granateen und Melastomaceen gehören zu dieser Section.

Granateae. Eine kleine, ein einziges Genus enthaltende Familie, welche in der Mitte steht zwischen den Pomaceen und Myrtaceen, zeichnet sich durch ein mehrfächeriges Ovarium aus, dessen Fächer in zwei Etagen übereinander gestellt sind, und zwar unten drei, oben fünf. Die Eier der unteren Fächer sitzen an der Basis derselben, die oberen sind wandständig. Die Frucht ist eine lederartige Beere, welche mit saftigem Mark erfuillt ist. Sträucher mit dornigen Zweigen und ganzrandigen, unpunktirten, zerstreuten, opponirten oder büschelförmigen Blättern ohne $\mathrm{Ne}$ benblätter.

Myrtaceae. Ausser den Merkmalen der Section zeichnet sich die Familie noch dadurch aus, dass die meist opponirten Blätter durchscheinend punktirt sind, sich an der Basis in den Blattstiel verschmälern und ausser dem Mittelnerven noch zwei den beiden Rändern parallel laufende Nerven haben. Das Ovarium ist unterständig oder halbunterständig mit einer fleischigen Scheibe bedeckt, einfächerig mit einem oder mehreren aufrechten Eiern im Grunde, oder zwei- bis mehrfächerig und dann die Eier an den centralen Placenten angeheftet. Frucht gewöhnlich mit dem Kelchsaum gekrönt, einfächerig, einsamig, nicht aufspringend; oder beerenartig; oder kapselartig, mehrfächerig, aufspringend. Gewöhnlich Bäume oder Sträucher selten krautartige Pflanzen, reich an ätherischem 0el, gewöhnlich ohne, selten mit sehr kleinen hinfälligen Nebenblättern, und Blättern von oben angegebener Beschaffenheit. 
I elastomaceae. Eine aus lauter tropischen Gewächsen bestehende Familie, welche sich von den Myrtaceen und allen anderen Verwandten durch die eigenthümlichc Bildung der Staubgefässe unterscheidet; diese sind nämlich vor dem Oeffnen der Blüthe zurückgeschlagen und die langen, sich in einen Schnabel endigenden Antheren in hohlen Räumen zwischen der Kelchröhre und dem Ovarium verborgen. Bäume, Sträucher oder Kräuter mit meist opponirten und ganzrandigen, nicht punktirten, drei-, fünf-, sieben-, neunnervigen Blättern ohne Nebenblätter.

\section{Sect. Caly ciflorae.}

Unter diesem Namen fassen Endlicher, Bartling u. A. einige kleine Familien zusammen, welche sich durch klappige Aestivation des Kelchs, Zahl und Insertion der Blüthentheile und gewöhnlich eiweisslosen Embryo den Myrtifloren anschliessen, aber durch die in der Regel bestimmte Anzahl der Staubgefässe, häufig einfächriges Ovarium und kapselartige, selten beerenoder nussartige Frucht von denselben verschieden sind. Der Name dieser Section ist nicht zu verwechseln mit der Unterklasse DeCandolle's, welche den gleichen Namen führt. Von den hieher gehörigen Familien erwähne ich nur die Philadelpheen, Onagrarien, Lythrarieen.

Philadelpheae. Die Staubgefässe sind noch in Mehrzahl vorhanden, das Ovarium mehrfächerig, wodurch sie den Myrtaceen ähnlich sind, mit welchen sie auch früler vereinigt waren; sie unterscheiden sich aber von ihnen durch den mit Arillus versehenen Samen, getrennte Griffel und nicht punktirte Blätter. Strauchartige Pflanzen mil opponirten, nervigen Blättern ohne Nebenblätter.

Onagrariae. Auch hier ist das Ovarium noch mehrfächerig, aber die Anzahl der Staubgefässe eine bestimmte; ebenso fehlen auch die Oeldrüsen in den Blättern, wodurch sie sich von den Myrtaceen unterscheiden. Die Frucht ist eine Kapsel oder Beere. Kräuter oder Sträucher mit einfachen, opponirten oder alternirenden, federnervigen Blätterı.

Lythrarieae. Der vorigen Familie ähnlich, aber durch 
das freie, nicht mit dem Kelch verwachsene Ovarium verschieden, welches anfangs zwar 2 bis 4 fächerig ist, aber sich später durch Einreissen der Scheidewände in eine einfächerige Kapsel verwandelt. Meist krautartige, selten strauchartige Pflanzen mit einfachen, federnervigen, ganzrandigen, gewöhnlich opponirten Blättern ohne Nebenblätter.

\section{Sect. Peponif erae.}

Blüthen häufig diclinisch. Kelch und Corolle fünftheilig oder -spaltig, Staubgefässe fünf oder weniger. Ovarium unterständig, gewöhnlich mehrfächerig mit wandständigen Placenten und zahlreichen Eiern. Frucht eine Beere oder Kapsel. Embryo eiweisslos, Cotyledonen blattartig.

Diese Section umfasst nach Endlicher die Cucurbitaceen und einige kleine Familien, von welchen die bekanntesten die Begoniaceen sind. Bartling stellt hieher auch die Cacteen, welçhe bei Endlicher eine besondere Section (Opuntiae) bilden, ferner die Passifloren und Grossularieen. Erstere stellt Endlicher zu den Parietales, letztere zu der folgenden Section. Was die Stellung der Peponiferae in System betriff, so ist diese bei Endlicher und DeCandolle ganz verschieden. Da ihre Blüthentheile eine epigynische Insertion haben, und die DeCandolle'schen Klassen auf die Art der Insertion gegründet sind, so haben diese Familien hier ihren Platz im System gefunden. Endlicher, der auf die Insertion der Blüthentheile keine Rücksicht nimınt, stellt die Peponiferae neben die Parietales und es dürfte wohl keinem Zweifel unterliegen, dass sie hinsichtlich ihrer übrigen Charaktere dort an einem viel natülicheren Orte stehen.

Cucurbitaceae. Blüthen diclinisch. Kelch mit dem Ovarium verwachsen, fünfzähnig mit dachziegelförmiger Knospenlage. Corolle fünfspaltig oder -theilig, an der Basis mit dem Kelch verwachsen. Die Staubgefässe stehen an der Basis der Corolle oder des Kelchs, sind selten frei, sondern triadelphisch verwachsen, nemlich $2+2+1$. Staubfäden sehr kurz. Antheren eigenthümlich hin und her gekrümmt. Das Ovarium besteht gewöhnlich aus drei Carpellarblättern, deren Ränder zu- 
erst nach innen, dann rückwärts wieder nach aussen gebogen sind, sich hier der Rückennaht der Carpellarblätter anschliessen und sich dort in wandständige Placenten endigen, welche init vielen anatropen Eiern besetzt sind. Die Frucht ist eine fleischige, oder trockene Beere - sogenannte Kürbisfrucht, Pepo.

Klimmende oder kriechende Gewächse mit zerstreuten, rauhen Blättern, neben welchen gewöhnlich eine Ranke steht. Die Verwandtschaft der Cucurbitaceen mit den Onagrarien beruht auf der bestimmten Zahl ihrer perigynischen Staubgefässe, dem einzigen Griffel, den eiweisslosen Samen und der fleischigen Frucht.

Be go niace ae. Blüthen wie bei der vorigen Familie getrennten Geschlechts init epigynischer Corolle und häufig verwachsenen Staubfäden; aber das dreifächerige Ovarium lıat centrale Placenten, die Frucht ist eine aufspringende Kapsel, und die Samen sind albuminos. Pflanzen mit saftigem, knotigem, nicht klimmendeın Stengel, gewöhnlich ungleichseitigen Blättern und häutigen, abfallenden Nebenblättern.

Pas sifloreae. Im Habitus den Cucurbitaceen ähnlich, da die meisten Pflanzen dieser Familie Schlingsträucher sind. Sie zeichnen sich durch einen Kranz fadenförmiger Anhängsel an der Corolle und durch ein gestieltes einfächeriges Ovarium mit wandständigen Placenten aus. Die Frucht ist entweder eine Beere oder eine aufspringende Kapsel.

Cacteae. Durch das unterständige Ovarium und die beerenartige Frucht ist diese Familie den Cucurbitaceen noch etwas ähnlich, sonst aber bedeutend verschieden und nähert sich eher den Grossularieen; es ist desshalb wohl gerechtfertigt eine besondere Section daraus zu bilden. Die zahlreichen Kelehblätter gehen allmälig in die ebenfalls zahlreichen Blumenblätter ïber, auf welchen die in grosser Anzahl vorhandenen Staubfäden inserirt sind. Mehrere Carpellarblätter sind mit ihren Rändern verwachsen und bilden ein Ovarium mit wandständigen Placenten. Die Fruclit ist eine Beere. Das Eiweiss fehlt beinahe oder ganz. Strauchartige Pflanzen gewöhnlich ohne Blätter mit fleischigem, kantigem, oft gegliedertem oder niedergedrücktem, kugligem Stamm. 
Zwischen den Passifloren und Cacteen stehen bei DeCandolle eine Anzahl Familien, von welchen die Ficoideen oder Mesembryanthemeen, die Portulaceen und Paronychieen hier kurz erwähnt werden sollen. Endlicher stellt sie wegen ihres albuminosen Samens mit peripherischem Embryo zu den Caryophyllinen. Die Ficoideen vermitteln durch die saftigen Stengel, zahlreichen Blumenblätter und Staubgefässe u. s. w. die Verwandtschaft dieser Familien mit den Cacteen.

\section{Sect. Corniculatae.}

Kelch verwachsenblättrig. Blumenblätter und Staubgefässe perigynisch, letztere gewöhnlich doppelt so viel als Kelchzipfel. Ovarium aus zwei oder mehreren Carpellen gebildet, welche quirlförmig angeordnet, theils getrennt, theils mehr oder weniger mit einander verwachsen sind. Samen mit Eiweiss. Die wichtigsten Familien sind die Grossularieen, Crassulaceen und Saxifragaceen.

Grossularieae. Kelch häufig gefärbt, gewöhnlich fünfspaltig, mit dem Ovarium verwachsen. Blumenblätter und Staubgefässe so viel als Kelchzipfel, erstere immer sehr klein, auf dem Kelchsaum stehend, mit den Kelchzipfeln alternirend, letztere in die Kelchröhre eingeschlossen, mit den Blumenblättern alternirend. Ovarium einfächerig, aus zwei, selten drei bis vier Carpellarblättern bestehend, mit wandständigen Placenten. Frucht eine mit saftigem Mark erfüllte, durch Fehlschlagen der Eier wenigsamige Beere. Samen mit eigenthümlich gelatinösem Ueberzug bekleidet.

Strauchartige Pflanzen mit alternirenden Blättern, haufig mit Stacheln versehen, Blüthen in Trauben. Durch ihre beerenartige Frucht mit wandständigen Placenten den Cacteen verwandt unterscheiden sie sich durch die bestimmte Anzahl der Blithentheile, die albuminosen Samen und den Habitus.

Crassulaceae. Kelchzipfel, Blumenblätter und Staubgefässe sowie auch die Carpelle in gleicher Anzahl vorhanden, drei bis zwanzig, gewöhnlich aber fün, je der folgende Kreis mit dem vorhergehenden abwechselnd, oder Staubgefässe doppelt so viel als Blumenbläiter, und dann die denselben opponir- 
ten kürzer und später sich entwickelnd. Die einfächerigen, vieleiigen, quirlförmig gestellten Carpelle sind den Blumenblättern opponirt, jedes an der Basis noch mit einer drüsenartigen Schuppe versehen, gewöhnlich frei, selten etwas verwachsen, und springen bei der Reife gewöhnlich an ihrer inneren Naht aufDurch diese in Mehrzahl vorhandenen einfächerigen Carpelle ist diese Familie mit den Ranunculaceen, Menispermeen u. s. w. verwand, in deren Nähe sie von Endlicher auch gestellt wird, von welchen sie sich aber durch den verwachsenblättrigen Kelch und die perigynische Insertion der Blüthentheile, sowie durch den Habitus unterscheidet. - Krautartige oder halbstrauchartige Pflanzen mit saftigen Stengeln, und zerstreuten, fleischigen, ganzrandigen Blättern ohne Nebenblätter. Blüthen in Afterdolden, mit centrifugaler Inflorescenz.

Saxifragaceae. Kelchröhre mehr oder weniger mit dem Ovarium verwachsen, Kelchzipfel und Blumenblätter wie bei der vorigen Familie in gleicher Anzahl (gewöhnlich fünf) und mit einander alternirend, ebenso Staubgefässe soviel als Blumenblätter oder doppelt so viel. Das Ovarium besteht gewöhnlich aus zwei verwachsenen Carpellen, seltener aus drei oder fünf, deren Ränder entweder ganz oder zur Hälfte oder kaum einwärts gebogen sind, und so eine zweifächerige oder halbzweifächerige oder einfächerige Kapsel bilden, welche bei der Reife in zwei Klappen aufspringt. Die Eier sind anatrop, die Samen albuminos. Meistens krautartige Pflanzen, aber auch Bäume oder Sträucher Init zerstreuten, opponirten oder quirlförmigen Blättern init und ohne Nebenblätter.

Die Saxifragaceen sind durch das mit dem Kelch verwachsene Ovarium mit den Grossularieen verwandt, unterscheiden sich aber durch die kapselarlige, nicht beerenartige Frucht und die aussen nicht gelatinösen Samen, sowie auch durch den $\mathrm{Ha}$ bitus. Von den Crassulaceen unterscheiden sie sich durch die geringere Anzahl der unter sich und mit dem Kelch verwachsenen Carpelle und durch das Fehlen der Schuppen ausserhalb derselben. Was den Habitus und Blütlenstand betrifft, sind sie auch mit den Caprifoliaceen verwandt durch das Genus Hydran- 
gea, unterscheiden sich aber durch die Kapselfrüchte und die hervorstehenden Griffel.

\section{Sect. U m belliflorae.}

Kelch mit dem Ovarium verwachsen, Blüthenblätter getrennt. Ovarium mit einer epigynischen Scheibe gekrönt, zwei- bis mehrfächerig, mit je einem Ei in jedem Fach. Samen albuninos, Blüthenstand eine Dolde. Es gehören hieher die Unbelliferen, Araliaceen, Corneen. Endlicher nennt diese Section Discanthae (wegen der epigynischen Scheibe) und stellt hieher ausser obigen und einigen kleinen ausländischen Familien noch die Loranthaceen und Ampelideen.

Umbelliferae. Eine der natürlichsten und am schönsten charakterisirten Familien des Pflanzenreichs, welche ebendesshalb eine geringe Verwandtschaft zu anderen Familien zeigt. Die Błüthen stehen in zusammengesetzten, selten einfachen Dolden, welche bei wenigen Gattungen durch Verkürzung der Strahlen zu Köpfchen zusammengedrängt sind (Umbelliferae anomalae). Der Kelchsaun ist gewöhnlich unvollständig entwickelt, selten fünfzähnig. Die fünf Blumenblätter haben eine schmale Basis, sind an der Spitze selır häufig zu einem schmalen, einwärts gebogenen Fortsatz verlängert, zugleich sind bei den an der Peripherie der Dolde stehenden Blütlen die drei äusseren Blumenblätter häufig grösser, als die zwei inneren. Knospenlage unvollkommen dachziegelförmig. Die fünf Staubgefässe sitzen am Rande einer epigynischen Scheibe - eines zweispaltigen sogenannten Stempelpolsters - stylopodium - aus welchem die beiden Griffel entspringen. Das Ovariun ist zweifächerig, enthält in jedem Fach ein hängendes anatropes Ei und entwickelt sich zu einer Spaltfrucht, schizocarpium, deren einzelne Theile Mericarpien heissen. Die Samen enthalten ein grosses, festes Albumen, in dessen oberer Seite der Embryo eingeschlossen ist.

Krautartige, selten strauchartige Pflanzen init rundem oder gefurchtem, knotigeın Stengel, alternirenden, häufig zusamınengesetzten, an der Basis scheidenden Blättern, reich an Harz 
und ätherischem 0el, ersteres hauptsächlich in der Wurzel, letzteres vorzugsweise in den Früchten.

Araliaceae. Diese Familie unterscheidet sich von den Umbelliferen durch den unvollkommen doldenartigen Blüthenstand, die an der Basis nicht verschmälerten Blumenblätter mit klappiger Knospenlage, und durch die Frucht, welche beerenartig ist, daher nicht aufspringt oder in einzelne Theile zerfällt, auch häufig mehr als zwei, bis zu fünf Fächern enthält. Durch ihre beerenartige Frucht stehen die Araliaceen den Ainpelideen nahe, letztere unterscheiden sich aber durch das oberständige Ovarium, wesshalb sie bei DeCandolle zu den Thalamifloren gehören. Bäume oder Sträucher, selten perennirende krautartige Pflanzen init meist alternirenden, häufig zusammengesetzten Blättern, deren Blattstiel an der Basis verdickt ist, olne Nebenblätter. Die

Corne ae stehen den Araliaceen durch die Beschaffenheit der Blüthentheile, besonders durch das unterständige, zweifächerige Ovarium mit je einem anatropen hängenden $\mathrm{Ei}$ in jedem Fach und durch die klappige Knospenlage der Blumenblätter sehr nahe, unterscheiden sich aber durch die Vierzahl der Blüthentheile, nemlich Kelch, Blumenblätter, Staubgefässe (bei den Araliaceen fünf), und durch die opponirten Blätter.

Bäume oder Sträucher mit opponirten, selten abwechselnden, cinfachen federnervigen Blättern ohne Nebenblätter.

Die bisher betrachteten Familien der Calycifloren DeCandolle's haben alle (mit Ausnahme der Cucurbitaceen) eine getrenntblättrige Corolle; sie bilden mit den Thalamifloren diejenige Abtheilung der Dicotylerlonen, welche Endlicher unter dem Namen der Dialypetalae zusammenfasst. Vergleicht man die Reihenfolge der Familien bei DeCandolle und Endlicher, so findet man eine grosse Verschiedenheit, welche, abgesehen von dem Unstand, dass Endlicher mit der am höclisten organisirten Familie auflörrt, DeCandolle danit anfängt, hauptsächlich aus zwei Ursachen entspringt. Einmal betrachtet Endlicher als höchst organisirte Familie nicht die Ranunculaceen, sondern die Leguminosen; sodann legt Endlicher keinen Werth darauf, ob das 
Ovarium ober- oder unterständig, ob die Insertion der Corolle hypogynisch, peri-, oder epigynisch ist. In der That lässt sich nicht verkennen; dass wenn man diesen Eintheilungsgrund DeCandolle's unberücksichtigt lässt, die Anordnung der Familien in manchen Fällen natürlicher wird. So stehen, un nur ein paar Beispiele anzuführen, die Cacteen mit ihren Verwandten bei Endlicher in der Nähe der Bixaceen, Violarieen u. s. w., mit welchen sie durch ilıre wandständigen Placenten übereinkommen; die Mesembryanthemen, Portulaceen, stehen wegen ihres peripherischen Embryo bei den Caryophylleen, wo sie natülicher placirt sind, als nach DeCandolle.

Die nun folgenden Familien, welche noch zur Klasse der Calycifloren gehören, haben alle eine verwachsenblättrige $\mathrm{Co}$ rolle; sie bilden mit der folgenden Klasse der Corollifloren die Gamopetalae Endlichers.

\section{Sect. Caprifolia.}

Kelch und Corolle oberständig, Staubgefässe auf der Corolle inserirt. Ovarium unterständig, zwei- oder mehrfächerig mit mehreren Eiern in jedeın Fach. Saınen albuminos. Blätter opponirt. Die wichtigsten Familien dieser Section sind die Caprifoliaceen (oder Lonicereen) und die Rubiaceen.

Cap r ifoliaceae. Kelch vier- oder fünftheilig, Corolle radförmig oder mit langer Röhre versehen. Staubgefässe so viel als Lappen der Corolle, oder ausnahınsweise eines weniger, wodurch letztere unregehnässig wird. Ovarium zwei- bis fünffächerig, mit je einem oder mehreren hängenden Eiern. Frucht in der Regel beerenartig, oft zwei solcher Beeren mit einander verwachsen.

Strauchartige oder lialbstrauchartige, seltener perennirende krautartige Pflanzen mit oft windendem Stengel. Blätter ohne Nebenblätter. Die Familie schliesst sich durch die Gattungen mit radförmiger Corolle (Sambucus, Viburnum), deren Blätter zugleich oft getheilt sind, an die Corneen und Araliaceen an und bildet so den Uebergang von den Dialypetalen zu den Gamopetalen Endlicher's. 
Rubiaceae. Abschnitte des Kelchs und der Corolle, und Staubgefässe in gleicher Anzahl vorhanden, vier bis fünf, und mit einander abwechselnd. Ovarium zweifächerig, mit einem oder seltener zwei Eiern in jedem Fach, oder mehrfächerig, mit mehreren Eiern. Frucht eine Steinfrucht, Beere, Kapsel oder Schliessfrucht. Samen mit grossem, hornartigem orler fleischigem Eiweiss.

Bäume, Sträucher, seltener krautartige Gewächse mit einfachen, ganzrandigen opponirten Blättern, welche immer mit Nebenblättern versehen sind. Letztere haben bei gewissen Gattungen, wie Asperula, Galium, Rubia, die Form der anderen Blätter, daher sie früher für quirlörmige Blätter angesehen, aus diesem Grunde auch diese Gattungen von den übrigen Rubiaceen getrennt und zu der besonderen Fanilie der Stellatae vereinigt wurden.

Die Rubiaceen sind den Caprifoliaceen am nächsten verwandt, unterscheiden sich hauptsächlich durch ihre Nebenblätter, welche den Caprifoliaceen fehlen, und dadurch, dass die Blätter immer ganzrandig sind. Durch diejenigen Gattungen, deren zweifächerige Frucht nur einen oder zwei Samen in jedem Fach enthält, schliessen sie sich an die folgenden Familien an.

\section{Sect. A g g r ega t a e.}

Kelch und Corolle epigynisch, ihre Abschnitte mit einander alternirend, Staubgefässe auf der Corolle inserirt, wie bei der vorigen Section, von welcher diese durch das ein- bis dreifächerige, aber immer nur einsamige Ovarium sich unterscheidet. Unfasst als hauptsächlichste Familien die Valerianeen, Dipsaceen, Compositen.

Va le ri an eae. Kelch mit dem Ovarium verwachsen, Kelchsaum oft eingeschlagen, zuletzt zu einem Pappus ausgerlelint (Annäherung an die Compositae). Corolle mil drei-, vier-, fünfspaltigem Saum, etwas unregelnässig, Staubgefässe vier oder weniger. Ovarium dreifächerig, aber nur ein Fach enthält ein hängendes, anatropes Ei, die zwei anderen Fächer sind leer. Frucht nicht aufspringend. Samen eiweisslos.

Krautartige oder halbstrauchartige Pflanzen mit opponirten 
einfachen oder getheilten Blättern ohne Nebenblätter. Blüthen Zwitter, oder durch Fehlschlagen diclinisch, gewöhnlich in Afterdolden.

D i p s a c e a e. Diese unterscheiden sich von den,Valerianeen durch einfächeriges Ovarium, welches oft innerhalb der Kelchröhre frei ist, und erst bei der Fruchtreife mit demselben verwachst, durch albuminose Samen, und durch kopfförmigen Blüthenstand mit gemeinschaftlicher Hülle, wodurch sie sich den Compositen nähern. Der Kelch der einzelnen Blüthe ist doppelt und steht in der Achsel einer Bractee.

Meist krautartige Pflanzen mit opponirten, selten quirlförgen Blättern ohne Nebenblätter.

Co m p o sita e. Eine der natürlichsten und ain besten characterisirten Familien des Pflanzenreichs. Die theils vollständigen, theils durch Fehlschlagen der Staubgefässe oder Stempel unvollständigen, oder geschlechtslosen Blüthen sitzen auf einer stark verkürzten und breit gewordenen Achse, receptaculum commune, zu einem Köpfchen dicht zusammengedrängt, von einer gemeinschaftlichen Hülle, invohucrum, anthodium, umgeben, in den Achseln von Deckblättern, welche paleae heissen, aber oft sich nicht entwickelt haben (receptaculum nudum), in welchem Falle die Blüthen oft von Borsten unstellt sind. Die Kelchröhre ist mit dem Ovarium verwaclısen, über dieses hinaus ragt der Kelchsaum in Form von Zähnen, häufiger aber als Federkrone, pappus, hervor. Die immer verwachsenblättrige Corolle hat fünf, bisweilen auch nur vier oder drei Abschnitte und ist entweder regelmässig, oder zweilippig (zwei Abschnitte oben, drei unten) oder auf der oberen Seite gespalten und daher zungenförmig. Die fünf Staubgefässe, welche auf der Röhre der Corolle inserirt sind und mit ihren Lappen abwechseln, sind frei, die Antheren aber verwachsen, an der Spitze immer mit einem Anhängsel versehen und häufig auch mit zwei an der Basis. Ovarium unterständig, einfächerig mit einem anatropen aufrechten Ei. Griffel nach oben gespalten. Die Narbensubstanz auf beiden Griffelarmen geht nicht immer bis zu ihrer 
Spitze. Auf der Unterseite des Griffels finden sich häufig Haare, welche wie eine Bürste wirken, und dazu dienen, die Pollenkörner auf die Narbe zu werfen; sogenannte Fegborsten, pili collectores. Frucht trocken, nicht aufspringend, einsamig, ein Achaenium, Samen eiweisslos.

Krautartige, selten strauchartige, häufig Milchsaft führende Pflanzen mit meist zerstreuten Blättern ohne Nebenblätter. Die nächste Verwandtschaft ist die mit den Dipsaceen, was sich, abgesehen von den übrigen übereinstimmenden Charakteren auch aus dem Habitus ergibt; sie unterscheiden sich aber von denselben durch verwachsene Staubbeutel, das hängende $\mathrm{Ei}$ und die eiweisslosen Samen.

\section{Sect. Campanulina e.}

Kelchröhre mit dem Ovarium verwachsen mit frei hervorstehendem Saum. Corolle sammt Staubgefässen auf dem Kelchsaum inserirt, also perigynisch. Ovarium ein- bis mehrfacherig mit gewöhnlich zahlreichen Eiern. Samen albuminos. Die hieher gehörigen Familien, von welchen die wichtigsten die Lobeliaceen und Campanulaceen sind, stehen in naher Beziehung zu den Compositen. So finden sich namentlich bei den Lobeliaceen die Sammelborsten unter der Narbe wieder, sowie auch die zusammenhängenden Staubbeutel, die unregelmässige, oben gespaltene Corolle. Der Milchsaft, der bei einem Theil der Compositae auftritt, ferner der kopfförmige Blüthenstand kommt ebenfalls theilweise bei den Lobeliaceen und Campanulaceen vor, so auch die anatropen Eier und der eiweisslose Samen. Dagegen unterscheiden sich diese Familien von den vorigen durch das mehrfächerige Ovarium und die zahlreichen Eier und allerdings auch durch den Habitus, indem der Blüthenstand häufig auch anders als kopfförmig ist.

Lobeliaceae. Kelch oberständig oder halboberständig. Corolle gewöhnlich unregelmässig und oben der Länge nach gespalten. Die fünf Staubgefasse mit den Lappen der Corolle abwechselnd, Staubbeutel zu einem Cylinder verbunden. Pollenkörner eiförmig. Ovarium aus zwei bis drei Carpellarblättern 
gebildet, welche entweder seitlich verwachsen und zu einem einfächerigen Ovarium verbunden, oder deren Ränder eingeschlagen sind und ein zwei- bis dreifächeriges Ovarium mit centraler Placenta bilden. Griffel einfach. Narbe mit gewimperter Krone oder einem häutigen Schüsselchen umgeben. Frucht kapselartig, aufspringend, oder fleischig, nicht aufspringend.

Krautartige oder halbstrauchartige Pflanzen, selten Sträucher oder Bäume, gewöhnlich Milchsaft führend, mit abwechselnden Blättern olme Nebenblätter.

C a m p a n lace a e. Mit der vorigen Familie haben sie den ober- oder halboberständigen Kelch, die fünf Staubgefässe, das mehrfächerige Ovarium und die aufspringende Kapsel gemein, unterscheiden sich aber durch regelmässige Corolle, freie Antheren, runde Pollenkörner und zwei- bis achttheilige, nur an Rücken, nicht ringsum haarige Narbe.

Meist krautartige Pflanzen mit alternirenden Blättern ohne Nebenblätter.

\section{Sect. Bi c or n e s.}

Kelch mit dem Ovarium verwachsen oder frei. Corolle regelmässig, hypogynisch oder perigynisch. Staubgefässe mit der Corolle, seltener auf derselben inserirt, so viel oder doppelt so viel als Lappen der Corolle. Antheren einfach oder an der Spitze zweitheilig. Samen mit Eiweiss. Ausser einigen kleineren Familien gehören hieher die Vaccinieen und Ericineen, welche Endlicher aber als e ine Familie betrachtet. Da bei den Vaccinieen das Ovarium unterständig, bei den Ericineen aber frei ist, so dürfte eine Trennung in zwei Familien wohl gerechtfertigt sein. Die Ericineen leiten dann durch ihr freies Ovarium zu der folgenden Unterklasse der Corollifloren hinüber, während sich die Vaccinieen noch den Campanulaceen einigermassen anschliessen.

V a ccinieae. Kelch ober- oder halboberständig, Corolle auf dem hervorstehenden Kelchsaum inserirt, vier- bis fünflappig. Staubgefässe gewöhnlich doppelt so viel als Abschnitte der Corolle, auf einer epigynischen Scheibe eingefügt. Antheren an der Spitze zweitheilig, in Poren aufspringend. Ovarium vier- 
bis fünfächerig mit mehreren anatropen Eiern in jedem Fach und centraler Placenta. Frucht eine mit dem Kelch gekrönte Beere. Samen albuminos. Strauchartige Pflanzen mit abwechselnden, lederartigen Blättern.

Ericineae. Der Hauptunterschied zwischen dieser und der vorigen Familie besteht in der freien, unterständigen Blumenkrone; in den übrigen Charakteren sind beide Familien fast ganz mit einander übereinstimmend, so namentlich auch hinsichtlich des Ovariums, dessen Anzahl der Fächer der Zahl der Kelchund Corollenabschnitte gleichkommt. Staubgefässe auf einer hypogynischen Scheibe inserirt, Antheren oft nit grannenartigen Fortsätzen. Frucht eine Beere oder eine Kapsel.

Sträucher, scltener Kräuter mit immergrünen, lıäufig nadelartigen Blättern olıne Nebenblätter.

Ein paar kleine Familien schliessen sich hier an und mögen kur'z erwähnt werden, weil sie auch bei uns vertreten sind.

Pyrolaceae. Unterscheiden sich von den Ericineen durch das Fehlen der hypogynischen Scheibe und den in einen Arillus eingeschlossenen Samen.

M. on otropeae. Auf den Wurzeln der Bäume wachsende Schmarotzerpflanzen von bleicher oder bräunlicher Farbe, mit Schuppen statt der Blätter; waren früher mit den Pyrolaceen vereinigt und verbinden diese Pflanzen mit den Orobancheen. Bei diesen beiden Familien ist das Ovarium wie bei den Ericineen oberständig.

\section{Corolliflorae. DC.}

Kelch und Corolle verwachsenblättrig, gewöhnlich frei, hypogynisch, Staubgefässe häufig mit der Corolle verwachsen. Ovarium oberständig, gewöhnlich frei, selten mit dem Kelch verwachsen. Wie schon oben bemerkt, umfasst diese Abtheilung (Unterklasse DC.) einen Theil von Endlicher's Gamopetalen, und entspricht der 8. Klasse Jussieu's. 
26. Sect. Contortae.

Kelch frei, Corolle regelmässig, Staubgefässe auf der Corolle stehend, an Zahl den Abschnitten derselben gleich und mit diesen abwechselnd, oder weniger. Ovarium aus zwei Carpellarblättern gebildet. Eier anatrop. Samen theils mit, theils olme Eiweiss. Die gedrehte Knospenlage der Corolle, von welcher die Section ihren Namen erhalten hat, kommt nicht bei allen Familien vor. Es gehören hielier die Oleaceen, Jasmineen, Asclepiadeen, Apocyneen, Loganiaceen, Gentianeen.

Oleaceae. Kelch und Corolle regelmässig, viertheilig, bisweilen fehlend. Knospenlage der Corolle klappig. Staubgefässe nur zwei, je zwischen zwei Abschnitten der Corolle stehend. Ovarium zweifächerig, die Fächer mit den beiden Staubgefässen abwechselnd, je zwei neben einander hängende Eier enthaltend. Frucht trocken oder fleischig, eine Kapsel- oder Flügelfrucht, oder eine Beere oder Steinfrucht, wonach die Familie in zwei Tribus zerfällt. Samen albuminos.

Bäume oder Sträucher mit opponirten, gestielten, einfachen oder unpaarig gefiederten Blättern ohne Nebenblätter. Blüthen bisweilen diöcisch. - Eine Merkwürdigkeit der hieher gehörigen Gewächse ist die, dass dieselben alle auf einander gepfropft werden können, woraus ihre sehr nahe Verwandtschaft trotz der verschiedenartigen Früchte deutlich hervorgelit. Die Oleaceen unterscheiden sich von den meisten übrigen Familien dieser Section dadurch, dass sie nur halb so viel Staubgefässe haben, als Abschnitte der Blumenkrone, und weil zugleich die Knospenlage der Corolle niclt gedreht ist, so werden sie wohl auch als besondere Section (Ligustrinae) aufgeführt. Die Gattung Fraxinus erinnert durch ihre zusammengesetzten Blätter an die Acerineen (Negundo).

Jasmineae. Kelch und Corolle fün- bis achtspaltig, Zipfel der Corolle in der Knospenlage spiralförmig zusammengerollt. Staubgefässe wie bei der vorigen Familie nur zwei. Ovarium zweifächerig mit je einem aufsteigenden Ei. Frucht eine Kapsel oder Beere. Das anfangs reichliche Eiweiss der 
Samen wird bei der Reife gänzlich verzehrt oder zu einer dünnen Haut reducirt, wogegen die Cotyledonen fleischig werden; die Familie nähert sich dadurch- den Apocyneen. Von den Oleaceen ist sie durch gedrehte Knospenlage, Zahl der Kelchund Corollen-Abschnitte, aufsteigende Eier und das fast fehlende Eiweiss verschieden. Beide Familien stimmen aber darin überein, dass die Anzahl der Staubgefässe weniger beträgt, als die der Corollen-Abschnitte, während bei den nun folgenden Familien so viel oder seltener doppelt so viel Staubgefässe als Lappen der Blumenkrone vorhanden sind. Die Jasmineen sind kleine Bäume oder Sträucher, häufig mit windendem Stamm, mit opponirten, oft gedreiten oder unpaarig gefiederten Blättern ohne Nebenblätter.

A s c le p i a d e a e. Kelch und Korolle fünfspaltig oder -theilig. Knospenlage des Kelchs fünfschichtig, die der Corolle gedreht oder klappig. Corolle abfallend. Staubgefässe fünf, gewöhnlich am Grunde verwachsen und nach aussen mit besonderen Anhängseln versehen, welche eine sogenannte Nebenkrone bilden. Die Staubfäden selbst sind gewöhnlich zu einer Röhre verwachsen, welche nach innen den Stempel umschliesst. Antheren meist durch einen häutigen Fortsatz des Connectivs zugespitzt, enthalten wachsartige Pollenmassen (Pollenarien), die sich nach dem Aufspringen der Antheren paarweise an fadenförmige Fortsätze anheften, welche von der Narbe gegen die Antheren hinwachsen; es geschieht diess gewöhnlich schon vor der Oeffnung der Blüthe. Narbe nach oben in der Regel ausgebreitet, fünfseitig, bedeckt das Ovarium, welches aus zwei getremnten Carpellen besteht, an deren Bauclmaht dic anatropen, hängenden Eier in zwei oder mehreren Reihen befestigt sind. Die Frucht besteht aus zwei Balgkapseln (wovon bisweilen eine fehlschlägt) und enthält eine grosse Anzahl zusammengedrückter, absteigend daclıziegelförmig gestellter Samen, welche mit einem Haarschop gekrönt sind und ein dünnes Eiweiss enthalten.

Kraut- oder strauchartige Pflanzen, oft Schlinggewächse mit meist opponirten ganzrandigen Blättern olne Nebenblätter; statt dieser bisweilen Borsten zwischen den Blattstielen. Bei vielen 
sind die Stengel sehr entwickelt und fleischig, wogegen die Blätter verkümmern (Stapelia). Häufig enthalten sie einen mehr oder weniger scharfen Milchsaft.

Apocyneae. Durch bleibenden Kelch, abfallende Corolle, gleiche Anzahl der Blüthentheile, aus zwei Carpellen bestehendes Ovariun den Asclepiadeen ähnlich, unterscheiden sie sich durch den pulverförmigen Pollen, die einfache Narbe, das Fehlen der Anhängsel an den Staubfäden (die Nebenkrone). Dagegen ist der Schlund der Corolle bisweilen mit Schuppen besetzt. Die Frucht besteht in der Regel aus zwei oder durch Fehlschlagen einer Balgkapsel, seltener aus einer Beere, Steinfrucht oder zweiklappigen Kapsel. Samen gewöhnlich albuminos, Eiweiss oft sparsam, bisweilen aber auch ganz fehlend.

Kraut- oder häufiger strauchartige, meist Milchsaft führende Gewächse, oft Schlingpflanzen mit in der Regel opponirten, einfachen, ganzrandigen Blättern ohne Nebenblätter; statt derselben, wie bei den Asclepiadeen, bisweilen Borsten oder Drüsen.

L og an i ac eae. Zu dieser Familie rechnet mau jetzt mehrere Gattungen, welche durch regelmässige Corolle, auf welche die Staubgefässe inserirt sind, durch zweitheiliges, freies Ovarium und opponirte Bläiter sich den vorigen Familien anschliessen, aber in mehreren anderen Stücken davon verschieden sind. Mèlırere derselben wurden früher unter die Apocyneen gestellt, andere bildeten die Repräsentanten eigener Familien (Strychneae), wie denn auch die Familie nach der Verschiedenheit der Knospenlage und der Frucht in zwei Unterfamilien und mehrere Tribus zerfällt. Die eine dieser Unterfamilien ist die der Strychneen mit klappiger Aestivation der Corolle, wodurch sie sich von den Apocyneen unterscheidet, die andere bildet die Loganieen mit gedrehter Knospenlage. Die Samen enthalten ein grosses Eiweiss.

Bäune oder Sträucher mit wässerigem Saft. Blätter opponirt, mit oder ohne Nebenblätter und dann der Blattstiel stengelumfassend.

Durch die regelmässige, die Staubgefässe tragende Corolle, 
zweigliedriges Ovarium und den Habitus stehen sie auch den Rubiaceen nahe, sind aber durch das oberständige Ovarium von denselben verschieden.

Gentianeae. Wie bei den vorigen Familien die Abschnitte des Kelchs und der Corolle sowie Staubgefässe in gleicher Anzahl vorhanden, gewöhnlich fünf, bisweilen auch vier, sechs, acht, zehn. Corolle welkend mit gedrehter oder eingefalteter Knospenlage (aestiv. induplicativa). Ovarium mit hypogynischer Scheibe umgeben oder diese fehlend; aus zwei Carpellarblättern gebildet, deren Ränder entweder zu einer einfächerigen Kapsel mit wandständigen Placenten vereinigt, oder mehr oder weniger eingefaltet sind, wodurch ein halb-oder ganz zweifächeriges Ovarium mit centraler Placenta entsteht. Samen zahlreich, albuminos. Embryo sehr klein.

Krautartige, bisweilen strauchartige Pflanzen mit wässrigem Saft und opponirten, quirlförmigen oder alternirenden Blättern ohne Nebenblätter. Unterscheiden sich von den Apocyneen, denen sie am nächsten stehen, durch das Fehlen des Milchsafts, das ungetheilte Ovarium, die welkende Corolle.

\section{Sect. Tu b if lo rae.}

Kelch und Corolle regelmässig, letztere die Staubgefässe tragend; diese mit den Corollenlappen abwechselnd, in gleicher Anzahl mit jenen, gewöhnlich fünf. Knospenlage der Corolle meist einwärts gefaltet (Annäherung an die Gentianeen). Ovarium zwei-, drei-, fünfgliedrig. Frucht eine Kapsel oder Beere. Samen albuminos. Die Convolvulaceen und Solanaceen sind die wichtigsten hieher gehörigen Familien.

Convolvulaceae. Kelch bleibend, oft fortwachsend. Corolle vier- bis fünflappig, abfallend. Ovarium auf einer unterständigen Scheibe sitzend, aus zwei-, seltener drei- bis vier Carpellarblättern gebildet, deren Ränder verwachsen sind; von einer centralen Säule gehen nach der Peripherie des Ovariums zweibis vier Scheidewände, die aber bisweilen unvollständig entwickelt sind, wenn die Säule nicht gehörig ausgebildet ist; selten sind zwei getrennte Carpelle vorhanden. Jedes Fach ent- 
hält wenige aufrechte anatrope Eier. Frucht nicht aufspringend, läufiger eine in zwei bis vier Ḱlappen, die sich von den Rändern der Scheidewände ablösen, oder mit einem Deckel aufspringende Kapscl. Embryo in ein sparsames, schleimiges Eiweiss eingeschlossen, gekrümnt, Cotyledonen blattartig, zerknittert.

Krraut- oder strauchartige. Milchsaft führende Pflanzen mit häufig windendem Stengel und alternirenden ganzrandigen Blättern ohne Nebenblätter.

S ol a naceae. In der Blüthenbildung und den Blättern mit den Convolvulaceen sehr übereinstimmend, unterscheiden sie sich durch zahlreiche Samen mit reichlichem, fleischigem Eiweiss. Das Ovarium ist in seltenen Fällen drei- bis fünffächerig, in der Regel aber zweifächerig oder durch falsche, secundäre Scheidewände vierfächerig, und sind die beiden Carpellarblätter, aus welchen dasselbe besteht, so gestellt, dass sie die rechte und linke Seite der Blüthenachse einnehmen.

Kraut- oder strauchartige Pflanzen mit alternirenden nach oben häufig paarweise stehenden Blättern, wovon das eine kleiner ist. Blüthen hảufig extraaxillär. Corolle bisweilen etwas unregelmässig.

\section{Sect. N u culifer a e.}

Kelch frei. Corolle regelmässig oder unregelmässig. Staubgefässe so viel als Lappen der Corolle oder weniger. Ovarium aus zwei Carpellarblättern gebildet, welche mit ihren Randern verwachsen und an ihrer Mitte tief eingefaltet sind, so dass vier scheinbar getrennte Carpelle entstehen, welche bei der Reife vier einsamige Nüsschen darstellen. Samen ohme oder mit sehr sparsamem Eiweiss.

Von den hieher gehörigen Familien sind hervorzuheben die Borragineen, Verbenaceen und Labiaten. DeCandolle stellt die Borragineen zwischen die Convolvulaceen und Solanaceen, und lässt die Labiaten und Verbenaceen erst nach den Rhinanthaceen folgen; allein wegen der ganz ähnlichen Bildung ihrer Ovarien gehören sie entschieden zusammen.

B or ragin e a e. Kelch bleibend, Corolle fünflappig, regel- 
mässig oder etwas unregelmässig, wodurch sich die Familie an die Solanaceen anschliesst. Ovarium vierlappig, auf einer hypogynischen Scheibe sitzend, scheinbar vier einfächerige Carpelle darstellend, oder je zwei solcher Carpelle verwachsen; in jedem Fach ein hängendes anatropes Ei. Der Griffel erhebt sich aus der Mitte der vier Lappen des Ovariums. Die Frucht besteht aus vier Nüsschen, welche in den Kelch eingeschlossen sind. Samen eiweisslos.

Kräuter, Sträucher oder Bäume mit runden Stengeln, meist mit steifen Haaren oder Borsten besetzt (daher sie auch Asperifoliae heissen). Blätter alternirend ohne Nebenblätter. -- Die Annäherung dieser Fanilie an die vorige wurde schon angedeutet; von den folgenden unterscheidet sie sich durch runde Stengel, den Mangel an Oeldrüsen und die Fünfzahl der Staubgefässe.

Verbenaceae. Kelch bleibend, Corolle unregelmässig. Staubgefässe vier, wovon zwei länger, oder zwei. Griffel endständig. Die vier Theile des Ovariums sind anfangs vereinigt, und trennen sich bei der Fruchtreife, oder sie bleiben verbunden und bilden eine Steinfrucht. Eier anatrop, aufrecht. Durch diese Charaktere ist die Familie von der vorigen und folgenden hinreichend unterschieden.

Kraut- oder strauchartige Pflanzen, bisweilen Bäume mit meist vierkantigen Stengeln, gewöhnlich opponirten Blättern ohne Nebenblätter.

Labiatac. Kelch bleibend, Blumenkrone unregelınässig, zweilippig. Staubgefässe meist vier, didynamisch, bisweilen nur zwei. Der Griffel erhebl sich aus dem Grunde des tief vierlappigen Ovariums, das auf einer hypogynischen Scheibe sitzt. Jede Abtheilung des Ovariums enthält ein aufrechtes anatropes Ei. Die Fruchl besteht aus vier in den Kelch eingeschlossenenNüsschen, welche Linnée für nackte Samen hielt, daher der Ausdruck: Gymnospermia. Samen eiweisslos.

Gewöhnlich krautartige oder halbstrauchartige Pflanzen, doch auch Sträucher mit ineist vierkantigen Stengeln und opponirten oder quirlförmigen Blättern ohne Ncbenblätter. Blïthen in den 
Blattachseln in zusammengezogenen Cymen, scheinbar Quirle darstellend, welche oft so genährt sind, dass der ganze Blüthenstand ährenförmig erscheint. Alle Theile sind reich an ätherischem Oel, welches in besonderen Drüsen enthalten ist.

Von den Verbenaceen, welchen sie in der Bildung der Corolle und in Habitus ähnlich sind, unterscheiden sich die Labiaten durch das viertheilige Ovarium, in welcher Hinsicht sie mit den Borragineen übereinstimmen, welch letztere aber dann durch die Fünfzahl der Staubgefässe und die hängenden Eier verschieden sind.

\section{Sect. Personatae.}

Kelch frei, Corolle unregelmässig, gewöhnlich zweilippig. Staubgefässe meist weniger als Lappen der Corolle. Ovarium aus zwei Carpellarblättern gebildet, ein- bis zweifächerig mit zahlreichen Eiern. Frucht eine Kapsel, seltener eine Beere. Samen gewöhnlich albuminos.

Durch unregelmässige Blüthen und meist zwei màchtige Staubgefässe schliessen sich die Familien dieser Section den Labiaten an, sind aber durch das ein- oder zweifächerige Ovarium davon verschieden. Die wichtigste Familie ist die der Scrophularineen, welcher sich noch einige weitere anschliessen.

Scrophularineae. Kelch vier- bis fünftheilig, bleibend, Blumenkrone unregelmässig, abfallend. Staubgefässe vier, didynamisch, seltener zwei oder fünf. Ovarium gewöhnlich von einer hypogynischen Scheibe umgeben, zweifächerig, mit vielen anatropen Eiern. Placenta mittelständig, mit der Scheidewand verwachsen. Die zwei Carpellarblätter, aus welchen das Ovarium gebildet ist, stehen auf der vorderen und hinteren Seite der Blüthenachse, haben also eine von den Salanaceen, denen sie sich in anderer Hinsicht nähern, verschiedene Stellung. Frucht eine auf verschiedene Art aufspringende Kapsel, seltener eine Beere. Samen albuminos, Embryo gerade. Die Familie zerfällt in mehrere Tribus, welche zum Theil auch als eigene Familien betrachtet werden. Die bei uns einheimischen derselben sind die Verbasceen, Antirrhineen, Digitaleen, Gratioleen, Veroniceen, Rhinanthaceen. 
Meist krautartige Pflanzen init alternirenden, opponirten oder quirlförmigen Blätternn ohne Nebenblätter.

O robancheae. Unterscheiden sich von den Scrophularineen durch einfächerige Kapsel mit wandständigen Placenten. Lauter blattlose, parasitische Pflanzen.

A c an thace ae. Unregelmässige Blüthen, meist didynamische oder zwei Staubgefässe, zweifächerige Kapsel haben sie mit den Scrophularineen gemein, unterscheiden sich aber wesentlich durch das gewöhnlich elastische Aufspringen der Kapsel, die sich in der Art öffnet, dass die Placenta in zwei Theile zerfällt, und durch eiweisslose Samen, die an verhärteten Nabelschnüren sitzen.

Big n o n i a c e a c. Blüthenbildung ähnlich wie bei den vorigen Familien, von den Acanthaceen durch geflügelte Samen, von den Scrophularineen, durch den Mangel des Albumens verschieden.

Lentibulariae. Corolle unregelmässig, gespornt. Staubgefässe zwei. Ovarium einfächerig, mit freier centraler Placenta. Diese Familie bildet den Uebergang zu der folgenden, indem sie sich durch unregelmässige Blüthen noch den vorigen Familien anschliesst, aber durch die freie centrale Placenta den Primulaceen ähnlich wird, von welchen sie sich jedoch durch eiweisslose Samen unterscheidet.

\section{Sect. P et a l a n tha e.}

Kelch und Corolle frei, regelmässig, Staubgefässe doppelt oder mehrmals so viel als Lappen der Corolle, oder gleichviel, aber dam denselben opponirt. Ovarium gewöhnlich einfächerig, mit freier centraler Placenta. Samen albuminos. Es gehören hieher die Primulaceen, Myrsineen, Sapotaceen, Ebenaceen, Styraceen. Dadurch, dass die Ebenaceen wegen der Befestigungsart der Samen mit den Oleaceen verwandt sind, steht diese Section mit jener (Contortae) im Zusammenhang.

Primulaceae. Kelch fünf-, seltener viertheilig. Corolle regelmässig, höchst selten undeutlich zweilippig. Abschnitte der Corolle so viel als des Kelchs und mit ihnen abwechselnd. Staubgefässe so viel als Corollenfappen, denselben opponirt, zwischen 
ihnen bisweilen noch Staminoidien. Ovarium einfächerig, mit freier centraler Placenta, welche ringsum mit Eiern besetzt ist, und mit einem spitzen Fortsatz in die Griffelsäule hineinragt. Eier halbgegenläufig (ovulum hemianatropum). Kapsel in Klappen, Zähnen, oder mit einem Deckel aufspringend. Samen albuminos. Embryo quer gegen den Nabel liegend.

Krautartige Pflanzen mit meist unterirdischem, verkürztem Stamm und schaftförmigen Aesten. Blätter kurzgestielt oder sitzend, gewöhnlich lauter Wurzelblätter. Nebenblätter fehlen.

Myrsinea e. In Zahl und Lage der Staubgefässe, Beschaffenheit des Ovariums u. s. w. ganz mit den Primulaceen übereinstimmend, unterścheiden sie sich von denselben durch die beerenartige Frucht.

Bäume oder Sträucher mit gewöhnlich alternirenden, einfachen, lederartigen oft drüsig punktirten Blättern ohne .Nebenblälter.

Sap otaceae. Bei den Pflanzen dieser Familie stehen nun zwischen den fünf fruchtbaren Staubgefässen, welche den Corollenlappen opponirt sind, füf unfruchtbare, wie diess bei den vorigen Familien nur theilweise vorkam; oder die fruchtbaren Staubgefässe finden sich in doppelter oder vierfacher Anzahl und stehen in zwei oder mehreren Reihen. In der Bildung des Ovariums. welches mehrfächerig ist, nähern sie sich der folgenden Familie. In jedem Fach findet sich ein aufsteigendes anatropes Ei. Die Frucht ist eine mehrfächerige, oder durch Fehlschlagen einfächerige Beere. Samen mit oder ohne Eiweiss.

Milchsaft führende Bäume oder Sträucher mit alternirenden, einfachen, lederartigen Blättern ohne Nebenblätter.

Ebenaceae. Staubgefässe doppelt oder viermal so viel als Lappen der Blumenkrone. Ovarium drei- bis mehrfächerig mit je einem oder zwei hängenden anatropen Eiern. Frucht eine Beere. Samen albuminos. Unterscheiden sich von den Sapotaceen durch das Fehlen des Milchsafts und die hängenden Eier, wodurch sie sich den Aquifoliaceen nähern.

Styraceae. Unterscheiden sich von der vorigen Familie durch perigynische, seltener hypogynische Corolle, verwachsene 
Staubgefässe und die Richtung der Eier, von denen die unteren aufrecht oder horizontal, die oberen hängend sind. Frucht eine fleischige oder trockene, durch Fehlschlagen häufig einsamige Steinfrucht. Samen albuminos.

Bäume oder Sträucher mit einfachen alternirenden Blättern ohne Nebenblätter.

\section{Sect. Plu m b a $\mathrm{g}$ in es.}

Kelch bleibend, Corolle trockenhäutig, verwachsen- oder getrenntblättrig. Staubgefässe so viel oder weniger als Lappen der Corolle. Ovarium frei, ein- oder zweifächerig, mit einem oder mehreren Eiern. Samen albuminos. Die Section bildet den Schluss der Corollifloren und begreift die Familien der Plumbagineen und Plantagineen. Mit der vorigen Section steht sie dadurch in einiger Beziehung, dass hier wie dort den Corollenlappen opponirte Staubgefässe, halbgegenläufige Eier und init einem Deckel aufspringende Kapseln vorkominen.

Plumbagin e a e. Kelch fünfähnig, gefaltet, Corolle regelmässig, fünftheilig oder fünfblättrig. Staubgefässe fünf, den Lappen der Blumenkrone opponirt, auf dem Blumenboden stehend, oder mit den Nägeln der Blumenblätter zusammenhängend. Ovarium gewöhnlich aus fünf mit den Rändern verwachsenen Carpellarblättern gebildet, daher einfächerig; enthält ein anatropes Ei, welches an der Spitze einer sich aus dem Grunde erlıbenden Nabelschıur hängt. Frucht trockenhäutig, an der Spitze oder nicht aufspringend.

Kräuter oder Sträucher mit häufig verkürztem Staın : Blätter einfach, ganzrandig, oft nur Wurzelblätter; Nebenblätter fehlen.

Plan tag in e ac. Kelch viertheilig. Corolle regelmässig, verwachsenblättrig mit vierspaltigem Saun, welkend. Staubgefïsse vier, auf der Corolle eingefügt und mit deren Lappen abwechselnd. Ovarium frei, einfächerig mit einem aufrechten Ei, oder zwei- bis vierfächerig, indem die centrale Placenta durch zwei oder vier Flïgel sich der Wandung des Ovariums anschliesst, und dann in jedem Fach ein oder mehrere Eier 
schildförmig angeheftet. Frucht ein einsamiges Nüsschen oder eine mit einem Deckel aufspringende Kapsel.

Habitus den Plumbagineen ähnlich; meist stamılose, krautartige Pflanzen mit schaftförmigen Blüthenstielen und einfachen, nervigen Blättern, häufig nur Wurzelblätter.

Es wurde schon oben bemerkt, dass DeCandolle's Corolliflorae mit einem Theil seiner Calyciflorae die Gamopetalae Endlicher's bilden. Was die von letzterem befolgte Reihenfolge der Familien (oder Sectionen) betrifft, so ist dieselbe aus den oben angefülrten Gründen wie bei der Klasse der Dialypetalae so auch hier von der DeCandolle'schen Anordnung abweichend, doch stimmen beide Systeme darin überein, dass die Plantagineen die Grenze gegen die nächste Unterabtheilung (Monochlamydeae oder Apetalae) hin bilden.

\section{Monochlamydeae. DC.}

Blüthen häufig eingeschlechtig. Blumenblätter fehlend, daher Blüthendecke einfach, Perigon genannt.

Diese Unterklasse DeCandolle's entspricht der 7., 6., 5. und 15. Klasse Jussieu's und kommt in der Hauptsache mit Endlicher's Apetalae überein. Der Hauptunterschied besteht darin, dass Letzterer die Coniferen als besondere Abtheilung unter dem Namen der Gymnospermae trennt. Ausserdem zieht Endlicher einige hieher gehörige Familien zu den früheren Abtheilungen, so die Euphorbiaceen, Phytolacceen, Juglandeen u. A. Die Verwandtschaft vieler Monochlamydeen mit höheren, mit vollständigen Blüthen versehenen Gewächsen ist nemlich oft so gross, dass selbst DeCandolle, und nach ihın andere Botaniker die Frage aufgeworfen haben, ob nicht diese Klasse ganz aufgehoben und die betreffenden Familien den übrigen Klassen eingetheilt werden sollten. Derselbe stellt z. B. auch die Ceratophylleen und Callitrichineen zu den Thalamifloren wegen ihrer Aehnlichkeit mit den Halorageen, obgleich sie unvollständige Blüthendecken haben. Es fehlt ja oft auch bei einzelnen Arten einer Gattung von verschieden höher organisirten Pflanzen die Corolle, 
ohne dass sie desshalb zu den Monochlainydeen gerechnet wurden.

32. Sect. 0 l e r a c e a e.

Perigon regelmässig, oft corollinisch gefärbt. Ovarium frei, einfächerig, mit mehreren Griffeln und gewöhnlich nur einem Ei (wie bei den Plantagineen). Frucht.schlauch- oder nussartig, vom Perigon umgeben, bisweilen mit demselben verwachsen. Samen mit Eiweiss, das aber oft gegen die Reife hị wieder verschwindet. Embryo gekrümmt. Die Amaranthaceen, Phytolacceen, Chenopodeen, Polygoneen gehören zu dieser Section.

Chenopodeae. Blüthen theils Zwitter, theils diclinisch, Perigon gewöhnlich grün, tief zwei- bis fünfspaltig, bisweilen saftig oder hart werdend. Staubgefässe perigynisch, auf der Basis des Perigons dessen Lappen opponirt, so viel oder weniger als diese. Ovarium frei, einfächerig, Ei krummläufig, aufrecht. Frucht in das auf verschiedene Art veränderte Perigon eingeschlossen, schlauchförmig. Samen mit mehligem Eiweiss, um welches der Embryo gekrümmt ist oder das Eiweiss fehlt und der Embryo ist spiralförmig gewunden.

Meist krautartige Pflanzen mit häufig saftigem Stengel, gewöhnlich alternirenden Blättern ohne Nebenblätter. Durch den peripherischen Embryo sind die Chenopodeen mit den Sileneen verwand, aher durch die unvollständigen Blüthen verschieden.

A maranthaceae. Dieselben unterscheiden sich von den Chenopodeen durch hypogynische Staubgefässe, von welchen fünf fruchtbare den Perigonblättern opponirt sind, während fünf unfruchtbare mit ihnen abwechseln. Ovarium häufig mehrfächerig.

Krautartige oder halbstrauchartige Pflanzen mit alternirenden oder opponirten einfachen Blättern ohne Nebenblätter, gewöhnlich kopfförmigem Blüthenstand und häufig corollinisch gefärbtem Perigon.

Phytolaccaceae. Staubgefässe hypogynisch, mit den Perigonblättern alternirend, oder in doppelter Anzahl vorhanden und dann die äusseren alternirend und die imneren opponirt. Ovarium mehrfächerig. Wegen dieser Charaktere, wodurch sie sich von den Chenopodeen wesentlich unterscheiden, werden 
sie von Endlicher mit der Section der Coryophyllinae vereinigt.

Kräuter oder Sträucher mit gewöhnlich alternirenden einfachen Blättern mit oder ohne Nebenblätter.

Polygoneae. Perigon drei-, fünf-, sechsblättrig oder -theilig, die inneren Perigonblätter häufig grösser. und mit der Frucht fortwachsend. Staubgefässe auf der Basis des Perigons in wechselnder Anzahl, fünf, sechs, acht oder neun, gewöhnlich den Perigonblättern opponirt. Ovarium frei, einfächerig, mit einem aufrechten geradläufigen Ei. Griffel zwei bis vier. Frucht nicht aufspringend, nussartig oder fleischig, häufig durch die inneren Perigonblätter bedeckt. Embryo in der Achse des Eiweisskörpers, oder um denselben gekrümmt.

Krautartige Pflanzen, bisweilen Sträucher mit knotig gegliedertem Stengel, einfachen, meist alternirenden, federnervigen Blättern, deren Ränder in der Jugend zurückgerollt, und Nebenblätlem, welche zu einer Tute verwachsen sind.

Durch einfächeriges, eineiiges freies Ovarium mit mehreren Griffeln, nicht aufspringender Frucht und oft gekrümmtem Embryo den Chenopodeen nahe verwand, unterscheiden sie sich von denselben, sowie von den anderen Familien dieser Section durch geradläufiges Ei, häıfig gefärbtes Perigon und die Tuten an der Basis der Blätter. Auch mit den Piperaceen findet eine. entfernte Verwandtschaft statt.

\section{Sect. T h y mel a e a c e a e.}

Perigon an der Basis gewöhnlich röhrig, corollinisch gefärbt. Staubgefässe gewöhnlich auf dem Perigon, selten auf dem Blumenboden inserirt. Ovarium in der Regel frei, selten mit der Perigonröhre verwachsen, mit einem oder mehreren Eiern. Frucht eine Balgkapsel, Nuss- oder Steinfrucht. Die Laurineen, Thymeleen, Santalaceen, Myristiceen gehören zu dieser Section.

L a u rin e ae. Perigon unterständig, vier- bis sechsspaltig oder -theilig mit dachziegelförmiger Aestivation. Staubgefässe auf der Basis der Perigonzipfel inserirt, sechs in einer, oder zwölf in zwei Reihen. Antheren durch eine Klappe von unten 
nach oben aufspringend. Ovarium frei, aus drei Carpellarblättern gebildet, einfächerig mit einem hängenden anatropen Ei und nur e ine m Griffel. Frucht eine Steinfrucht oder Beere. Samen eiweisslos, Embryo gerade.

Meist baumartige Pfianzen mit alternirenden, häufig sehr genäherten einfachen Blättern ohne Nebenblätter. Bluithen regelmässig, oft diclinisch. Die Verwandtschaft dieser Familie zu den vorigen ist nicht gross; das einfache eineiige Ovarium, die bisweilen diclinischen Blüthen finden sich auch bei den Chenopodiaceen, aber der Habitus ist ganz verschieden. Das Hauptkennzeichen ist die Art des Aufspringens der Antheren. Das dreiblättrige Ovarium erinnert an die Polygoneen.

Thymeleac s. Daphnoideae. Durch unterständiges Perigon mit dachziegelförmiger Knospenlage, freies, einfächeriges Ovarium mit einem hängenden $\mathrm{Ei}$, zum Theil auch durch den Habitus, nähert sich diese Familie der vorigen, unterscheidet sich aber durch röhriges Perigon, das die Staubgefässe auf der Röhre oder am Schlunde trägt, und durch die in Längsspalten aufspringenden Antheren.

Sträucher oder kleine Bäume, seltener krautartige Pflanzen mit zerstreuten oder opponirten, einfachen Blättern ohne Nebenblätter und bisweilen durch Fehlschlagen diclinischen Blüthen.

Santalaceae. Durch röhriges, corollinisch gefärbtes Perigon nicht aufspringende Frucht, den Thymeleen ähnlich, unterscheiden sie sich von denselben durch unterständiges Ovarium mit mehreren Eiern, welche an der Spitze einer freien centralen Säule hängen, von welcher indess nur eines zur Entwicklung komınt, so dass die Frucht wie bei der vorigen Fanilie einsamig ist.

Krautartige Pflanzen, Sträucher oder Bäume mit alternirenden, federnervigen; lederartigen oder etwas fleischigen Blätlern olne Nebenblätler. Auch hier werden die Blithen bisweilen durch Fehlschlagen diclinisch.

Myristiceae. Perigon dreilappig mit klappiger Aestivation. Staulgefässe zu einer festen Säule verwachsen mil drei bis achtzehn Antheren. Ovarium einfächerig mit cinem aufrech- 
ten, anatropen Ei. Frucht eine kapselartige, zweiklappige Beere. Samen mit grossem, runzligem, öligem Eiweiss. Die harte Samenhaut, welche von dem Kern getrennt ist, mit einem fleischigen, geschlitzten Arillus (Macis) umgeben.

Bäume oder Sträucher mit diclinischen Blüthen und alternirenden, lederartigen, häufig durchscheinend punktirten Blättern ohne Nebenblätter. Durch die unansehnlichen, unvollständigen Blüthen, und den Habitus den Laurinieen ähnlich, mit welchen sie auch in ihren chemischen Eigenschaften übereinstimmen. Von Endlicher werden sie zu den höher organisirten Pflanzen gerechnet und in die Nähe der Magnoliaceen gestellt, mit welchen sie durch Vermittlung der Anonaceen verbunden sind.

\section{Sect. Serpentariae.}

Perigon dreitheilig, Staubgefässe epigynisch, Ovarium scheinbar mehrfächerig, Eier zahlreich, anatrop. Frucht kapselartig, aufspringend, oder nicht aufspringend. Samen eiweisshaltig. Diese Section enthält nur zwei Familien, die Aristolochiaceen und Nepenteen, wovon die letztere nur wenige in den Tropenländern Asiens vorkommende Arten zählt, die sich durch ihre schlauch. förmigen, mit Wasser erfüllten Blätter auszeichnet.

A ristolochiaceae. Perigon epigynisch, dreilappig, bisweilen unregelmässig. Staubgefässe sechs oder zwölf, seltener neun, auf einer ringförmigen Scheibe inserirt, welche auf dem Ovarium sitzt, oder mit der Basis des Griffels verschmolzen ist, daher epigynisch oder scheinbar gynandrisch. Ovarium unterständig, durch die nach innen gebogenen Ränder der Carpellarblätter unvollständig sechsfächerig, seltener drei- bis fünffächerig, die falschen Scheidewände mit vielen anatropen Eiern besetzt. Narbe drei- bis sechslappig, strahlenförmig über die Staubgefässe ausgebreitet. Frucht eine aufspringende oder geschlossene Kapsel. Cotyledonen vor der Keimung kaum sichtbar.

Krautartige Pflanzen mit kriechendem oder knolligem Rhizom, oder Sträucher mit oft windendem Stengel olne Jahresringe und alternirenden einfachen, an der Basis häufig herzförmigen Blättern. Die Verwandtschaften dieser Familie sind zwei- 
felhaft; unter den Dicotyledonen kann man sie wegen ihres Habitus und unterständigen Ovariums mit den Cucurbitaceen vergleichen; durch das dreitheilige Perigon und die Structur des Stengels nähern sie sich den Monocotyledonen, und unter diesen den Dioscoreen, und stehen so auf der Grenze zwischen diesen beiden Abtheilungen des Pflanzenreichs.

\section{Sect. Tricoc cae.}

Blüthen häufig diclinisch, theils unvollständig, theils aber auch vollständig. Ovarium gewöhnlich dreifächerig. Frucht eine Kapsel, welche bei der Reife sich in Knöpfe theilt, die elastisch von der Mittelsäule abspringen. Es gehören hieher die Euphorbiaceen und Empetreen. Diese Section wird von Endlicher und Anderen zwischen die Frangulaceen und Therebinthaceen gestellt, mit welchen durch die oft vollständigen Blüthen und die Besclıaffenheit der Frucht eine Verwandtschaft stattfindet.

Euphorbiaceae. Blüthen monöcisch. Corolle meist fehlend, oft auch der Kelch; oder Perigon vier- bis sechstheilig oder -spaltig, unterständig. Staubgefässe in unbestimmter Anzahl, theils mehr, theils weniger als Perigonzipfel, im Centrum der Blüthe, unterhalb dem Rudiment des Ovariums inserirt. Staubfäden frei oder verwachsen. Ovarium frei, aus gewöhnlich drei Carpellen gebildet, welche kreisförmig um eine griffeltragende centrale Achse gestellt und mit ihr verwachsen sind. Jedes Carpell (oder Fach) enthält ein bis zwei anatrope hängende Eier. Frucht bei der Reife in ihre Elemente zerfallend. Samen albuminos.

Bäume, Sträucher oder krautartige Pflanzen, welche einen wässrigen, oder häufiger einen scharfen, seltener milden Milchsaft enthalten. Stengel bei einigen fleischig, wie Cactus, und dann die Blätter fehlschlagend; bei den anderen die Blätter meist einfach, bisweilen mit kleinen, läutigen Nebenblättern. Die

Empetreae haben vollständige Blüthen mit Kelch und Corolle, und aufrechte Eier, wodurch sie sich von den Euphorbiaceen unterscheiden. 
36. Sect. Urticinae.

Blüthen meist diclinisch, seltener hermophroditisch. Perigon mit in der Regel dachziegelförmiger Ḱnospenlage. Ovarium einbis zweifächerig, in jedem Fach ein Ei, immer oberständig. Frucht nicht aufspringend. Samen theils mit theils ohne Eiweiss. Begreift die Familien der Urticeen, Cannabineen, Artocarpeen, Moreen.

Die ganze Section wird von Endlicher mit der folgenden der Amentaceen unter dem Namen Juliflorae (Kätzchenblüthige) vereinigt; allein eine Trennung ist sehr wohl gerechtfertigt, denn die Urticinae blühen nicht immer in Kätzchen und zeichnen sich vor den Amentaceen ausserdem noch aus durch ihren Milchsaft, die Brennhaare, oft albuminosen Samen, das vollkommenere Perigon, die oft fleischige Frucht und durch das Ovarium, welches nur ein bis zwei Eier enthält, während diese bei der folgenden gewöhnlich in Mehrzahl vorhanden sind, wenn sie auch nicht alle zur Entwicklung kommen.

Urtic eae. Perigon frei, vierspaltig, Staubgefässe vier, den Perigonzipfeln opponirt, einwärts gekrümmt. Ovarium einfächerig, mit einem aufrechten geradläufigen Ei. Frucht eine Caryopse. Samen albuminos, Embryo gerade.

Bäume, Sträucher oder Kräuter, oft mit rauhen, stechenden Haaren oder Brennborsten besetzt; Blätter abwechselnd oder opponirt, mit freien, abfallenden Nebenblättern. Eine nähere Verwandtschaft zu den vorigen Familien ist ausser der Aehnlichkeit in den unvollständigen Blüthen kaum nachzuweisen. Mit den Chenopodeen haben sie das einfächerige Ovarium mit aufrechtem Ei gemein, das aber dort nicht gerade, sondern gegenläufig ist.

Cannabineae. Blüthen diöcisch; männliche Blüthe mit fünfblättrigem Perigon und fünf Staubgefässen; weibliche Blüthe mit einblättrigem, an einer Seite gespaltenem Perigon, das aber von einigen Botanikern als Deckblatt angesehen wird, indem dieselben annehmen, dass das eigentliche Perigon eng an das Ovarium anliegend sey. Ovarium einfächerig, mit einem hängenden 
campylotropen Ei. Frucht eine Caryopse. Embryo fast eiweisslos, gekrümmt.

Krautartige oder Schlingpflanzen mit opponirten oder zerstreuten Blättern und freien oder verwachsenen Nebenblättern. Von vielen Botanikern werden die Cannabineen mit den Urticeen vereinigt; sie unterscheiden sich aber durch das hängende Ei und den gekrümmten Embryo.

Moreae. In der Bildung des Ovariums stimmen sie mit den Cannabineen überein, unterscheiden sich aber durch albuminose Samen und durch das verschiedene Perigon. Sodann zeichnen sie sich vor den anderen Familien dieser Section durch ihre Frucht aus, welche eine Sammelfrucht oder falsche Beere darstellt; es wird nemlich das Receptaculum, auf welchem viele einzelne Blüthen vereinigt sind, fleischig, oder die Blüthen stehen in einem Kätzchen gedrängt beisammen, und ihr Perigon wird saftig.

Baumartige oder krautartige Pflanzen mit abwechselnden Blättern und hinfälligen häutigen Nebenblättern. Viele enthalten Milchsaft. Die

A rtocarpeae waren früher mit den Moreen vereinigt und unterscheiden sich von denselben durch den Mangel des Albumens.

\section{Sect. A m e n t a e a e.}

Blütlıen diclinisch, die männlichen immer, die weiblichen bisweilen in Kätzchen. Perigon beider Geschlechter sehr unvollkommen. Ovarium mehrfächerig, mit mehreren Eiern. Frucht meist einsamig. Samen eiweisslos. Es gehören hieher die $\mathrm{Cu}$ puliferen, Juglandeen, Salicineen.

Cupulif erae. Blüthen monöcisch, die männlichen in Kätzchen, in den Achseln von Deckschuppen oder auf diesen selbst inserirt. Perigon vier- bis sechsspaltig oder fehlend. Staulgefässe fünf bis zwanzig, dem Perigon, oder wenn dieses fehlt, der Deckschuppe eingefügt. Weibliche Blüthen einzeln oder in Büscheln, je eine bis drei Blüthen von fortwachsenden Hüllblättchen eingeschlossen. Perigon mit dem Ovarium verwachsen mit gezähneltem, oft fehlendem Saum. Ovarium unterständig, zwei- 
bis sechsfächerig mit je einem bis zwei anatropen hängenden Eiern. Frucht nussartig, nicht aufspringend, an der Basis von einer becherartigen Hülle, cupula, umgeben, oder ganz davon eingeschlossen. Frucht durch Fehlschlagen der Fächer gewöhnlich einfächerig, einsamig. Samen eiweisslos, Embryo gross, mit dicken fleischigen Cotyledonen.

Bäume oder Sträucher mit alternirenden, einfachen, federnervigen Blättern und hinfälligen Nebenblättern. Durch die Becherhülle der Frucht ist diese Familie vor allen anderen ausgezeichnet.

Jugla ndeae. Dieselben nähern sich durch unterständiges Ovarium und die in Kätzchen stehenden männlichen Blüthen den Cupuliferen, haben aber sonst wenig Aehnlichkeit mit denselben, sind sowohl durch ihr einfächeriges Ovarium mit aufrechtem, geradläufigem Ei und die mit zwei- bis vierklappiger Schale versehene Steinfrucht ohne Becherhülle, als auch namentlich durch ihren Habitus ganz verschieden, indem sie gefiederte Blätter ohne Nebenblätter besitzen, wodurch sie sich mehr den RhusArten nälıern, daher sie auch von Endlicher zu den Terebinthaceen gestellt werden.

S a li c i n e e. Blüthen diöcisch, die männlichen und weiblichen in Kätzchen. Perigon sehr unvollständig, Staubgefässe zwei bis zwanzig. Ovarium frei, aus zwei Carpellarblättern gebildet, einfächerig mit vielen hängenden Eiern an zwei wandständigen Placenten. Kapsel zweiklappig, Samen mit einem Haarschopf versehen.

Bäume und Sträucher mit alternirenden einfachen Blättern und Nebenblättern. Die Aehnlichkeit mit den Cupuliferen liegt in den Blüthen; sonst sind sie aber durch die Beschaffenheit der Frucht und des Samens sehr verschieden.

\section{Sect. Piperitae.}

Ausser zwei unbedeutenden Familien, welche hier übergangen werden, gehören in diese Section nur die Piperaceen. Durch ihren kätzchenförmigen Blüthenstand schliessen sie sich der vorigen Section an, nähern sich aber durch die häufig zerstreuten 
Gefässbündel des Stanmes und parallelnervigen Blätter den Monocotyledonen.

Piperaceae. Blüthen Zwitter oder diclinisch, ohne Perigon, von einem Deckblättchen unterstützt auf einem meist fleischigen, cylindrischen Kolben inserirt. Staubgefässe zwei oder mehrere, Ovarium einblättrig, einfächerig, mit einem aufrechten geradläufigen Ei. Frucht eine Beere. Samen albuminos. Das Albumen besteht aus dem - aus dem Keimsack hervorgegangenen Endospermium.

Krautartige, oft saftige Pflanzen mit im Stamm zerstreuten Gefässbündeln, oder Sträucher mit strahlenförmigen Gefässbündeln und kaum zu unterscheidenden Jahresringen. Blätter opponirt oder quirlförmig, bisweilen durch Fehlschlagen alternirend, mit scheidendem Blattsiel. Durch die Beschaffenheit des Ovariums sind die Piperaceen mit den Urticeen und Polygoneen, mit letzteren auch im Habitus, verwandt, erinnern durch ihren Blüthenstand mit fleischiger Spindel aber auch an die Spadicifloren, mit welchen sie früher sogar vereinigt wurden; sie gehören jedoch unzweifelhaft noch zu den Dicotyledonen.

\section{Sect. Conifera e.}

Blüthen diclinisch, in Kätzchen. Eier aufrecht oder umgekehrt, meist geradläufig, auf der Oberseite des Carpellarblatts sitzend, das entweder aus einer flachen Schuppe besteht oder die Form einer becherförmigen Scheibe angenommen hat. Griffel und Narbe fehlend, dagegen die Eier mit einer narbenälnlichen Micropyle versehen, auf welcher der Pollen zur Befruchtung auffällt.

Baum- oder strauchartige, harzreiche Pflanzen, deren Stamm in seinem anatomischen Bau von allen anderen Pflanzen, sowohl Dicotyledonen als Monocotyledonen verschieden ist. Das Holz besteht nämlich nur aus verlängerten, spindelförmigen Zellen mit Tüpfeln entweder auf allen oder einzelnen Seiten, und enthält keine Gefässe mit alleiniger Ausnahıne von Ephedra. Blätter meist nadelförmig, einzeln oder in Büscheln.

Es gehören hiehır die Familien der Ephedrineen, Taxineen, 
Cupressineen und Abietineen. Früher wurde der Name "Coniferae" zur Bezeichnung der Familie gebraucht und die jetzigen Familien als Unterfamilien oder Tribus betrachtet. Endlicher bildet aus den Coniferen eine besondere Abtheilung, die Gymnospermae, so dass also diese und seine Apetalae den Monochlamydeen DeCandolle's entsprechen.

Ephedreae s. Gnetaceae. Männliche Blüthen mit röhrigem, oben zweitheiligem Perigon und einem oder mehreren verwachsenen Staubgefässen. Weibliche Blüthen nackt, oder zn zweien von einer zweiblättrigen Hülle umgeben. Ein einzelnes Ei ist am Grunde von einem Perigon umschlossen. Samen in die aus dem saftig gewordenen Perigon und der Hülle entstandene falsche Beere eingeschlossen. Embryo mit zwei Cotyledonen.

Die Annäherung der Familie an die übrigen Monochlanydeen ergibt sich aus dem Vorhandensein eines Perigons, das bei den anderen Coniferen fehlt, und aus der Anwesenheit von Gefässbündeln im Stamm.

T a $\mathrm{x}$ in e a e. Durch die einzelnen, nicht in Zapfen gestellten, weiblichen Blüthen den vorigen ähnlich unterscheiden sie sich durch den Mangel des Perigons, wodurch sie sich den folgenden Familien nähern. Die nussartigen Samen sind von einer mehr oder weniger verdickten und fleischig gewordenen Scheibe eingeschlossen. Embryo mit zwei Cotyledonen.

Cu p ress in e ae. Männliche Kätzchen aus zahlreichen nackten, fast wagrecht rings um eine Achse angehefteten Staubgefässen gebildet. Staubfaden dick, mit excentrisch scliildförmigem Connectiv, das unten zwei bis zwölf Antherenfächer trägt. Weibliche Blüthen in Kätzchen, aus wenigen deckblattlosen offenen Carpellarblättern bestehend. Eier einzeln oder zu zweien oder mehreren an der Basis der Carpellarblätter, aufrecht, geradlaufig. Frucht eine falsche Beere oder Zapfen, aus den eng an einander schliessenden, fleischig verdickten oder holzig gewordenen Carpellarblättern entstanden. Embryo mit zwei oder drei Cotyledonen.

Von den Taxineen durch die verschiedene Form des Car- 
pellarblatts und die zusammengesetzte Frucht verschieden nähert sich diese Familie eben dadurch der Folgenden.

Abietineae. Männliche Kätzchen denen der Cupressineen ähnlich, aber das Connectiv schuppenförmig. Weibliche Kätzchen aus offenen Carpellarblättern zusammengesetzt, welche in den Achseln dachziegelförmig gestellter Bracteen sitzen; oder letztere selten fehlend. Eier zu zweien oder dreien umgekehrt an der Basis der Carpellarblätter. Frucht ein Zapfen, aus den vergrösserten lederartig oder holzig gewordenen Carpellarblättern gebildet, während die Deckblätter zwischen denselben im Wachsthum zurückgeblieben sind. Sainen ungekehrt, gewöhnlich geflügelt, Embryo mit zwei bis zwölf Cotyledonen.

Unterscheiden sich von den Cupressineen durch die Form der Zapfen und die ungekehrten Eier.

\section{Sect. Z a m i a e.}

Diese Section ist allein durch die Familie der Cycadeen repräsentirt und der vorigen dadurch ähnlich, dass auch hier die Eier nackt sind. Sonst haben diese Pflanzen wenig Verwandtschaft zu den Coniferen, nähern sich in ihrem Habitus den Palınen und in der Entwicklung der Blätter den Farren, in deren Nähe sie von Endlicher gestellt werden, obgleich sie deutliche Befruclıtungswerkzeuge besitzen.

Cycadeae. Blüthen nackt, diöcisch, in endständigen Zapfen. Staubgefässe blattartig, horizontal an gemeinschaftlicher Spindel befestigt, unterseits den Blüthenstaub absondernd. Weibliche Zapfen aus flachen gekerbten, oder schildförmigen Carpellarblättern bestehend, welche in den Einschnitten oder unten die nackten Eier tragen. Frucht ein Zapfen. Samen albuminos mit zwei ungleichen Cotyledonen.

Baumartige Pflanzen mit kurzem, dickem, nicht ästigem Stanm und einem Büschel grosser gefiederter Blätter an der Spitze, deren Blattnerven fast immer parallel verlaufen. 
Die Reihenfolge, in welcher Endlicher die Apetalen aufführt, ist der von DeCandolle's Monochlamydeen so ziemlich gleich, nur folgen die Serpentariae vor den Thymelaeaceen, die Oleraceen nach denselben. Diese Anordnung ist vielleicht vorzuziehen, weil die Serpentariae durch ihr corollinisch gefärbtes Perigon sich mehr an die Corollifloren anschliessen, während die Oleraceen durch ihren Habitus den Urticineen und Amentaceen ähnlicher sind. Berücksichtigt man aber die Beschaffenheit des Ovariums, so stehen den Plantagineen die Oleraceen jedenfalls näher, als die Serpentarien. Den Schluss der Monochlamydeen bilden in beiden Systemen die Gymnospermae, bei Endlicher jedoch nicht mit Einschluss der Cycadeen, welchen er, wie schon bemerkt, einen anderen Platz anweist.

Wir haben manche solcher Familien, bei welchen man nicht absolut sagen kann, sie seien an diesen oder jenen, und an keinen anderen Ort zu stellen, sondern bei welchen es eben darauf ankommt, ob wir diesen oder jenen Charakteren am meisten Gewicht beilegen. Wir finden übrigens auch, dass je einfacher die Pflanzen organisirt, je weniger mannigfaltig ihre Formen sind, je weiter unten sie in System stehen, um so geringer der Unterschied der Systeme selbst, oder der darin befolgten Anordnung wird.

\section{B. Endogeneae phanerogamae. DC.}

Endorhizae Rrch. Monocotyledoneae Juss. Amphibrya ExdL.

Bei den Blüthentheilen herrscht die Dreizahl vor und die Blüthendecken sind einfach, bestehen also nur aus einem Perigon. Die übrigen Charaktere sind in der Einleitung erklärt. Die hieher gehörigen Pflanzen lassen sich eintheilen in solche mit albuminosem und in solche mit exalbuminosem Samen. $\mathrm{Zu}$ den letzteren gehören nur wenige Familien, meist Wassergewächse, welche sich in zwei Sectionen, Helobiae und Fluviales, gruppiren lassen.

41. Sect. H e 10 b i a e.

Perigon sechsblättrig; die drei äusseren Perigonblätter stellen 
einen grünen Kelch dar. Ovarien mehrere oberständige, oder ein unterständiges. Balgkapseln ein- bis vielsamig. Umfasst die Familien der Hydrochorideen, Alismaceen, Butomeen.

Hydrocharideae. Perigon sechsblättrig, die drei inneren Perigonblätter grösser als die äusseren, blumenblattartig. Staubgefässe drei, mit den inneren Perigonblättern alternirend, oder sechs oder mehr. Ovarium unterständig, aus mehreren Carpellarblättern zusammengesetzt, einfächerig oder sechs- bis neunfäçherig. Placenten wandständig oder den Scheidewänden angewachsen. Eier zahlreich, anatrop, aufsteigend. Frucht untergetaucht, fleischig, nicht aufspringend. Embryo cylindrisch, gerade.

Meist perennirende Wasserpflanzen mit untergetauchten, selten schwimmenden, gewöhnlich lauter wurzelständigen Blättern. Endlicher stellt diese Familie zu den Ensaten, mit denen sie wegen ihres regehmässigen, oberständigen Perigons Aehnlichkeit hat, von welchen sie sich aber durch das Fehlen des Albumens unterscheidet.

Alismaceae. Die Aehnlichkeit mit der vorigen Fanilie besteht in der blumenblattartigen Beschaffenheit der drei inneren Perigonblätter und dem Fehlen des Eiweisskörpers. Sie unterscheiden sich aber durch unterständiges Perigon, gekrümmten Embryo und durch das aus inehreren einzelnen Garpellen bestehende Ovariun. In dieser lezteren Hinsicht haben sie unter den Dicotyledonen an den Ranunculaceen ein entsprechendes Analogon.

Perennirende krautartige Sumpfpflanzen mit kriechendeın Rhizom und breiten, ganzrandigen Wurzelblättern.

Butomeae. Unterscheiden sich von den Alisinaceen dadurch, dass auch die äusseren Perigonblätter blumenblattartig gefärbt und die einzelnen an der Basis bisweilen verwachsenen Carpelle auf ihrer ganzen imneren Oberfläche mit Eiern besetzt sind, wodurch sie an die Nymphaeaceen erinnern.

Habitus der vorigen Familie ähnlich.

In der Mitte zwischen dieser und der folgenden Section stehen die 
$\mathrm{J}$ u n c a g in e a e, bei welchen die inneren Perigonblätter den äusseren gleich sind, oder das ganze Perigon fehlt. Endlicher vereinigt sie mit der Familie der Alismaceen, von welchen sie aber durch geraden Embryo verschieden sind.

\section{Sect. Fluviales.}

Blüthen häufig diclinisch, Perigon fehlend oder unvollständig. Staubgefässe in bestimmter Anzahl. Ovarien mehrere oder ein einfaches, ein- oder mehrsamig. Es gehören hieher drei kleine Familien, die Potameen, Najadeen, Lemnaceen, wovon bei Endlicher die beiden ersten zu einer Familie (Najadeae) vereinigt sind. Von den übrigen einsamenlappigen, eiweisslosen Wassergewächsen unterscheiden sie sich durch ihr unvollkommenes Perigon und nähern sich durch ihren ährenförnigen (seltener büschelförmigen) Blüthenstand der folgenden Section.

Potomeae. Ovarium aus vier oder mehreren einzelnen, eineiigen Carpellen bestehend.

Untergetauchte krautartige Wassergewächse mit knotig gegliedertem Stengel und gewöhnlich alternirenden Blättern mit stengelumfassendem Blattstiel und häutigen Nebenblättern.

Najadeae. Ovarium einfach, eineiig, Blüthen diclinisch. Habitus wie bei der vorigen Familie.

Lein naceae. Ovarium einfach mit zwei bis séchs Eiern. Blüthen Zwitter oder monöcisch.

Schwimmende Wasserpflanzen, bei welchen der Stengel mit den Blättern verschmolzen ist.

Weitaus den grössten Theil der Monocotyledonen, sowohl an Zahl der Familien als der Arten, bilden die nun folgenden Gewächse mit albuminosem Samen, denn es gehören hieher neben vielen anderen die sehr umfangreichen Familien der Gramineen, Cyperaceen, Palmen u. s. w.

\section{Sect. Spadiciflorae.}

Die Blüthen stehen dicht gedrängt auf eineın Kolben, der von einer blattartigen Scheide ungeben ist, und sind gewöhn- 
lich diclinisch, selten Zwitter. Das Perigon fehlt, oder ist sehr unvollständig, meist unsymmetrisch. Die Typhaceen, Aroideen, Pandaneen gehören zu dieser Section.

A roideae. Blüthen gewöhnlich monöcisch; am oberen Theil des Kolbens männlich, am unteren weiblich, seltener Zwitter. Blüthenkolben von einer oft corollinisch gefärbten Blüthenscheide, spatha, umgeben. Perigon aus sechs Schuppen bestehend oder fehlend. Staubgefässe zahlreich, frei oder verwachsen, bei den Zwitterblüthen den Perigonblättern opponirt. Antheren in das dicke Connectiv eingesenkt. Ovarium frei, einfächerig, selten dreifächerig, mit mehreren Eiern. Frucht trocken oder beerenartig, nicht aufspringend, ein- bis mehrsamig, Embryo gerade, in der Achse des Eiweisskörpers, mit seitlicher Spalte, in welcher das Federchen liegt.

Perennirende krautartige Pflanzen mit oft knollenförmigem Rhizom, schaftartigem oder beblättertem Stamın und alternirenden, aderigen, in der Knospenlage eingerollten Blättern.

Thyphaceae. Diese Familie unterscheidet sich von der vorigen dadurch, dass die männlichen und weiblichen Blüthen auf getrennten Kolben stehen, dass das Connectiv der Staubgefässe sich über die Antherenfächer hinaus zu einer conischen Spitze verlängert, und dass die Scheide des Kolbens fehlt. Das Perigon ist aus Schuppen oder Haaren gebildet, das Ovarium einfächerig, mnit einem hängenden Ei.

Krautautige perennirende Pflanzen mit grasähnlichem Habitus. Die

Pandeneae bilden den Uebergang von den Spadicifloren zu den Palmen; sie zerfallen in zwei Abtheilungen, wovon die eine, mit einfachen Blättern und fehlenden Perigon den Aroideen und Typhaceen, die anderen mit gefiederten oder fächerförmigen Blättern und meist vollständigem Perigon den Palmen ähnlicher sind. Die Blüthen sind diclinisch und stehen auf einfachen oder ästigen Kolben, welche mit einer ein- oder mehrblättrigen Hülle umgeben sind. Frucht eine Beere oder Steinfrucht, häufig aus mehreren Ovarien zusammgesetzt.

Perennirende Pflanzen mit geradem, baumartigem, oder nie- 
derliegendem Stamm und einfachen oder gefiederten oder handförmig getheilten, dicht gedrängten Blättern mit scheidendem Blattstiel.

\section{Sect. Principes.}

Die einzige Familie dieser Section ist die der Palmen; sie wird von manchen Botanikern wohl auch der Section der Spadicifloren beigezählt, an welche sie sich durch den Blüthenbau und Blüthenstand anschliesst. Ueberhaupt nähert sich die Familie, obgleich sie wegen ihres meist hohen und starken Stammes und der grossen Blätter den höheren Monocotyledonen anzugehören scheint, durch ihre unscheinbaren Blüthen auch anderen, niederer stelıenden Fainilien der Monocotyledonen, z. B. den Juncaceen, und durch den Habitus mancher Arten den Gräsern.

Palmae. Blüthen auf einem einfachen oder verästelten Kolben sitzend oder gestielt, durch Fehlschlagen diclinisch oder polygamisch. Kolben von einer ein- oder mehrblättrigen Hülle umgeben. Perigon unterständig, sechsblättrig, in zwei Reihen, in Kelch und Corolle geschieden. Staubgefässe drei, sechs oder mehrere, auf den inneren Perigonblättern (der Corolle) eingefügt. Ovarium oberständig, gewöhnlich aus drei Carpellarblättern gebildet, ein- bis dreifächerig oder dreilappig, mit je einem, meist geradläufigen, aufrechten Ei. Frucht eine Beere oder Steinfrucht, dreifächerig oder durch Fehlschlagen zwei- bis einfächerig, dreibis einsamig. Eiweiss anfangs inilchartig, später fest, oft in der Nitte hohl. Embryo an der Peripherie des Eiweisskörpers in einer Grube, durch eine dünne Lage Eiweiss wie mit einem Deckel bedeckt.

Prächtige baumartige Pflanzen mit einfachem, selten zweitheilig verästeltem Stamın, an seinem Gipfel eine Blätterkrone tragend. Die Blätter, welche Wedel genannt werden, sind meist fächerförnig oder fiederspaltig getheilt.

\section{Sect. Scit a mine a e.}

Perigon oberständig, unregelmässig, doppelt oder einfach. Ovarium ein- bis dreifächerig mit einem oder mehreren Eiern. Frucht eine Kapsel oder seltener eine Beere. Embryo gerade, 
in der Achse des Albumens. Diese Section, welche die drei Familien der Zingiberaceen, Cannaceen und Musaceen umfasst, zeigt gegen die vorigen keine Verwandtschaft, das oft doppelte Perigon und .dreifächerige Ovarium ausgenommen, was aber bei den Monocotyledonen überhaupt häufig, ja gewöhnlich ist. Dagegen zeigen die drei Familien unter sich eine grosse Verwandtschaft, und auch $\mathrm{zu}$ den Orchideen.

$\mathrm{Z}$ ingiber a ceae. Perigon doppelt, das äussere (der Kelch) gewöhnlich corollinisch gefärbt, röhrig, ganz oder gespalten und dann die Spalte gegen die Hauptachse gerichtet. Das innere Perigon (Corolle) dreiblättrig, am Grunde zu einer Röhre verwachsen, das hintere, gegen die Hauptachse oder die Spalte des äusseren Perigons gerichtete Blatt (Fig. 41. c.) häufig grösser. Staubgefässe sechs, in zwei Reihen auf dem Perigon stehend, die drei der äusseren Reihe unfruchtbar: die beiden seitlichen sehr kurz, der mittlere, vordere (l) zu einer Honiglippe, labellum vergrössert; von der inneren Reihe die beiden vorderen a. a. zu kleinen Schüppchen verkümmert, der obere, hintere (s) fruchtbar, blumenblattartig, mit zweifächeriger Anthere. Ovarium aus drei Carpellarblättern gebildet, dreifächerig. Eier zahlreich, anatrop. Griffel fadenförmig, zwischen den Antherenfächern durchgehend, aber nicht damit verwachsen. Frucht dreifächerig, fachspaltig dreiklappig aufspringend, selten beerenartig, nicht aufspringend. Samen häufig init einem Arillus versehen, Eiweiss aus Endospermium und Perispermium bestehend.

Krautartige Pflanzen mit kriechendem oder knolligem Rhizom, seltener mit perennirender Faserwurzel. Stengel einfach oder fehlend. Blätter alternirend, die Stengel scheidenartig umfassend, ganzrandig. Die

Cannaceae s. Marantace ae sind den Scitamineen ganz ähnlich, unterscheiden sich aber dadurch, dass der einzige frucht"bare Staubfaden einer der zwei vorderen, seitlichen a a, ist und eine einfächerige Anthere trägt, auch der Arillus des Samens fehlt.

Mus aceae. Von den vorigen Familien sind sie dadurch verschieden, dass alle sechs Staubgefässe ausgebildet, jedoch 
einige davon steril sind. Habitus der beiden letzten Familien wie bei den Zingiberaceen.

\section{Sect Gynandrae.}

Perigon oberständig, unregelınässig, sechsblättrig, corollinisch gefärbt. Staubfäden mit dem Griffel verwachsen, gewöhnlich nur einer oder zwei fruchtbar. Ovarium ein- bis dreifächerig. Eier zahlreich, anatrop. Frucht eine Kapsel oder Beere. Der Embryo ist noch ganz unentwickelt, ein sogenannter embryo homogeneus, nach neueren Ansichten eiweisslos. Ausser den Orchideen gehören hieher noch die Apostasieen, eine kleine Fanilie des tropischen Asiens. Durch unregelmässige Blüthenbildung mit einer Honiglippe und tbeilweises Fehlschlagen der Staubgefässe schliesst sich diese Section eng an die vorige an, daher beide wohl auch unter dem Nameu der Labelliflorae vereinigt werden, unterscheiden sich aber durch die verschiedene Stellung der einzelnen Blüthentheile.

O rchideae. Perigon sechsblättrig, und zwar drei äussere und drei innere Perigonblätter, deren Stellung zur Hauptachse ursprünglich dieselbe ist, wie bei den Zingiberaceen, aber durch eine halbe Drehung des Ovariums un seine Achse umgekehrt wird, so dass also jetzt das vorher innere, hintere Perigonblatt nach vorne gestellt ist. Eben dieses Perigonblatt hat sich hier zur Honiglippe, Fig. 42 1. umgestaltet, und nicht wie bei den Zingiberaceen einer der Staubfäden. Die übrigen fünf Perigonblätter p ppp. bilden zusammen den Helm, galea. Von den Staubgefüssen, deren ursprünglich wahrscheinlich sechs in zwei Reihen vorhanden sind, haben sich nur einer oder zwei entwickelt, und zwar entweder von der äusseren Reihe der obere, der Hauptachse $\mathbf{x}$ opponirte e, oder von der inneren die beiden seitlich nach oben gestellten a a.

Die Staubfäden sind mit dem Griffel zu einer sogen. Griffelsäule, gynostegium, verwachsen, die unfruchtbaren vielleicht zum Theil auch mit der Honiglippe verschmolzen; der Pollen zu einer wachsartigen oder körnigen Masse zusammengeballt. Ovarium unterständig, einfächerig, sechsrippig, gewöhnlich uı seine 
Achse gedreht. Narbe eine grosse, klebrige Fläche darstellend, nach oben in eine blattartige Spitze oder Schnabel endigend. Kapsel gewöhnlich in drei Längsspalten mit stehen bleibenden Rippen aufspringend (dehiscentia fenestralis). Samen meist in eine netzförmige Haut eingeschlossen.

Krautartige Pflanzen mit scheidenden oder stengelumfassenden Blättern, welche bisweilen zu Schuppen verkümmert sind, mit büschelförmiger oder aus zwei Knollen bestehender Wurzel, wovon eine alljährlich abstirbt.

\section{Sect. Ensata e.}

Perigon oberständig, regelmässig oder unregelmässig, sechstheilig. Staubgefässe drei oder sechs, selten mehr, nicht mit dem Griffel verwachsen. Ovarium unterständig, dreifächerig, mit vielen Eiern an centralen Samenträgern. Von den grösstentheils ausländischen Familien, welche zu dieser Section gehören, heben wir die Irideen, Amaryllideen und Bromeliaceen hervor.

Irideae. Blüthen in Scheiden eingeschlossen. Perigon blumenblattartig. Staubgefässe drei, an der Basis der äusseren Perigonlappen inserirt. Antheren nach aussen aufspringend. Eier anatrop, zweireihig. Narben gewöhnlich verbreitert, blnmenblattartig. Kapsel dreiklappig fachspaltig aufspringend, die Scheidewände bleiben in der Mitte der Klappen. Embryo in das Eiweiss eingeschlossen.

Durch die corollinische Färbıng sowolıl der äusseren als inneren Perigonb!ätter und das unterständige Ovarium ist diese Familie mit der vorigen verbunden, unterscheidet sich aber durch regelmässige Blüthen, drei vollständige Staubgefässe und dreifächeriges Ovarium.

Krautartige Pflanzen mit gewöhnlich kriechendem Rhizom, selten einer Zwiebel, und zweizeilig gestellten (Ausnahme: Crocus), häufig schwertförmigen Blättern.

A maryllideae. Sowohl hinsichtlich der in Scheiden eingeschlossenen Blüthen und des corollinisch gefärbten Perigons, als auch der Bildung des Ovariums und der Kapsel stimmt diese Familie ganz mit der vorigen überein, unterscheidet sich aber 
durch sechs Staubgefässe mit nach innen aufspringenden Antheren. Im Habitus weichen sie sehr von einander ab; es sind grösstentheils Zwiebelgewächse mit einem Blüthenschaft, wenige aber besitzen eine büschelförmige Wurzel und beblätterten Stengel mit einfachen, ganzrandigen, an der Basis scheidenden Blättern.

B romeliaceae. Wie bei der vorigen Familie sind auch hier sechs Staubgefässe vorhanden; von den sechs Perigonblättern sind aber nur die drei inneren corollinisch gefärbt, die äusseren von derberer, kelchartiger Beschaffenheit. Das Ovarium ist theils unterständig, theils aber auch nur halbunterständig oder ganz frei, wodurch sich die Familie zu der folgenden hinneigt und so den Uebergang zwischen den Ensaten zu den Coronarien bildet. In Form und Stellung der Blätter sind die Bromeliaceen manchen Hydrochorideen (Stratiotes) sehr älnlich, aber durch eiweisshaltige Samen verschieden.

Krautartige oder halbstrauchartige, häufig stengellose Pflan«en mit faserigen Wurzeln und gewöhnlich lauter Wurzelblättern, welche steif, rinnenförmig, am Rande dornig gezähnt sind. Viele leben als Schmarotzer auf den Stämmen der Bäume.

\section{Sect. Coronariae.}

Blüthen bisweilen diclinisch. Perigon unterständig, sechstheilig, regelmässig, meist corollinisch gefärbt. Ovarium dreifächerig mit gewönlich zalılreichen Eiern. Frucht eine Kapsel oder Beere.

Die wichtigsten Familien dieser Section sind die Asparageen, Liliaceen, Colchicaceen, Juncaceen.

A sparageae. Blüthen bei einigen Gattungen eingeschlechtig. Perigon gewöhnlich sechstheilig (selten drei- bis viertheilig). Staubgefässe so viel als Perigonzipfel. Antheren nach innen gekehrt, oft mit nach oben verlängertem Connectiv zugespitzt. Ovarium gewöhnlich dreifächerig mit je einem oder mehreren Eiern. Frucht saftig, nicht aufspringend, dreifächerig, bisweilen durch Fehlschlagen einfächerig und einsamig. Samen mit sehr dünner Schale. 
Perennirende krautartige Pflanzen oder Halbsträucher mit kriechendem Rhizom. Blätter alternirend oder quirlförmig, bisweilen klein, schuppenförmig und dann die Aeste blattartig verbreitert.

Liliace a e. Diese Fanilie ist in ihrer Blüthenbildung der vorigen sehr ähnlich; der Hauptunterschied besteht in der nicht saftigen Frucht, welche eine fachspaltig aufspringende Kapsel darstellt. Im Habitus und der Beschaffenheit des Samens sind die Pflanzen sehr verschieden, wonach die Familie in mehrere Tribus zerfällt. Endlicher stellt hieher auch einen Theil der Asparageen, namentlich die Genera: Asparagus, Cordyline, Dracaena u. A., und fasst die übrigen Gattungen jener Familie, Paris, Streptopus, Convallaria, Smilax, Ruscus, unter dem Namen der Smilaceae zusammen.

Colchicaceae s. Melanthaceae. Die Pflanzen dieser unterscheiden sich von denen der vorigen Familien hauptsächlich dadurch, dass bei der Fruchtreife sich die einzelnen Carpelle von einander lösen und in der Bauchnaht aufspringen, und dass die Antheren häufig nach aussen gekehrt sind.

Meist stengellose Pflanzen mit faserigem oder zwiebelförmigem Rhizom und ganzrandigen, an der Basis scheidenden Blättern. Die

Juncaceae schliessen sich durch den Bau ihres Ovariums eng an die übrigen Coronarien an, sind aber durch die derbere, grasähnliche Textur ihres Perigons von ihnen verschieden und nähern sich in ihrem Habitus den Cyperaceen und Gramineen.

Krautartige Pflanzen mit nacktem Schafte oder beblättertem Halme und scheidenden Blättern. Die Blüthen bilden eine Spirre, anthela, eine Art centrifugalen Blüthenstandes, bei welchem die unteren ' Zweige länger als die oberen sind; dieselbe ist oft $\mathrm{zu}$ einem Köpfchen oder Büschel zusammengezogen.

\section{Sect. Glum a c e a e.}

Blüthen in Aehren in der Achsel von spelzenartigen Deckblättern. Perigon schuppen- oder borstenförmig oder fehlend. Ovarium frei, einfächerig, mit einem aufrechten Ei. Frucht eine 
Caryopse. Embryo an der Basis des mehligen Eiweisskörpers. Diese Section begreift die beiden Familien der Cyperaceen und Gramineen.

Cyperaceae. Blüthen Zwitter ocier diclinisch in zweizeiligen oder dachziegelförmigen Aehren, welche - nach Analogie der Gräser A ehrchen, spiculae, genannt werden. Die Bracteen, welche man Spelzen oder Balg nennt, stehen entweder einzeln oder zu zweien, und dann die innere entweder an die Spindel angewachsen oder in einen Schlauch umgewandelt. Das Perigon besteht aus sechs oder mehr, selten weniger Borsten oder ist ganz verkümmert. Staubgefässe drei, Antheren an der Spitze ungetheilt. Ovarium frei, durch Fehlschlagen zweier Carpellarblätter einblättrig, einfächerig, mit einem aufrechten anatropen Ei. Griffel einer, Narben zwei bis drei. Coryopse nackt, oder mit dem bleibenden Perigon ungeben, oder in den vergrösserten Schlauch eingeschlossen. Samen nicht mit der Fruchthülle verwachsen. Embryo sehr klein, von mehligem Eiweiss eingeschlossen.

Ausdauernde Pflanzen von grasähnlichem Habitus, gewöhnlich dreikantigem Stengel und verwachsener Blattscheide ohne Blatthäutchen. Die Wurzeln häufig knollig angeschwollen; die Blïthenährchen zu Aehren, Rispen, Spirren oder Köpfchen zusammengestellt. Die Fanilie nähert sich im Habitus, besonders im Blüthenstand, den Juncaceen, ist aber durch Blüthen- und Fruchtbildung wesentlich verschieden, in welcher Hinsicht sie der folgenden Familie näher steht.

Gramine ae. Blüthen in der Regel Zwitter, sehr selten diclinisch, zu zweizeiligen Aehrchen geordnet. Jede Blüthe ist von zwei Deckblättchen umgeben, welche Spelzen, paleae, heissen, einer äusseren oder unteren, palea exterior s. inferior, und einer inneren oder oberen, $p$. interior $s$. superior. Die äussere Spelze hat einen Mittelnerven, der oft über dieselbe hinaus fadenförmig verlängert ist, und Granne, arista, heisst. Die innere Spelze ist mit zwei Nerven versehen, scheint also eigentlich aus zwei verwachsenen Blättchen zu bestehen. Innerhalb dieser Spelzen folgen nun die eigentlichen Blüthentheile, nemlich das Perigon und 
die Befruchtungswerkzeuge. Ein, zwei oder mehrere solcher Spelzenpaare sammt ihren Blüthen, welche an einer Achse immer zweizeilig gestellt sind, bilden das Grasährchen, spicula; sie sind von einer gemeinschaftlichen Hülle umgeben, die gewöhnlich aus zwei Deckblättchen, den Klappen, Balgspelzen, glumae, glumae calycinae, besteht, wovon man ebenfalls eine äussere oder untere, und eine innere oder obere unterscheidet. Das Perigon, welches sich also innerhalb der beiden Spelzen befindet, besteht aus drei sehr kleinen Schüppchen, squamulae, lodiculae, welche Linnée als Nectarien betrachtete, wovon aber das innere häufig fehl schlägt. Staubgefässe finden sich in der Regel drei, selten durch Fehlschlagen weniger. Die Antheren sind an beiden Enden zweispaltig, das Ovarium aus einem Fruchtblatt gebildet, eineiig. Frucht eine Caryopse, Samen mit der Fruchthülle und oft auch mit den Blüthenspelzen verwachsen. Embryo schildförmig, ausserhalb des Eiweisskörpers liegend.

Der Stamm heisst Halm, culmus, ist cylindrisch, knotig, gewöhnlich hohl, meist nur an der Basis verästelt, selten strauchartig. Blätter zweizeilig mit stengelumfassender gespaltener Scheide, deren oberes Ende zu dem Blatthäutchen, ligula, verlängert ist; Blattscheibe linienförnig, nie gespalten oder getheilt. Die Blüthenährchen sind zu zusammengesetzten Blüthenständen, Rispen, oder zu Aehren oder Kolben vereinigt.

Die Gräser bilden wegen ihrer unvollkommenen Blüthenhüllen die niederste Familie der Phanerogamen, sind am nächsten mit den Cyperaceen verwandt, unterscheiden sich von ihnen durch den Habitus (runde, knotige Halme, Blatthäutchen, gespaltene Blattscheide), besonders aber durch das Verwachsensein des Samens mit der Fruclthülle und den ausserhalb des Eiweisskörpers gelegenen Embryo. Nanche in den T'Tropen vorkommende baunarlige Gräser erinnern an die Palmen.

Endlicher's Anordnung der Familie der Monorotyledonen weicht von der DeCandoll'schen etwas ab. Zwar bilden die Gräser als die niederste Familie auf beiden Seiten das eine 
Ende, aber bei Endlicher stehen am anderen Ende die Palmen, welche sich durch ihren baumartigen Habitus einigermassen den Coniferen anschliessen. Ueberhaupt wird von Endlicher der Unterschied zwischen albuminosen und exalbuminosen Monocotyledonen nicht berücksichtigt.

Mit der Familie der Gräser schliesst sich diejenige Abtheilung des Gewächsreichs ab, deren Fortpflanzung durch wahren Samen geschieht, in dessen Keim die Anlage zur neuen Pflanze deutlich sichtbar ist. Bei den nun folgenden Familien fehlt dieser Keim. Das Vorhandensein oder Fehlen des Keims wurde von Richard, wie bereits oben bemerkt, benützt, um das ganze Pflanzenreich in zwei Abtheilungen, plantae embryonatae und exembryonatae zu bringen. Die letztere Abtheilung entspricht der 24. Klasse Linnés, den Krpytogamen. Im Uebrigen wird in dieser Beziehung auf das Seite $35 \mathrm{ff}$. Gesagte verwiesen.

\section{Kryptogamische Gewächse.}

Die Fortpflanzungsorgane dieser Pflanzen bestehen aus einzelnen Zellen, Sporen genannt, welche ganz die Beschaffenheit der Pollenkörner der Phanerogamen besitzen und keinen Embryo, sondern eine Flüssigkeit enthalten. Während bei den Phanerogamen die Bildung eines keimfähigen Samens immer von der gegenseitigen Einwirkung der männlichen und weiblichen Befruchtungsorgane abhängig ist, erfolgt die Bildung der Sporen häufig ohne vorhergegangene Befruchtung und es wurde sogar das Vorhandensein von zweierlei Geschlechtern früher überhaupt bestritten, obgleich schon Linné, und nach ihm noch viele Andere an die Anwesenheit derselben glaubten, aber freilich, ohne sie gehörig nachweisen zu können, und desshalb oft zu Erklärungen ihre Zuflucht nahmen, die sich als falsch erwiesen.

Neuere Untersuchungen haben ergeben, dass bei den höheren Kryptogamen, den Farren und Moosen unzweifelhaft zweierlei Befruchtungsorgane existiren und dass die gegenseitige Einwir- 
kung beider auf einander zur Bildung entwicklungsfähiger Sporen eben so nothwendig ist, als die Einwirkung des Pollenschlauchs auf das Ei zur Bildung eines keimfähigen Samens.

Die Spore entwickelt sich nicht unmittelbar zur neuen Pflanze, sondern bildet zuerst einen sogenannten Vorkeim, prothallium, der erst eine Knospe und endlich das neue Individuuın hervorbringt; die Kryptogamen unterscheiden sich auch hierin wesentlich von den Phanerogamen, bei welchen die neue Pflanze unmittelbar aus dem Samen hervorkomint. Ausser den Sporen finden sich bei den Kryptogamen auch noch Fortpflanzungsorgane anderer Art, die Brutzellen oder Gonidien.

Linné theilt die Kryptogamen in vier Ordnungen: Filices Musci, Algae und Fungi; zu der ersten Ordnung zählte er die eigentlichen Farren, dann die Lycopodiaceen und Equisetaceen, überhaupt die Gefässkryptogamen; zu den Algen rechnete er die wirklichen Algen und die Flechten. DeCandolle's Eintheilung wurde schon oben besprochen, und dort gesagt, dass es nicht naturgeınäss ist, die kryptogamischen Gefässpflanzen zu den Monocotyledonen zu stellen. Gewöhnlich bringt man die Kryptogamen in zwei Hauptabtheilungen, in Stammkryptogamen, welche dann wieder in Gefässkryptogamen und in Gefässlose (Moose und Lebermoose) zerfallen; und in Lagerpflanzen, Thallophyta unter denen die Algen, Pilze und Flechten begriffen sind.

\section{Enlogeneae cryptogamae. DC.}

Acotyledoneae vasculares Juss. Cormophyta acrobrya protophyta ENDL.

Die männlichen Befruchtungswerkzeuge, Antheridien, entwickeln sich entweder auf der Pflanze selbst, oder auf dem Vorkeim. Die weiblichen, Archegonien, nur auf dem Vorkeim, und enthalten cine centrale Zelle, welche später zur Pflanze auswächst. Nach der Beschaffenheit und Entwicklung ihrer Früchte und Sporen zerfallen die Gefäss-Kryptoganen in Equisetaceen, Marsileaceen, Lycopodiaceen und Farren. 


\section{Equisetaceae.}

Die Fruchte bilden eine endständige Fruchtähre, welche aus schildförmigen, gestielten Körpern, sporidochia, besteht, auf deren Unterseite mehrere einfächerige Sporengehäuse, sporangia, sitzen, in welchen viele Sporen enthalten sind. Jede Spore ist kreuzweise von zwei Spiralfasern umschluugen, die inan Schleudern, elaleres, nennt, und welche vermöge ihrer Hygroscopicität dazu dienen, die Sporen auszustreuen. Bei der Keimung wachsen die Sporen zuerst zun Prothallium aus, auf welchem die Antheridien und Archegonien entstehen. Die Stengel sind gegliedert, haben an den Knoten gezahnte Blattscheiden, welche die Stelle der Blätter vertreten, sind bald einfach, bald ästig, und kommen aus kriechenden Rhizomen hervor. Bei manchen Arten haben die fruchttragenden und sterilen Stengel verschiedene Formen.

\section{Lycopodiaceae.}

Die Sporangien stehen in den Blattachseln entweder am ganzen Stengel zerstreut, oder an seiner Spitze zu einer Aehre vereinigt, sie enthalten entweder einerlei Sporen, oder zweierlei, grössere und kleinere. Die grösseren entwickeln sich auf der Pflanze selbst zu einem Vorkeim, auf welchem die Archegonien entstehen, während aus den kleineren Sporen eine Menge Schwärmfäden hervorkommen, wodurch die Archegonien befruchtet werden. Die kleinen Sporen sind also als Antheridien zu betrachten. Der Stengel der Lycopodiaceen ist dichotom getheilt, dicht mit kleinen moosähnlichen Blättern besetzt, welche da, wo die Früchte in Aehren am Gipfel des Stengels stehen, in dünnhäutige Bracteen übergehen.

\section{Marsileaceae.}

Unter diesem Namen werden gewöhnlich die Gattungen Pilularia, Marsilea, Salvinia und Isoëtes zusammengefasst. Alle sind Wasserpflanzen, bei welchen die Früchte an der Basis der Blätter oder zwischen den Wurzelfasern sitzen, daher sie auch Rhizocarpae heissen. Die Sporen sind von zweierlei Art, und 
entweder jede besonders oder beide zusammen in die Sporenfrucht eingeschlossen. Endlicher nennt sie Hydropterides, trennt aber davon die Gattung Isoëtes, welche er in e.ine Section mit den Lycopodiaceen unter dem gemeinschaftlichen Namen der Selagines stellt.

\section{Filices.}

Die kapselähnlichen Früchte sitzen auf der Unterseite der Blätter, selten oben oder an ihrem Rande, sind entweder ohne Ordnung über die untere Blattfläche zerstreut, oder zu kleinen Häufchen, sori, gruppirt; bald nackt, bald mit einer Haut, dem Schleierchen, indusium, bedeckt. Bei den meisten Farren lauft über den Scheitel der Frucht ein elastischer Ring weg, der sich bei der Reife streckt, und dadurch die sonst dünne Membran der Kapsel zerreisst; bei anderen geht der Ring in horizontaler Richtung un die Kapsel, oder er ist nur zur Hälfte ausgebildet. Bei einigen Arten ist die Kapsel sehr dickhäutig und mit der Substanz des Blatts verschmolzen, das dann auf beiden Seiten mit Friichten besetzt ist und eine Fruchtähre bildet. Nach dieser verschiedenen Beschaffenheit der Sporangien zerfallen die Farren in mehrere Familien. Die Spore entwickelt sich zuerst zu einem nierenförmigen, blattartigen Prothallium, das auf seiner Unterfläche Wurzelhaare, auf der Oberseite die Antheridien und Archegonien hervorbringt.

Die Farren haben gewöhnlich ein unter- oder oberirdisches, kriechendes, einfaches oder verästeltes Rhizom, selten einen aufrechten, baumartigen Stamm, der dann nie verästelt ist; sie enthalten entweder ein einziges, centrales, oder einen ganzen Kreis netzförmig mit einander verbundener Gefässbündel. Die Blätter, welche man Wedel, frons, nennt, sind in der Knospe schṇeckenförmig zusamınengerollt, sehr häufig vielfach getheilt; die Blattnerven gabelförmig gespalten, wodurch sie sich von den Cycadeen unterscheiden. 


\section{Plantae cellulares.}

\section{Acotyledoneae cellulares.}

Diese Klasse enthält diejenigen Pflanzen, denen die Gefässe fehlen, also blos aus Zellen bestehen. Sie zerfallen in beblätterte und blattlose; die Vegetationsorgane der ersteren sind noch in Stamm und Blatt geschieden, dieselben gehören also noch zu Endlicher's Cormophyten.

\section{Acotyledoneae foliaceae.}

Acrobrya anophyta ENDL.

Wurzel, Stengel und Blätter sind getrennt. Es sind zweierlei Geschlechtstheile, Antheridien und Archegonien vorhanden, von denen die ersteren gewöhnlich mit gegliederten Fäden, sogenannten Saftfäden, paraphyses, umgeben sind; die Befruchtung findet auf der Pflanze selbst, nicht auf dem Vorkeine statt; nachher entwickelt sich das Antheridium zur Sporenfrucht, sporangium, welche entweder sitzend oder gestielt ist und zahlreiche Sporen enthält. Die Sporen entwickeln sich zuerst zu einem fadenförmigen Prothallium. Sie zerfallen in zwei Klassen oder Sectionen: Moose, Musci, von welchen neuerdings die Torfmoose, Sphagna, als besondere Section getrennt werden, und Lebermoose, Hepaticae.

\section{Musci.}

Archegonien und Antheridien in einer gemeinschaftlichen Hulle vereinigt oder beide Geschlechter getrennt, und zwar entweder auf derselben, oder auf zwei verschiedenen Pflanzen. Die Moose sind daher Zwitter, oder monöcisch, oder diöcisch. Die Frucht der Moose heisst Büchse, theca, ist sitzend, oder mit einem Stiel, Borste, seta, versehen, und gewöhnlich mit einer Haube oder Mütze, calyptra, bedeckt; dieselbe ist aus der Hülle des Archegoniums entstanden, welche bei der Entwicklung der Büchse an der Basis abgerissen und in die Höhe gehoben wurde. 
Die Rudimente der Archegoniumhülle umgeben die Basis der Büchse als Scheidchen, vaginula. Die Büchse bleibt entweder geschlossen, und die Sporen treten erst aus, nachdem die Büchse durch Verwitterung zerstört ist, musci cleistocarpi, oder sie springt in Längsspalten auf, musci schizocarpi, oder, was am häufigsten der Fall ist, sie öffnet sich mit einem Deckel, musci stegocarpi. Bei den letzteren, den bedeckelten Moosen findet sich gewöhnlich zwischen Büchse und Deckel ein aus einer oder mehreren Zellenreihen gebildeter Ring, annulus, der sich zur Zeit der Sporenreife ganz oder stückweise ablöst und eben dadurch das Abfallen des Deckels veranlasst. Der Saum der Büchse ist entweder nackt, oder mit Zähnen besetzt. Im Centrum der Büchse findet sich ein aufrechter, cylindrischer Körper, das Säulchen, columella. Der Stengel der Moose ist meist dicht beblättert, die Blätter immer sitzend, nie gestielt, immer einfach, und bestehen fast ohne Ausnahme aus einer einzigen Zellenschichte. Die Moose leben theils in der Luft, theils in Wasser.

\section{Hepaticae.}

Die Lebermoose sind entweder einlıäusig, oder zweihäusig. Die Frucht öffnet sich gewöhnlich in Klappen; das Vittelsäulchen fehlt in der Regel. Blatt und Stengel sind getrennt, oder aber zum Laub, frons, verschinolzen, bilden also schon den Uebergang zu den Thallophyten.

\section{Aphyllae. DC. Thallophyta. ENDL.}

Achsen- und Seitenorgane in ein gemeinschaftliches Gebilde, der Trieblager, thallus, verschmolzen, eine besondere Wurzel, Stamm oder Blatt können also nicht unterschieden werden. Wirkliche Antheridien kommen nur bei den Characeen vor; bei den anderen Familien sind sie unvollständig oder fehlen ganz. Man theilt sie in drei Klassen: Flechten, Lichenes, Pilze, Fungi, und Algen, Algae, welche jedoch unter sich mehrfache Uebergänge zeigen. Flechten und Algen zusamınen nennt Endlicher Protophyta, die Pilze Hysterophyta. 


\section{Lichenes.}

Die Sporen sind gewöhnlich zu vier bis acht in Schlauche, asci, eingeschlossen, welche in Mehrzahl parallel neben einander stehend und mit sogenannten Saftäden, paraphyses, umgeben, in eineın Schlauchbehälter, apothecium, enthalten sind, welcher meist eine schüsselförmige Gestalt hat, und dalıer auch Schüsselchen, scutella, genannt wird. Dieselben finden sich auf dem Thallus sitzend, oder gestielt, oder in denselben eingesenkt. Ausser diesen Sporenbehältern finden sich auch noch andere Fortpflanzungsorgane, nämlich Brutzellen oder Gonidien. Der Thallus entsteht aus einem flockigen Vorkeim, ist sehr verschieden gebildet, bei den niedersten Flechten staub- oder krustenartig, dann blattartig, und endlich bei den höheren Familien stiel- oder strauchartig. Die Flechten leben in der Luft an Steinen, an Holz, anderen Pflanzen, auf der Erde, aber nie auf faulenden organischen Körpern.

\section{Fungi.}

Die Sporen sind entweder auch in einem Fruchtbehälter ein geschlossen, und zwar innerhalb derselben entweder in Schlauchzellen, asci, enthalten, oder in einem Fadengewebe zerstreut, oder auch frei liegend; aber bei den niedersten Pilzen ist die Vegetationszelle zugleich Fortpflanzungsorgan. Das Trieblager, thalius floccosus, mycelium, tritt in Form lockerer, wenig verzweigter Fäden auf und findet sich meist unter der Erde, oder es dringt in die Intercellulargänge der Pflanzen ein, auf welchen die Pilze leben. Die Fruchtbehälter bilden häufig den grössten Theil des Pilzes, wie diess z. B. bei den im gemeinen Leben init dem Namen Schwä in me bezeichneten Pilzen der Fall ist. Die Pilze leben hauptsächlich an schattigen, feuchten Orten, auf faulenden vegetabilischen und tbierischen Stoffen, entstehen meist sehr schnell, vergehen aber eben so schnell wieder; einige sind auch holzig und von unbestimmt langer Dauer.

Von der Klasse der Pilze trennt DeCandolle eine besondere 
Gruppe, die sich in manchen Stücken mehr den Flechten nahern, unter dem besonderen Namen Hypoxila.

\section{Algae.}

Die Sporen sind bei den höheren Algen in eigenen Behältern, Sporangien, enthalten, bei den niedersten fehlen diese, und jede beliebige Zelle kann zum Fortpflanzungsorgan werden. Bei der am höchsten stehenden Algenfamilie, den Characeen, finden sich noch wahre Antheridien, bei anderen ist eine Geschlechtsverschiedenheit noch angedeutet durch Auftreten von zweierlei Sporen, von welchen sich die einen nur entwickeln, wenn sie mit den anderen in Berührung gekommen sind. Die Algen leben fast alle im Wasser, wenige auf feuchter Erde und haben ein fadenförıniges oder blattartiges Lager. Die allerniedersten bestehen bloss aus einer einzigen Zelle. - 
Druckfe hle r.

Seite 4 Zeile 3 von oben ist das Wort „aber" zu durchstreicher.

\begin{tabular}{|c|c|c|}
\hline & 4 & $\Rightarrow 18$ \\
\hline & 6 & $\Rightarrow 3$ \\
\hline & 14 & $" 15$ \\
\hline & 14 & 9 \\
\hline & 24 & $" 21$ \\
\hline & 34 & $n$ \\
\hline
\end{tabular}

» statt Lobiaten lies L a bi a ten.

unten "Wahsthum lies Wachsthum.

oben Fig. 16 lies Fig. 17.

unten "Stengels lies Stempels.

oben " bei lies beim.

unten in den Anmerk. statt "und enthält" lies: welche die Familien der u. s. w. enthält.

$\begin{array}{lllll}\eta & 44 & & 5 & \\ \eta & 49 & \# & 8 & \end{array}$

oben statt Polycorpicae lies Pol y carpicae.

$\Rightarrow 60,10 "$

,

"Canyophylleen lies Caryophylle en.

, 86,17 ,

unten

" S aphyleaceae lies $\mathrm{Staphyleaceac.}$

" rt

oben

" zwei mächtige lies $z$ weim $\ddot{a} \mathrm{chti} g e$.

"92 1 1 oben

unten "Salanaceen lies Solanace en.

, 94,16 unten

"Coryophyllinae lies Cariophyllinae.

$105 \% 10 \%$,

, auszeichnet lies a u s z ichne $n$.

, 110

13

oben

"Pandeneae lies Pand a nea e.

, zwischen lies $\mathrm{v}$ on. 


\section{Register der Familien.}

Abietineae . . . . . . 101

Acanthaceae . . . . . 87

Acerineae . . . . . . 54

Alismaceae . . . . . 103

Alsineae . . . . . . . 49

Amaranthaceae . . . . . 91

Amaryllideae . . . . . . 109

Ampelideae . . . . . 72.75

Amygdaleae . . . . . . 64

Anacardiaceae . . . . . . 61

Apocyneae . . . . . . 82

Apostasieae . . . . . . . 108

Araliaceae . . . . . . . 73

Aristolochiaceac . . . . . 94

Aroideae . . . . . . . 105

Artocarpeae . . . . . . 97

Asclepiadeae . . . . . . 81

Asparageae . . . . . . 110

Asperifoliae . . . . . . 85

Aurantiaceae ..... 52

Balsamineae . . . . . . 57

Begoniaceae . . . . . 69

Berberideae . . . . . . 43

Bignoniaceae . . . . 87

Bixineae . . . . . . . 47

Borragineae . . . . . 84

Bromeliaceae . . . . . 110

Burseraceae . . . . . 61

Butomeae . . . . . 103

Büttneriaceae . . . . . 51

Cacteae . . . . . . . . 69

Caesalpineae . . . . . 63

Camelliaceae . . . . . 52

Campanulacere . . . . 78

Cannabineae . . . . . . 96

Canellaceae . . . . . 55

Cannaceae . . . . . 107

Capparideae . . . . . . 46

Caprifoliaceae . . . . . 74

Caryophylleae . . . . . . 49

Cedrelaceae .
Celastrineae

60

Chenopodeae . . . . . . 91

Cistineae . . . . . . . 47

Clusiaceae . . . . . . 52

Colchicaceae . . . . . . 111

Compositae . . . . . . . 76

Convolvulaceae . . . . . . 83

Corneae . . . . . . . . 73

Crassulaceae . . . . . 70

Cruciferae . . . . . . . 45

Cucurbitaceae . . . . . . 68

Cupressineae . . . . . . 100

Cupuliferae . . . . . . . 97

Cycadeae . . . . . . . . 101

Cyperaceae . . . . . 112

Daphnoideae . . . . . . 93

Dipsaceae . . . . . . . 76

Droseraceae . . . . . . 47

Ebenaceae . . . . . 88

Empetreae . . . . . . 95

Ephedreae . . . . . I00

Ericineae . . . . . . 79

Euphorbiaceae . . . . . 95

Ficoideae . . . . . 70

Fumariaceae . . . . . . 45

Gentianeae . . . . . 83

Geraniaceae . . . . . 56

Gnetaceae . . . . . 100

Gramineae . . . . 112

Granateae . . . . . 66

Grossularieae . . . . . 70

Mippocastaneae . . . . . 54

Hydrocharideae . . . . 103

Hypericineae . . . . . 51

Irideae . . . . . . . . 109

Jasmineae . . . . 80

Juglandeae . . . . . 61. 98

Juncaceae . . . . . . 111

Juncagineae . . . . . 104

Labiatae . . . . . . 85 
Laurineae

Lemnaceae

Plantagineae

Lentibulariae

Liliaceae .

Lineae

111

Lobeliaceae 56

Loganiaceae 77

Lonicereae. 82

Loranthaceae

Lythrarieae .

Magnoliaceae

Malvaceae

Malpighiaceae . . . . . 54

Marantaceae . . . . . 107

Melanthaceae . . . . 111

Melastomaceae . . . . 67

Meliaceae . . . . $55 . \quad 53$

Menispermeae . . . . . 43

Mesembryanthemeae . . . 70

Mimoseae . . . . . . 63

Monotropeae . . . . . . 79

Moreae . . . . . . . 97

Musaceae . . . . . . 107

Myristiceae . . . . . . 93

Myrsineae . . . . . . 88

Myrtaceae . . . . . 66

Najadeae . . . . . 104

Nepentheae . . . . . . . 94

Nymphaeaceae . . . . . 44

Oleaceae . . . . . 80

Onagrariae . . . . . 67

Orchideae . . . . . . 108

Orobancheae . . . . . 87

Oxalideae . . . . . 58

Palmae . . . . . 106

Pandaneae . . . . . 105

Papaveraceae . . . . . 44

Papilionaceae . . . . . 62

Paronychieae . . . 49. 70

Passifloreae . . . . . 69

Philadelpheae . . . . . . 67

Phytolaccaceae . . . 49. 91

Piperaceae .

Plumbagineae

Polygaleae - 48

Polygoneae . . . . . . . 92

Portulaceae . . . . 4 49.70

Pomaceae . . . . . 65

Potameae . . . . . . . . 104

Primulaceae . . . . 87

Pyrolaceae . . . . . . . 79

Ranunculaceae . . . . 42

Resedaceae . . . . . . . 46

Rhamneae . . . . . 60

Rosaceae . . . . . . 64

Rubiaceae . . . . . 75

Rutaceac . . . . . . . 59

Salicineae . . . . . . 98

Santalaceae . . . . . 93

Sapindaceae . . . . . . 53

Sapotaceae . . . . . . 88

Saxifragaceae . . . . . 71

Sclerantheae . . . . . . 49

Scrophularineae . . . . 86

Sileneae . . . . . 49

Simarubaceae . . . . $\quad 59$

Solanaceae . . . . . . 84

Sterculiaceae . . . . . . 51

Styraceae . . . . . 88

Taxineae . . . . . 100

Terebinthaceae . . . . 61

Ternstroemiaceae . . . . 52

Theaceae . . . . . . 52

Thymeleae . . . . . . 93

Tiliaceae . . . . . . 50

Trophaeoleae . . . . 57

Typhaceae . . . . . . 105

Umbelliferae . . . . . 72

Urticeae . . . . . . . . 96

Vaccinieae . . . . . . 78

Valerianeae . . . . . 75

Verbenaceae . . . . 85

Violarieae . . . . . . 47

Zingiberaceae . . . . 107

Zygophylleae . . . . . . 58 

In demselben Verlage sind erschienen:

Schimper, W. Ph.. IBryologia Europaea sell Genera Muscorum Europaeorum monographice illustrata auctoribus Ph. Bruch, W. Ph. Schimper et Th. Gümbel. 6 Bde. in 65 Lieferungen gr. 4 ., enthalteind 640 Tafelı Abbildungen nebst Text in lateinischer, deutscher u. französischer Sprache. Preis des Ganzen, genau geordnet und collationirt fl. $260 .-$ R. $162.15 \mathrm{sgr}$.

\section{- Musci Europaei novi vel Bryologiae Eu-} ropaeae Supplementum.

Fasciculus I., II., cum Tabulis XX. 4. 1864.

$$
\text { " III., IV., ” " XX. 4. } 1866 .
$$

à fl. $4 .-$ R. 2.15 sgr.

Das Ganze wird aus ungefähr 10 Lieferungen bestehen, und in wenig Jahren rollständig erschienen sein.

- - Symopsis Muscorun Europacorum praemissa introductione de elementis bryologicis tractante. Accedunt tabulae VIII, typos genericos exhibentes et mappa bryogeographica. : fl. $12 .-$ R. $7.10 \mathrm{sgr}$.

- Xcones morphologicae atque oraanographicae introductionem Synopsi Muscorum Europaeorum praemissam illustrantes. Ad naturam vivam delineavit et explicavit. Tabulae lapidi incisae XI. $\quad$ ก. $5.20 \mathrm{kr}$. - R. $3.6 \mathrm{sgr}$.

- - Versuch einer sntwicklungsgeschichte der Torfmoose (Sphagnum) und einer Mlonographie der in Europa vorkommenden Arten dieser Gattung. 25 Bogen Text mit 27 Kupfertafeln in Folio

fl $14 .-$ R. 8 . -

Mit colorirten Kupfern fl. 18. 20 kr. -- R. 10. $15 \mathrm{sgr}$.

Lorentz, Dr. P. C... Verzeichniss der europäischen Laubmoose. Zum praktischen Gebrauche zusammengestellt.

$18 \mathrm{kr}$. $-6 \mathrm{sgr}$.

- Bryologisches Notizbuch. Zum praktischen Gebrauche zusammengestellt.

fl. $1.12 \mathrm{kr}$. $-221 / 2 \mathrm{sgr}$.

M. Vilkomm et J. Lange. Prodromus FIorae Hispanicae seu synopsis methodica omnium plantarum in Hispania sponte nascentium vil frequentius cultarum quae innotuerunt. I. Band fl. $4.20 \mathrm{kr}$. - R. $2.16 \mathrm{sgr}$. II. Bandes erste Hälfte fl. 3. 30 kr. - R. 2. - 



